Portland State University

PDXScholar

Fall 1-17-2013

\title{
Taiwanese Language Medical School Curriculum: A Case Study of Symbolic Resistance Through The Promotion of Alternative Literacy and Language Domain Norms
}

Philip John Sweeney

Portland State University

Follow this and additional works at: https://pdxscholar.library.pdx.edu/open_access_etds

Part of the Anthropology Commons, Chinese Studies Commons, and the Modern Languages Commons

Let us know how access to this document benefits you.

\section{Recommended Citation}

Sweeney, Philip John, "Taiwanese Language Medical School Curriculum: A Case Study of Symbolic Resistance Through The Promotion of Alternative Literacy and Language Domain Norms" (2013). Dissertations and Theses. Paper 938.

https://doi.org/10.15760/etd.938

This Thesis is brought to you for free and open access. It has been accepted for inclusion in Dissertations and Theses by an authorized administrator of PDXScholar. Please contact us if we can make this document more accessible: pdxscholar@pdx.edu. 
Taiwanese Language Medical School Curriculum: A Case Study of Symbolic Resistance Through The Promotion of Alternative Literacy and

Language Domain Norms

by

Philip John Sweeney

A thesis submitted in partial fulfillment of the requirements for the degree of

Master of Science

in

Anthropology

Thesis Committee:

Sharon Carstens, Chair

Michele Gamburd

Keith Walters

Portland State University

2012 


\begin{abstract}
In contemporary Taiwan, Mandarin language proficiency and literacy in Han characters are not only key skills needed for success in academic institutions and employment markets, but they also carry meaning as symbolic markers of national and supranational Chinese identity. This study examines how Taiwanese-language medical studies curriculum planners are promoting alternative linguistic practices as a means of resisting the influence of Chinese nationalism in Taiwan and striving to replace it with a rival Taiwanese nationalism. I conducted research for this study during the 2010-2011 school year in Kaohsiung, Taiwan. I collected data for this study by engaging in participant observation research at Taiwanese-language curriculum-editing meetings; auditing Taiwanese-language courses at Kaohsiung Medical University; and conducting interviews with both curriculum planners and students at KMU. The role of official languages, literacy, and historical narratives are examined as symbolic components of a Chinese nationalist hegemony, which was constructed through the policies of the Kuomintang's Republic of China administration in post-war Taiwan. This study also examines the relationship between occupation, language skills, and national identification in the context of the contemporary Greater China regional economy. The curriculum
\end{abstract}


planners who are the subjects of this study are employed in the field of medical care, where Taiwanese language skills are valued resources for communicating with patients from a variety of socioeconomic backgrounds. In addition, medical doctors have historically been vocal opponents of the Kuomintang administration's pro-Chinese nationalist policies. Therefore, this case study illustrates how the curriculum planners' occupations and language practices are utilized as resources in their efforts to foster Taiwanese autonomy in the Greater China region. This study also examines current limits to the effectiveness of language preservation and revitalization policies in Taiwan due to the importance of Mandarin-language literacy in the majority of high-status occupations in Greater China and to changing conceptions of the relationship between language practice and national identity. This study contributes to the fields of linguistic anthropology and Asian studies by examining relationships between nationalism, employment, language practice, and literacy in the context of Taiwan's ambiguous status as a national entity. It also analyzes ways in which language practices and literacy forms are created and modified as strategic acts to both identify people with competing nationalisms and allow them access to employment opportunities in the context of shifting administrative and economic power structures in the Greater China region. 


\section{ACKNOWLEDGMENTS}

I would like to thank all of the people who participated in this study and took time out of their busy schedules to meet with me for recorded interviews. I would especially like to thank the following study group members for inviting me to participate in their curriculum-editing meetings and allowing me to audit Taiwanese-language medical studies classes at Kaohsiung Medical University: Dr. Tenn Si-chong, Dr. Tiu Hok-chu, Professor Lim Chheng Siang, I Giok-ngo, Ng Kheng Goan, Huang Jyh-Min, Tan Honghui, Huang Wen-zhang, Chen Jin-hua, and Jason Jiang.

I would like to thank my thesis advisor, Dr. Sharon Carstens, for all of her

guidance, support, feedback, and patience throughout my graduate studies and during the three years that I spent living, researching, and writing my thesis in Taiwan. I would also like to express my gratitude to Dr. Michele Gamburd and Dr. Keith Walters for their suggestions, guidance, and critical feedback on this project.

Thank you to my parents and siblings for their love, support, and understanding

during the time that I have been living overseas while doing research and writing for this project. I would also like to thank my classmates in the Anthropology Department for their support and friendship during my graduate studies at PSU. 
Abstract $\quad$ i

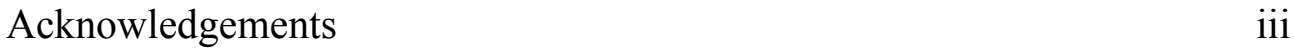

List of Figures viii

$\begin{array}{ll}\text { List of Tables } & \text { ix }\end{array}$

Chapter I - Introduction 1

Literacy, Historical Narratives, Language Domain

Norms, and Nationalism 4

Hegemony, Power, Agency, and Resistance 10

Occupation, Literacy, Language, and Nationalism 13

Han Characters, Mandarin, and Chinese Nationalism in Taiwan 19

Resistance Through Taiwanese Language

Medical School Curriculum 22

State Power and Nationhood 23

Research Site and Methodology 27

Thesis Organization 32

Chapter II - Historical Background 35

Introduction $\quad 35$

Language and Ethnicity $\quad 36$

Identification as Social Practice $\quad 38$

Aboriginal Cultures in Taiwan $\quad 40$

Early Migration Patterns $\quad 42$

Dutch Colonial Rule $\quad 43$

Dynastic Rule $\quad 44$

The Japanese Colonial Era 46

Kuomintang Rule in the Post-War Era 48

Diplomatic Isolation and Political Democratization 51

Contemporary Greater China Hegemony 54

Conclusion $\quad 57$ 
Chapter III - A History of Language and Literacy in Taiwan 59

Introduction $\quad 59$

Authentication and Denaturalization 63

The Dutch Colonial Era 65

Dynastic Rule 66

Literacy and Missionary Work during the Qing Dynasty 68

The Japanese Colonial Era 69

Kuomintang Dominance During the Martial Law Era 71

Language Use and Occupation 76

The Rise of Taiwanese Nationalism 78

Challenging the Kuomintang's Chinese Nationalism 81

Multilingualism in Political Discourse $\quad 84$

Language, Literacy, and Education in Taiwan 86

Academic Credentials and Employment 88

Resistance Through Mother Language Education 90

Conclusion 93

Chapter IV - The Sunday Study Group 96

Introduction 96

Language in Interviews $\quad 97$

The Socioeconomic Position of Doctors 99

Personal and Professional Backgrounds and Language Ideology 104

The Influence of Christian Missionaries 109

Nationalism, Practicality, and Taiwanese Language Literacy 111

Language, Identification, and Historical Narrative 115

$\begin{array}{ll}\text { Ethnicity and Nationalism } & 118\end{array}$

Authentication and Identification $\quad 121$

Language Domain Ideology 123

Gender and Language Ideology 126

Likely Accomplishments $\quad 127$

Conclusion 131

$\begin{array}{ll}\text { Chapter V - Curriculum and Learning Materials } & 134\end{array}$

Part I: Testing Materials and Medical Language 135

Textbook Chapters 139 
Style and Content Issues $\quad 141$

Part II: The Courses at KMU 144

Introductory Lecture: Course Ideology 147

Pronunciation, Reading, and Writing 150

Medical Terminology 151

Literacy and Taiwanese Identification 152

History and Literacy 153

International Links

Conclusion 156

Chapter VI - The Students Enrolled in Taiwanese Language Medical

Studies Classes at Kaohsiung Medical University 159

Part I: Students' Linguistic Behavior on University

Campuses in Kaohsiung 162

Part II: Questionnaire Data 166

Part III: Student Interviews 177

Language Use During Childhood 180

Student Life and Linguistic Habits 182

Gender and Language 184

Occupation and Language 187

Language and Character Type 189

Language and Authenticity 193

Language Loyalty 194

Students' Evaluations of the Writing System 198

Conclusion 200

$\begin{array}{ll}\text { Chapter VII - Conclusion } & 204\end{array}$

$\begin{array}{ll}\text { Overview } & 204\end{array}$

Predicted Effects 208

Future Research $\quad 212$

Value of Case Study $\quad 219$

$\begin{array}{ll}\text { References } & 223\end{array}$ 
Appendices

236

Appendix A: Written Questionnaire for KMU Students

236

Appendix B: Informal Interview Questions for KMU Students

238

Appendix C: Informal Interview Questions for

Study Group Members

240 
LIST OF FIGURES $\quad$ Page

Figure 2.1 Map of Taiwan and Fujian Province 36

Figure 3.1 Han Characters with Zhuyinfuhao $\quad 87$

Figure 3.2 Simplified Han Characters with Romanized Writing 88

$\begin{array}{ll}\text { Figure 3.3 Romanized Beiweiji Taiwanese } & 91\end{array}$

Figure 3.4 Romanized Taiwanese Mixed with Han Characters 93

Figure 5.1 Han Characters with Romanized Writing 137

$\begin{array}{ll}\text { Figure 5.2 Romanized Taiwanese } & 140\end{array}$

Figure 5.3 Han Characters with some Romanized Terms $\quad 140$ 


\section{LIST OF TABLES}

Page

Table 6.1 Students' Linguistic Backgrounds

168

Table 6.2 Regional Backgrounds

172

Table 6.3 Parents Occupations

174

Table 6.4 Students' Majors

176 


\section{Chapter I: Introduction}

This case study utilizes contemporary anthropological theory to describe and analyze a group of medical care workers and language teachers who are developing Taiwanese language medical school curriculum. The organization of Taiwanese language medical studies curriculum is an example of social action to resist symbolic aspects of a pervasive cultural and political hegemony of Chinese nationalism in Taiwan. People in Taiwan are identified with this nationalism through linguistic practices that privilege Mandarin as the dominant language in spoken contexts and Han characters as the standard writing system. The subjects of this study are resisting this hegemony by promoting the use of an alternative Roman letter-based writing system; alternative language practices designed to elevate the status of the Taiwanese language; and an alternative historical narrative in an effort to create a Taiwanese national identity. This rival nationalism rejects the authenticity of the Chinese nationalism that was promoted by the Kuomintanggoverned Republic of China in post-war Taiwan.

Since the end of the Chinese Civil War in 1949, when the Kuomintang's Republic of China military forces lost to the Communist Party of the People's Republic of China and retreated to Taiwan, Taiwan's status as a national entity has been ambiguous. While the 
Kuomintang forces originally planned to be based in Taiwan temporarily before staging an attack in order to win back control of Mainland China from the People's Republic of China, these plans were gradually abandoned. Instead, since 1949, there has been an unresolved military standoff, with the Communist Party ruling all of Mainland China as the People's Republic of China and the Republic of China being the de facto state government ruling over Taiwan.

Since 1949, both the Republic of China and the People's Republic of China have claimed sovereignty over Taiwan. In addition, in Taiwan, under the administrative rule of Republic of China state apparatus, the Kuomintang has gone from being the uncontested ruler of a one-party totalitarian state to being one of two major political parties that competes for votes every four years in democratic elections. In this two-party democratic system, Taiwan's national status has become further complicated by a movement initiated by the Kuomintang's rival political party, the Democratic Progressive Party, to declare independence from China and create a separate Taiwanese nation, known as the Republic of Taiwan.

The People's Republic of China vehemently opposes movements towards Taiwanese independence, and it vows to invade Taiwan and use military force to bring it under the 
full control of the People's Republic of China in the event that the Democratic

Progressive Party wins full electoral control of Taiwan and declares independence. Fear of military reprisal from Mainland China is therefore one factor influencing voters to refrain from supporting the DPPs movements towards independence.

In addition to being dissuaded from severing their links with China due to fear of military threats from the PRC, voters are also strongly influenced by Taiwan's increasing integration into the economy of Greater China, which includes Mainland China, Hong Kong, and Taiwan. Therefore, while in the past two decades, there has been an increasing consciousness of and support for Taiwanese identity, there is a simultaneous movement towards economic integration into Greater China (Chu 2004:498). It is in this context that language use is symbolically meaningful for young Taiwanese people as both a mark of ethnic and national identification and as a component of the educational requirements needed to gain status and qualify for employment in job markets in both Taiwan and the Greater China regional area.

The purpose of this case study is to illustrate how language use and the promotion of literacy are related to national and ethnic identification and participation in different occupational fields. Therefore, this study seeks to answer the following four research 
questions: What roles have literacy conventions, language practices, and historical narratives played in the construction and maintenance of the Kuomintang's Chinese nationalist hegemony in Taiwan? How do people in Taiwan utilize and modify writing systems, language practices, and historical narratives to serve as identification markers that position themselves and others in relation to this nationalist hegemony? What is the relationship between different occupational backgrounds and people's agency in creating, adopting, resisting, and transforming these different symbolic components of nationalist hegemony? How have relationships between language, identity, and hegemony shifted during the past two decades as conceptions of nationhood in Taiwan have become increasingly ambiguous and disassociated from the Republic of China's administrative state structure?

\section{Literacy, Historical Narratives, Language Domain Norms and Nationalism}

Contemporary nationalist theory views language use and literacy as key factors in the rise of nationalisms. Literacy in a national language is related to national identity in two ways. First, communities of people who read the same print media tend to develop common national identifications. Second, people develop nationalist identifications through the common experience of being educated in the same standardized medium of 
instruction in national education systems. Benedict Anderson views the rise of print media in vernacular languages, especially the mass production of German-language Bibles in the sixteenth century, as constituting a strong contribution to the development of nationalism in Europe (1991:37-40). Anderson similarly cites the importance of vernacular language newspapers in the Americas during the eighteenth century in creating communities of readers who identified themselves as having shared common experiences and feelings of belonging to geographically-based communities through reading the same print media (1991:61-63). These "imagined communities" in Europe and the Americas then formed the basis for the development of national identities (Anderson 1991:84).

In addition to creating national cultural imaginaries through common readership of print media, educating the public in a common standardized print vernacular through public school systems also serves to create further associations between literacy and national identification. For example, Marxist historian Eric Hobsbawm espouses the belief that educational institutions have played highly influential roles in indoctrinating students with a sense of belonging to national power structures and instilling students with a further sense of identification with national polities through the participation in ritualized national "traditions" (1990:73,92). 
The historical consciousness that is associated with a language variety through participation in formal education systems also involves learning certain narrative choices at the expense of others. In their writings on nationalism theory, Philip Spencer and Howard Wollman state that nationalist intellectuals typically employ historical narratives and linguistic categorizations in order to justify standardizing language varieties in a manner that privileges certain language varieties over others and construct categorization schemes that form the basis for ethnic and national identifications (2006:74-76). In addition, the historical narratives taught in education institutions are selectively constructed through the inclusion of some aspects of the past and exclusion of others in ways that are designed to legitimate the existence of nationalist power structures (Spencer and Wollman 2006:81). Using the national language and standardized writing format as the medium of instruction in public schools has the further effect of creating associations between these officially recognized historical narratives and literacy in the standard national language.

Through the teaching of official languages in educational institutions, the symbolic properties of language become more potent as national identification and historical consciousness are both evoked through the act of participation in a speech community. 
Sue Wright notes that language functions both as a medium for communication and as a mark of identity; furthermore, "in national education systems, the learning of a national language is always accompanied by having students internalize other aspects of national identification, such as historical narratives and conceptions of ethnic identification" (Wright 2004:46,63). Judith T. Irvine and Susan Gal use the term "idexicality" to refer to the manner in which language practice marks people as being members of different social groups (2009:403). As Irvine and Gal write:

"Participants' ideologies about language locate linguistic phenomena as part of, and evidence for, what they believe to be systematic behavioral, aesthetic, affective, and moral contrasts among the social groups indexed. That is, people have, and act in relation to ideological constructed representations of linguistic differences" (2009:403).

Therefore, in the context of the nation state, the decision to speak one language variety over another is also a decision for speakers to identify themselves with specific national constructs and symbolically disassociate themselves from others.

In the context of a nationalist hegemony, the power dynamics between different social groups influence linguistic choices that speakers make in interactions with one another. For instance, Wright notes that in environments where speakers of different language varieties come into contact with one another, and the different language varieties are imbued with differing degrees of social prestige, speakers of the less powerful 
language variety typically alter their speech to accommodate the linguistic practices of speakers of the more powerful language variety (Wright 2004:7). As a result of the power dynamics that are symbolized through language use, speakers typically attempt to strategically use language as a means of creating situational identification markers that are influenced by language domain norms regarding the appropriateness of different language varieties for different situations. For instance, in her writings on language and power dynamics, Susan Gal states that when bilingual members of disempowered groups alter their speech to the dominant language in the presence of monolingual members of dominant groups as a gesture of "politeness," it is an indicator of what she terms "linguistic domination" (1988:257-8).

Nationalisms are commonly accompanied by language domain norms that privilege the use of the national language over other language varieties as the language of prestige in domains of official public discourse. For instance, Pierre Bourdieu writes:

"It is in the process of state formation that the conditions are created for the constitution of a unified linguistic market, dominated by the official language. Obligatory on official occasions and in official places (schools, public administrations, political institutions, etc.), this state language becomes the theoretical norm against which all linguistic practices are objectively measured" (1991:45).

Therefore, the ability to speak, read, and write the national language and conform to these 
language domain norms is also a symbolic identification marker of power and prestige.

Language domain norms also reflect power relations through different linguistic choices that are associated with dialog about different types of subject matter. In the context of a nationalist hegemony, the national language is used in more prestigious domains of discourse, while alternative language varieties are reserved for the use of less prestigious and informal discourse domains. For instance, in his research on linguistic minorities in Austria, John Gumperz observed this tendency and wrote that bilingual members of disempowered groups usually spoke in their native language during informal activities and spoke the national language during more institutionalized, formal, and impersonal activities (1982:66). Gal has also noted the existence of language domain norms favoring the dominance of national languages and has observed that bilingual speakers of less prestigious language varieties tend to switch to the national language when they wished to convey expertise and social authority (1988:254-5). By conforming to these language practices, then, speakers reinforce power relations that grant greater status to those who can speak the national language, and deny access to power to those who are unable to conform to mainstream language domain norms. 


\section{Hegemony, Power, Agency, and Resistance}

The second research question seeks to understand how people creatively adopt and modify literacy conventions, historical narratives, and language practices in order to create identities that position themselves and others in relation to a nationalist hegemony. On one hand, this positioning can be done with the intention of creating identities that are positively associated with the hegemony in order to gain access to the benefits of being in positions of power and prestige within a nationalist power structure. On the other hand, however, these same identification markers can also be created and utilized as a means of resisting a nationalist hegemony by calling its legitimacy into question and instead creating identifications with alternative rival power structures.

Raymond Williams describes hegemony as structures of domination in which the interests of a ruling group are served and legitimated as natural through not only consciously articulated ideology but also through "the whole lived process as practically organized by specific dominant meanings and values" (1977:108-109). While hegemonic forms, such as "movements and tendencies in intellectual and artistic life," serve to create the cultural conditions that enable certain social groups to establish and maintain dominance over others, the role of these forms in creating and maintaining hegemony is 
not necessarily apparent through the analysis of the workings of formal state institutions

(Williams 1977:117). Consequently, Williams states that in order to understand how

hegemony serves to create the conditions in which people voluntarily act in compliance

with unequal social structures, both formally recognized institutions and informal cultural "formations" must both be analyzed (1977:119,138).

Pierre Bourdieu's concepts of "symbolic capital" and "cultural capital" are helpful conceptual tools for understanding the roles that cultural forms, such as language practices, literacy, and academic degrees, play in relation to nationalist hegemonies. Bourdieu advocates adopting a "general science of the economy of practices," which views all practices as being "directed towards the maximizing of material or symbolic profit" (1977:183). Because people make use of these different forms of capital in the context of hegemonic power structures, researchers can make use of this theoretical framework by observing which kinds of behaviors and practices enable people to gain status and prestige and then viewing these practices as forms of symbolic capital. People make use of these different forms of capital to gain power and position themselves in relation to hegemonic power structures.

The power relations that are created and maintained through hegemonies can also be 
understood through analyses of how people exercise "agency," which Laura Ahearn defines as a "the sociocultural mediated capacity to act" (2001:112). Practice theorist Sherry Ortner states that the power that is exercised through agency can come from people acting in both positions of dominance and from those resisting dominance from subordinate social positions (2006:139). Therefore, power structures and culturallyrecognized forms of capital serve as contextual parameters for social action, and as Ahearn states, although they restrict people's abilities to act, they also serve as resources that enable people to exercise agency (2012:23). Ahearn also notes that although power structures shape the ways in which people are able to exercise agency, people also have the potential to modify the workings of macro-level social structures through practices of resistance in their everyday practices within the framework of nationalist and hegemonic power structures (2012:23). In his assertion that "Where there is power, there is resistance," Post-structuralist Michel Foucault conceptualizes resistance as an integral component of how people act in relation to power structures (1978:95). Lila Abu-Lughod further elaborates on Foucault's theoretical approach and advocates viewing resistance as "a diagnostic of power" (1990:42). This study draws from these theoretical frameworks and views Taiwanese nationalists' attempts to challenge status quo literacy conventions, 
historical narratives, and language domain norms in Taiwan as both acts of resistance and evidence that the symbolic forms being resisted function as forms of symbolic capital that support Chinese nationalist hegemony in Taiwan.

The study group members, who are the subjects of this thesis, are resisting Chinese nationalist hegemony in Taiwan by rejecting the dominance of Mandarin in the domain of public speech and Han-character-based Mandarin-language literacy as the dominant writing system, both of which symbolically identify people in Taiwan with the Kuomintang's Chinese nationalist hegemony. Study group members are instead promoting alternative linguistic practices as a means of challenging this hegemony and creating a rival Taiwanese national identity.

\section{Occupation, Literacy, Language, and Nationalism}

The third research question seeks to gain an understanding of the relationship between people's occupational backgrounds and their willingness and motivation to participate in activities that involve creating, adopting, and transforming different symbolic components of a nationalist hegemony. There are two reasons why there is a strong relationship between different people's occupational backgrounds and their adherence to specific language practices and literacy conventions. The first reason is that 
language aptitude and literacy in national languages typically function as gateways to employment opportunities in most prestigious and desirable professions. The second reason is that the people who construct nationalisms are typically employees in specific occupational fields, and when they act to determine which language variety and writing system will become the national standard, they typically choose the linguistic resources that are valuable in their fields of employment.

Because credentials in academic institutions are required prerequisites to gain access to employment opportunities, prospective employees are required to demonstrate language proficiency and a strong command of literacy as a part of the certification process. This study defines literacy as the ability to read and write in text formats that are written using an established and officially sanctioned writing system, which is the written counterpart of an official language. Linking symbolic markers of national identification such as language aptitude and literacy in the national language to access to employment opportunities has the effect of making them more than just aspects of national imaginaries and instead makes conforming to these norms have real consequences on people's livelihoods in their everyday lived experiences.

According to Pierre Bourdieu, "linguistic capital" is a resource that is unequally 
distributed to different members of society, and the establishment of high-status languages, such as "official languages" and "national languages" serves to grant greater empowerment to those who have the greatest competence in the use of dominant languages (1991:45-6,71). Therefore, people act to create hierarchies in which dominant languages are viewed as the norm, and people who do not have access to the standard forms of "linguistic capital" are accorded lower socioeconomic status (Bourdieu 1991:109). However, in addition to political power, language practices are also economic status markers because people with highly-valued language skills are also granted greater access to employment opportunities in job markets that value certain forms of "linguistic capital" over others (Bourdieu 1991:45-6,71). This is largely because the ability to achieve linguistic competence in languages of prestige is also usually contingent on academic achievement in state-approved education institutions (Bourdieu 1991:61). Linking aptitude in standardized languages and literacy formats taught in national education systems as both prerequisites for employment and symbolic marks of national identification has the effect of firmly entrenching them as unquestioned symbolic components of status quo behavior. This also has the effect of deterring most people from resisting these forms because refusal to conform to mainstream language domain norms 
and literacy conventions typically excludes them from eligibility for employment in most occupational spheres of political and economic power.

Occupation is also an important component of national identification because nationalisms are typically created by people who are involved in specific economic activities. Furthermore, as nation builders, members of these occupational circles have leeway to legitimate their power as national leaders by basing the standard national languages and officially recognized literacy forms on the linguistic resources that are valued as linguistic capital in their own professional lives. This has the effect of boosting nation builders' prestige within a national power structure and legitimating their domination over other social groups. Members of subordinate social groups are instead identified both through the speaking of alternative language varieties to the national standard and through their failure to meet the standards of literacy that grant them access into membership in social groups and occupational fields of prestige and power.

Benedict Anderson notes this tendency in his historical analysis of the rise of nationalism in Europe. Anderson states that the rise of literate bureaucratic middle classes was an important development in the development of nationalism in the seventeenth century (Anderson 1991:84). These bureaucratic administrators gained access to 
employment based upon their literacy in print vernacular language varieties, and as early participants in the "lexicographic revolution" brought about by print capitalism they were some of the early proponents of European nationalism (Anderson 1991:84). As members of the literate bourgeois populace, they were one of the first occupational groups to subscribe to the belief that groups of people who spoke common languages were members of the same "imagined communities," and this belief was symbolized in their use of standardized literacy forms in daily life (Anderson 1991:84).

As power relations between social groups and the structure of the participants' social networks change, linguistic practices adhered to by network members also shift (Gumperz 1982:50). In addition, people can use language and literacy conventions as resources to promote their interests or they can contest them by either refusing to adhere to them or by creating and practicing alternative norms. As Susan Gal notes, the development of new language-domain conventions is "not only symbolic of a newly forming social entity; it is instrumental in creating it" (1988:259). Therefore, bilingual speakers do not just modify their linguistic practices in order to alter their identities so that they can fit into pre-established social networks. They also act to create novel forms of language use as a means of strategically forming new identifications and new social 
networks. These new social networks are frequently influenced by both the shared occupations of the participants in the social networks and the linguistic practices that are associated with the participants' occupations.

Laura Ahearn conceptualizes language practice as a form of agency that is done in the context of other social practices and social meanings, which are indexed through language ideologies $(2012: 8,12,22)$. Ahearn also views language as a symbolic resource and states that "questions about social relations and cultural meanings can be best understood by paying close attention to language" (Ahearn 2012:17). Because linguistic practices and the power relations embedded in social structures mutually influence one another, Ahearn advocates the study of language practices as a means "to connect microwith macro-level social interactions and to analyze questions of cultural identity, morality, power, inequality, and social stereotypes" (Ahearn 2012:8,22). Ahearn also states that language ideologies generally serve to protect the power and interests of specific social groups; furthermore, people may or may not be consciously aware of these ideologies $(2012: 20,22)$. Therefore, the study of language use can provide insight into the nature of power relations that are unarticulated components of hegemonic power structures. In addition, by adopting Abu-Lughod's approach of viewing "resistance as a diagnostic of 
power," linguistic changes that are brought about as a result of people using language practice as a resource to resist power structures can serve as empirical data to "detect historical shifts in configurations and methods of power" (1990:48). In the context of this study, the acts of speaking Taiwanese in language domains that have conventionally been dominated by Mandarin in mainstream discourse and promoting an alternative writing system to Han characters are both representative of and instrumental in the creation of an alternative Taiwanese nationalism.

\section{Han Characters, Mandarin, and Chinese Nationalism in Taiwan}

The link between occupation, literacy, and nationalist identification is particularly relevant to this study because the Taiwanese language curriculum planners who are the subjects of this study practice alternative language domain norms and utilize an alternative writing system to those used in mainstream public discourse. They practice these alternative norms as tactics of resistance against the Kuomintang's Chinese national hegemony in Taiwan. Furthermore, the curriculum planners' decision to engage in these linguistic practices is also due, in part, to the nature of the language skills and literacy formats that are associated with their occupations as medical care workers.

Han characters play a powerful role in the creation and maintenance of Chinese 
hegemony because they function as both a medium of communicating and documenting information and as a way of marking Chinese identification. Because Mandarin language proficiency and Han character literacy are prerequisites for access to economic and political power in Taiwan, in contemporary contexts, most people feel compelled to conform to the practice of using these identification symbols in their daily lives. During the Qing Dynasty (1644-1912), Han characters were used by a minority of the population in Taiwan, who were mostly educated in order to gain qualifications for employment in occupations related to public administration (Wei: 2006:96). The use of this writing system also symbolically marked Taiwan as a peripheral territory in the dynastic power structure's spheres of influence (Wei: 2006:96). In the post-war national education system established by the Kuomintang in Taiwan as a province of the Republic of China, Han characters were again adopted as the standard writing system to correspond with the officially-recognized Mandarin standard language. This writing format symbolically associates the use of Han characters as a component of the Republic of China's nationalism with a corpus of literary documents used during previous dynastic empires that existed in much of the same territory that has been claimed by the Republic of China during the twentieth century (Wright 2004:110). In addition, it has the effect of 
compelling people to adopt this writing format in their everyday lives as a means of securing access to social positions of prestige and influence. As will be further discussed in Chapter III, even though most people in Taiwan no longer ideologically identify themselves with the Republic of China's nationalism, they continue to adhere to these linguistic practices in their everyday lives.

Due to the influence of this Chinese nationalist hegemony, for most of the twentieth century language varieties other than Mandarin have been marginalized in Taiwan. Therefore, in the mainstream paradigm of literacy in Taiwan, which was originally created based on the KMT's Chinese nationalist ideology, the Taiwanese language has typically been spoken by the elderly and people in rural locations and consigned to the status of a spoken "dialect." As a "dialect" it has been considered unfit to be used as a communication medium in prestigious spheres of discourse and therefore consigned to low-status and unofficial spheres of discourse. Furthermore, as will be discussed in greater detail in Chapters II and III, during the post war period of Kuomintang rule, speakers of this language were denied access to political and economic power on the basis of this linguistic identification. 


\section{Resistance Through Taiwanese Language Medical School Curriculum}

The group participants who are documented in this thesis seek to challenge the dominance of the Republic of China's literacy conventions and language domain norms, which grant preferential status to Han characters and the Mandarin language in public discourse. They instead seek to replace it with literacy in Romanized Taiwanese language texts and encourage the use of the Taiwanese language in spheres of discourse which are currently dominated by Mandarin. Taiwanese language medical studies curriculum and testing materials serve as a platform to champion the cause of bringing about a shift in language ideology and literacy forms in Taiwan. This shift is symbolically associated with an alternative form of Taiwanese nationalism and an alternative narrative of history to that associated with the Chinese nationalism of the Kuomintang Party. The curriculum planners draw on this alternative historical narrative to support the legitimacy of their project and construct an alternative Taiwanese national identification.

The study group participants' occupations as medical care workers enable them to exercise noncompliance with mainstream linguistic norms, and they incorporate linguistic resources that are valued in their professional lives into their nationalist identifications. Medical doctors occupy an occupational niche where the ability to speak Taiwanese is 
advantageous, because they need to communicate with patients who are from a variety of social backgrounds. Their social position is an asset in facilitating their ability to present Taiwanese language literacy as a legitimate and desirable education initiative, first in medical universities, and then in mother language education programs in public schools, which will be described in greater detail in Chapter III. This is a unique occupational niche because although medical care workers enjoy a privileged socioeconomic status, they regularly interact with patients who are disproportionately elderly and from a wide variety of socioeconomic backgrounds. Consequently, in contrast to employees in most other high-status occupations, who are symbolically identified by speaking exclusively in Mandarin in the workplace, many doctors continue to speak Taiwanese on a regular basis while carrying out their occupational duties.

\section{State Power and Nationhood}

The fourth research question concerns changes in the relationships between language, identity, and hegemony that have taken place over the past two decades as conceptions of nationhood in Taiwan have become increasingly ambiguous and disassociated from the Republic of China administrative state structure. Anthony D. Smith's distinction between the nation and the state is a useful framework for 
understanding this issue. According to Smith, "The latter is a legal and institutional concept. It refers to autonomous public institutions which are differentiated from other, social institutions by their exercise of a monopoly of coercion and extraction within a given territory. The idea of the nation, by contrast, is fundamentally cultural and social. It refers to a cultural and political bond which unites in a community of prestige all those who share the same myths, memories, symbols and traditions" (Smith 1992:61-62). As will be described in greater detail in Chapter II and Chapter III, in Taiwan since the lifting of martial law in the later 1980s, the Kuomintang has lost its monopoly on political power, and it is now one of two political parties that compete for votes in Taiwan. Due to the Kuomintang's failure to successfully retake control of Mainland China after 1949, Taiwan's diplomatic isolation, and an increasing shift from Chinese national identification towards Taiwanese identification among the population in Taiwan, the Republic of China has lost its ideological viability as a national entity. This creates a unique situation because although the state apparatus and infrastructure of the ROC still exists and is used as the default administrative structure in Taiwan due to a lack of other viable alternatives, very few people currently identify with the ROC nationalism that was the ideological counterpart of the state during the martial law years. However, the 
democratization and ideological shift among the Taiwanese population towards an increasing sense of Taiwanese identity, has occurred at the same time that Taiwan has been increasingly incorporated into a Greater China regional hegemony through economic processes.

Comparative disjunctures between state power and nationalism have also been noted by scholars studying nationalism in the European Union. For instance, in analyzing the changing relationship between the nation and the state in the EU, Neil Brenner states that since the 1970s, European states have responded to the increasing globalization of capitalist economic structures by "denationalizing" regulatory state powers and instead allocating some of their former functions to EU supranational regulatory structures $(1999: 439,441)$. Brenner states that although the state has given up some of its regulatory powers over economic matters, there has not been a corresponding "contraction, retreat or dissolution of state territoriality" (1999:438). Philip Schlesinger has also noted the existence of "stateless nations," such as Catalonia and Scotland, where people have developed increased feelings of national identity that exist independent of a corresponding state power in the EU (1997:392).

Aiwa Ong compares the Greater China regional economy to the European Union, 
noting that they share the common characteristic of being large regional economic structures that operate across the borders of state administrations (2006:98). However, Ong states that they differ in the sense that the EU is a formal structure that has been created through overt negotiations between state governments, while Greater China is an informal structure that has developed as a byproduct of economic policies in the People's Republic of China (2006:98). According to Ong, the People's Republic of China is using economic integration and allowing for administrative autonomy of Special Administrative Regions, such as Hong Kong and Macau, under the umbrella of a single common Chinese national structure as a means of derailing movements towards Taiwanese national autonomy (2006:98-99). Ong uses the term "graduated sovereignty" to describe the balance of power in Greater China and notes that although regional areas, such as Hong Kong, Macau, and Taiwan have state structures with varying degrees of de facto autonomy, they are still constrained from pursuing formal national autonomy due to the threat of war with the central government of the People's Republic of China (2006:7). In the context of overlapping administrative structures in the Greater China region, some localized groups have new opportunities to stake claims to alternative regional, ethnic, and linguistic identifications. In Taiwan the situation is particularly unique because 
the Republic of China state apparatus is perhaps the only "nationless state" in the world today. Furthermore, as will be further discussed in Chapter V, conceptions of Taiwanese identity co-exist with people's participation in the Greater China regional economy and job markets. It is in this context of Taiwan's ambiguous status as a political entity in the community of contemporary nation states that people use language as a resource to negotiate conceptions of national and ethnic identity and to gain access to power and prestige in the Greater China regional hegemony. Because group membership and cultural capital are highly influenced by linguistic practice and those who are able to claim different group identifications have differential access to economic and political resources, this study seeks to arrive at a greater understanding of the relationship between language use, occupation, ethnic identification, and national identification in the context of shifting and competing hegemonic national power structures in contemporary Taiwan.

\section{Research Site and Methodology}

I conducted the fieldwork for this project at two research sites in Kaohsiung, Taiwan, where I collected data through participation observation, written questionnaires, and recorded semi-structured interviews. Due to its prominence as a port city and industrial center, Kaohsiung is the second largest city in Taiwan, and it has a sizable minority 
population of people who are descendents of people who migrated to Taiwan as refugees from Mainland China with the Kuomintang and spoke Mandarin as an identification mark one generation ago (Van Den Berg 1986:102). However, Kaohsiung is also located in the south, which is a political stronghold of the pro-independence Democratic Progressive Party (DPP). In the south of Taiwan, Taiwanese is still widely spoken, and it is the location where curriculum planners for Taiwanese language education programs are predominantly based.

Prior to moving to Kaohsiung in 2009, I already had Mandarin-language skills that enabled me to conduct participant observation research and interviews with Mandarin speakers for this project. I learned to speak, read, and write Mandarin through four years of formal Mandarin-language classes at Tonghai University and Providence University in Taichung, Taiwan from 1999-2003. I also had two years of experience working as an editor at a bilingual news magazine in Taipei County from 2004-2006. While living in Taipei, I received one year of Taiwanese-language instruction at Taipei Language Institute (TLI), and during the two years that I lived in Kaohsiung City from 2009-2011, I was also enrolled in Taiwanese language classes at the TLI branch in Kaohsiung. I learned about the implementation of Taiwanese language courses at Kaohsiung Medical University in 
the fall of 2010 when I was conducting preliminary research to seek out environments where students speak Taiwanese on university campuses in Kaohsiung. Through eight months of ethnographic fieldwork, using participant observation, written questionnaires, and recorded semi-structured interviews, I interacted with both the doctors and language instructors who design Taiwanese language medical studies curriculum and with university students who were enrolled in the courses. The coursework involved the promotion of a writing system using Roman letters instead of Han characters for the Taiwanese language. It also involved teaching a historical narrative that promotes Taiwanese national identification while refuting the historical narrative and conceptions of literacy characteristic of the Chinese nationalism taught in public schools in Taiwan.

My first research location was at bimonthly study group meetings between December 2010 and July 2011, where participants collaborated in the editing of Taiwanese language medical studies curriculum and testing materials. The participants were either doctors, medical care workers, or language instructors, and meetings were held from 1:00 pm to approximately 4:30 on Sunday afternoons in a suburb of Kaohsiung. I collected data by both taking written notes during meetings and conducting recorded semi-formal personal interviews with regular participants at the meetings. Eight study 
group participants agreed to meet with me individually in order to conduct recorded interviews that were on average one hour in length. Five of the interviews were recorded in the study group members' homes, and three were conducted in restaurants.

After my initial visit to the study group when the other members became aware that I was able to recognize the meaning of many of the medical terms by reading the Han characters due to my previous experiences working and studying in Taiwan, I was asked to assist the study group by editing the sections of the dialog that were translated into English. Therefore, as a researcher, I became a full participant in the editing process. I believe that the members liked having a western participant in their meetings because it represented a link with the outside world and they felt that by being the subject of an academic paper, their nationalist ideology could gain publicity and legitimacy in international academic circles. In addition, by having English translations of the dialogs in the textbook chapters, study group members felt that the instructional materials would be more accessible to international audiences and symbolically associate the Taiwanese nationalism promoted in the coursework with the power of developed western nations. The second research location was two medical studies courses that were taught during Spring Semester 2011 at Kaohsiung Medical University (KMU) in Kaohsiung, 
Taiwan. KMU was founded in 1954 as Taiwan's first private medical school, and it is considered one of the most prestigious universities in southern Taiwan. KMU ranks in the top ten by USA Essential Science Indicators, and admissions to KMU is very competitive, especially the medical school, which has an admissions rate of 4.16\% (Newsweek 2012). The primary criterion for admission to universities in Taiwan is a high test score on the National Entrance Examination, which is written in Mandarin using Han characters. Therefore, language proficiency in the Mandarin language and literacy in Han characters are crucial prerequisites for enrollment at KMU.

I engaged in participant observation by auditing two ninety-minute classes each Tuesday afternoon, and during classes, I took written notes on both the students' behavior and the course curriculum. In addition, I also conducted semi-structured recorded interviews with thirteen students who were enrolled in the classes and collected data about the students' demographic backgrounds through written questionnaires. My presence in the class as a graduate student conducting participant observation research was welcomed by the instructors, and during the lectures, they occasionally made reference to my presence in the room. I believe that my conspicuous presence in the classroom served, in part, to legitimate the claim made by instructors that the Romanized writing system taught 
in the course is fit to function as a symbolic identification marker for their vision of a Taiwanese nation which is symbolically linked to an international community of modern developed nation-states that also use the Roman alphabet. Therefore, my role as a researcher allowed me to be welcomed into the group of curriculum planners, and I became a full participant in the project of editing the English translations of the Taiwanese language medical curriculum and testing materials.

\section{Thesis Organization}

This thesis is organized into six chapters. Following this introductory chapter, the second chapter is a historical review of power dynamics between different ethnic groups

and political administrations in Taiwan during the past five hundred years. The inhabitants

of Taiwan have participated in and been influenced by interactions between aboriginal populations, migrants from southern China, European and Japanese colonial forces, and Chinese dynastic and nationalist power structures. Chapter III describes how different language and education policies have been used to shape ethnic and national identifications by different administrations during different historical eras in Taiwan. The role of official languages, literacy conventions, and historical narrative in the creation and maintenance of hegemonic power structures are examined in the context of Taiwan's 
historical background. Chapter IV is an ethnographic study of doctors and Taiwanese language instructors who were participants in curriculum editing "study group" meetings from December 2010 to July 2011 in Kaohsiung. The linguistic and occupational background of the curriculum planners are analyzed as key resources in their activities of resistance against Chinese nationalism and their promotion of an alternative Taiwanese nationalism. Chapter $\mathrm{V}$ is a description of the testing and curriculum materials that were developed at the study group meetings and a description of the course curriculum used in the Taiwanese language medical studies classes during spring semester 2011 at Kaohsiung Medical University. The curriculum and testing materials are being used as a platform with the goal of creating alternative language domain norms and promote an alternative writing system and historical narrative in order to persuade students to reject being identified with Chinese nationalism and instead identify themselves with a rival Taiwanese nationalism. Chapter VI is an ethnographic description of students' language practices and ideologies based on data from written questionnaires and semi-structured interviews with students enrolled in the Taiwanese-language medical studies classes at KMU. The students' demographic backgrounds and academic fields of study are analyzed as factors that influence their linguistic practices and their willingness and motivation to 
adopt different symbolic components of the rival national identification promoted through the Taiwanese language medical studies curriculum. The final chapter is a conclusion that summarizes the findings from the ethnographic data and relates them back to the theoretical foundations presented in this chapter. The conclusion also includes a discussion of the theoretical implications of this study and plans for future research. 


\section{Chapter II: Historical Background}

\section{Introduction}

In order to provide the reader with the background information needed to understand the social and political climate in contemporary Taiwan, this chapter provides an overview of Taiwanese history. Outlining the historical background facilitates a greater understand of how selective constructions of the past are used to create narratives. In contemporary Taiwan, competing Chinese and Taiwanese nationalisms stake their claims to legitimacy through the use of different historical narratives, and allegiance to these narratives of the past are symbolized through the strategic use of literacy conventions and language domain norms in contemporary contexts.

Taiwan is a subtropical island that lies approximately 442 kilometers off the coast of China's Fujian Province, and it covers a landmass of 32,260 square kilometers. Approximately one third of the land in the west is flat plains that are suitable for agriculture, while the eastern portion of the island is rugged and mountainous (CIA 2012). The estimated population is $23,113,901$, with most of the population concentrated in urban centers in the northern and western plains regions (CIA 2012). 




Figure 2.1. Map of Taiwan and Fujian Province (Source: Reader's Digest Atlas of the World 1989)

\section{Language and Ethnicity}

Taiwan is composed of four major ethnic groups that are predominantly identified by the languages that the group members spoke at the end of World War II. According to a 1999 study by Feng-fu Tsao, the descendents of refugees from Mainland China who migrated to Taiwan with the Kuomintang military government between 1947 and 1949 comprise approximately $12.6 \%$ of the population (Tsao 1999:329). Known as the Waishengren, members of this refugee population, who originated from diverse locations in Mainland China, were identified by speaking Mandarin as both a lingua franca and as 
the national language of China (1999:332). Mandarin was constructed in the early twentieth century by standardizing a spoken version of written vernacular that was commonly used by officials and already spoken by $70 \%$ of the population in northern China (DeBernardi 1991:2; Tsao 334-335). In 1912, Mandarin was selected as the new official vernacular language for the Republic of China by a branch of the Ministry of Education, known as the Committee for the Unification of Pronunciation (Tsao 1999:3345). The remainder of the Taiwanese population, known collectively as Benshengren, consists of Taiwanese speakers, who comprise $73.7 \%$ of the population; Hakka speakers, who comprise $12 \%$ of the population; and aboriginal people, or Yuanzhuming, who comprise $1.7 \%$ of the population. The linguistic categorization of Taiwanese is controversial because, while Chinese nationalists emphasize its commonality with other Min-nan language varieties spoken in Fujian Province, Taiwanese nationalists emphasize its uniqueness as a distinctive Taiwanese language (DeBernardi 1991:8,13; Mair 1991).

According to Chinese nationalists, the Min language group in Fujian Province is one of seven main branches of the Sinitic Language Family, and the Min-nan language varieties comprise one of five sub-branches of this language group (Stranzny 2005:190191). According to this interpretation, Taiwanese is a dialect of the Min-nan language, and 
it is comprised of a mixture of dialects spoken by migrants from the Zhangzhou and Quanzhou areas of Fujian Province (Stranzny 2005:190-191). Taiwanese nationalists refute this interpretation and instead emphasize the distinctiveness of Taiwanese from other Min language varieties due to the influence of colonial Dutch, Spanish, Japanese, and aboriginal languages (DeBernardi 1991:8,13). The Hakka language is categorized as another one of the seven branches of the Sinitic Language Family and it is spoken by an estimated forty million people residing in pockets throughout Guangdong Province, Fujian Province, Southeast Asia, Taiwan, and the New Territories in Hong Kong (Dalby 127-128:1998). Speakers of this language variety in Taiwan migrated to Taiwan from the sixteenth to nineteenth centuries from Guandong and Fujian Provinces (Sandel 2003:527). The remaining $1.7 \%$ of the population in Taiwan are members of Austronesian-languagespeaking aboriginal tribes, and their language practices and social organization patterns will be discussed in further detail in the first history section of this chapter.

\section{Identification as Social Practice}

Mary Bucholtz and Kira Hall's (2004) theoretical constructs of "authentication," and "denaturalization" and Rogers Brubaker and Frederick Cooper's (2000) concept of "identification" are useful approaches to understanding how language users and policy 
makers act in calculated ways to create and legitimate social and national categories through language use. These theoretical approaches share the common viewpoint that identities are not essential character traits that different groups of people have, but rather, both identities and groups themselves are constructed over periods of time through strategic processes of social action and linguistic behavior. Mary Bucholtz and Kira Hall state that:

“identity inheres in actions, not in people, and as the product of situated social action, identities may shift and recombine to meet new circumstances. This dynamic perspective contrasts with the traditional view of identities as unitary and enduring psychological states or social categories" (2004:376).

Therefore, instead of using the term "identity," Rogers Brubaker and Frederick Cooper advocate using the term "identification" because it emphasizes the variety of processes and contexts in which different groups identify themselves and others as belonging to or not belonging to different social groups (2000:14).

In addition to emphasizing how identifications are actively constructed by specific groups of people, these theoretical approaches also recognize that the construction of group identification requires investments of time dedicated to engaging in symbolically meaningful behavior. According to Sue Wright, the speaking of a language is a salient marker in establishing group identification because learning how to speak a language 
variety is a time-consuming process that usually requires speakers to have spent significant amounts of time speaking with other members of a given social group (2004:25). As will be discussed in greater detail later in this chapter and in Chapter III, language practice has been an important resource in the creation and maintenance of ethnic and national identities in Taiwan.

\section{Aboriginal Cultures in Taiwan}

Prior to the founding of the Ming Dynasty in the fourteenth century, when Taiwan fell increasingly under the commercial, political, and administrative influence of Chinese dynastic regimes, a variety of aboriginal tribes had already inhabited Taiwan for at least 6,000 years (Blundell 2009:14). Members of these aboriginal groups were clearly distinctive from future settlers in their physical appearances, languages, means of sustenance, and social organization. The contemporary Republic of China government recognizes twelve tribes that are descended from these aboriginal societies, and all of these groups shared the common trait of speaking Austronesian language varieties (Blundell 2009:9, 26). In contrast to future settlers on the island, none of the tribes had developed indigenous writing systems (Brundell 2009:19)..

In addition to speaking distinctive languages, the different aboriginal tribes also 
exhibited a wide variety of social organization and sustenance practices (Brunell 2009:27).

For example, whereas members of the Bunun Tribe lived in high altitude central mountainous regions and were organized according to a parilineal and patrilocal kinship structure, the Amis tribe inhabited the eastern coastal region and practiced matrilineal and matrilocal kinship structures (Brunell 2009:27). The kinship practices of the aboriginal tribes who lived in the western plains region, where most Han settlers came, are of particular interest to this study. In contrast to the patrilineal and patrilocal practices of future ethnic Han settlers from Fujian Province, these groups were organized according to matrilineal descent patterns. Later in history, these differences between the plains aboriginal tribes and ethnic Han kinship structures and their descent conventions became a contributing factor in the plains aborigines' future assimilation into Han culture (Blundell 2009: 28). Finally, in contrast to future Han settlers who engaged in rice farming and colonial trade, the aboriginal inhabitants' means of sustenance was based on millet farming, domesticating animals, such as chickens and pigs, and hunting deer and wild boar (Brundell 26).

In addition to speaking distinctive languages, the different aboriginal tribes also exhibited a wide variety of social organization and sustenance practices (Brunell 2009:27). 
For example, whereas members of the Bunun Tribe lived in high altitude central mountainous regions and were organized according to a parilineal and patrilocal kinship structure, the Amis tribe inhabited the eastern coastal region and practiced matrilineal and matrilocal kinship structures (Brunell 2009:27).

\section{Early Migration Patterns}

Family structure, language use, and economic factors formed the basis for group membership among the early migrants from Fujian Province, who interacted with aboriginal tribes in the western plains region of Taiwan. In the sixteenth century, the coastal region of Fujian province had an economy based on agriculture, fishing, and overseas trade links between Fujian, Japan, and Southeast Asia (Vermeer 1999:46). During this period, seafaring Fujian traders created temporary settlements in Taiwan, where they traded salt and fish with aboriginal tribes in exchange for deer hides (Willis 1999:86,88; Vermeer 1999:80). Men living in the coastal populations of Fujian province became increasingly inclined to migrate overseas during the final decades of the Ming Dynasty, when social conditions declined due to inefficient government administration, increasing tax burdens, epidemics, and an economic downturn in the global silver trade (Vermeer 1999:78). During the early seventeenth century, this trend continued, and men 
from coastal Fujian province began migrating to Taiwan permanently, where they frequently intermarried with aboriginal women and formed communities that were comprised of members who spoke the same languages due to the common geographic origins of their paternal lineages (Vermeer 1999:80).

\section{Dutch Colonial Rule}

During the Dutch colonial era from 1642 to 1662 , the people living in Taiwan's

ethnic identifications and group membership were influenced by the both the roles they played in economic trade with colonial powers and their language use. The first Dutch records regarding Taiwan, from the early 1620s, indicate the presence of between 1,000 and 1,500 Han settlers in Taiwan (Willis 1999:87). The Dutch sought to compete with Han, Spanish, and Japanese traders by establishing a colonial trading outpost in southwest Taiwan, near present-day Tainan (Willis 1999:89,91,93). After a period of initial conflict with Ming Dynasty forces, who monopolized trade along the Fujian coast, the Dutch made peace with the Ming naval forces, and more Han settlers migrated to Taiwan to farm rice and sugarcane (Willis 1999:8993) The Dutch also enlisted aborigines to serve in militias to control the Han population and collect taxes from Han farmers, so during this brief era, aboriginal tribe members who filled these occupational roles enjoyed a degree of 
power over Han settlers (Brown 2004:36-37).

The Dutch colonial era was cut short in 1661, when a Ming naval commander, Zheng Cheng-gong, who was at war with the newly established Qing Dynasty, retreated to Taiwan (Willis 1999:95). The force of over 25,000 troops outnumbered the Dutch forces, and the colonial administrators were forced to sign a treaty agreeing to leave the island peacefully along with the Dutch missionaries (Willis:1999:95). Zheng Cheng-gong's role in bringing Taiwan under the territorial control of a Han-Chinese regime and ending Dutch colonial control of Taiwan is especially important in the history of Taiwan because it would later become an important component of historical narratives employed by both Taiwanese and Chinese nationalists to legitimize their claims about Taiwan's position in the twentieth-century community of nation-states.

\section{Dynastic Rule}

The Zheng regime in Taiwan was only short-lived, and the Qing forces eventually succeeded in defeating the remnants of Zheng's forces in Taiwan in 1682 (Willis 1999:96,101). Under the Qing government, Taiwan became a prefecture of Fujian province in hopes that maintaining a presence in Taiwan would prevent it from becoming a base for rival foreign colonists and anti-Qing Han dissidents (Willis 1999:102). 
The shift from Dutch colonial rule to being incorporated into the periphery of Qing Dynasty rule brought about a massive shift in ethnic affiliation among the mixed Hanaborigine populace, which is estimated to have comprised between 39 and 50 percent of the population (Brown 2004:140-141). Members of the population who identified themselves as aborigine during the later years of the Dutch regime on the basis of their matrilineal descent had leeway to shift to Han ethnic identification during the Zheng regime by instead recognizing their patrilineal descent in response to the shifting value systems that accompanied the regime change (Brown 2004:140). Under the new regime, the status of the aborigines declined, and they came to be viewed as a source of cheap labor (Brown 2004:41). Therefore, whereas during the Dutch colonial era it would have been advantageous for children of mixed Han-aborigine ancestry to claim aboriginal identity, during the Zheng regime it was more advantageous to claim Han identity (Brown 2004:138-139).

The distinctions between different ethnic groups were highly influenced by the niches occupied by members of these groups in the political economy, and language use also served as a symbolic marker of group identification. Unmarried men, who were predominantly Hokkien speakers from Zhangzhou and Quanzhou in Fujian province and 
Hakkanese speakers from Guangdong province continued to migrate to Taiwan (Shepherd 1999:109,112-113). These male migrants frequently acquired land for rice farming by intermarrying with plains aborigine women, and their offspring adopted Han ethnicity using patrilineal descent as a criterion for determining their ethnic identification (Blundell 28; Shepherd 1999:109,112-113). Plains aborigines maintained their identification as a distinctive group from both mountain-dwelling aborigines and Han settlers because they filled an economic niche of leasing land for farming rice to Han settlers (Shepherd 1999:116).

During the second half of the nineteenth century, Taiwan became increasingly integrated into global trade and involved in power struggles between the Qing Dynasty and foreign colonial powers. The Qing dynasty's response to challenges to their power by other foreign interests influenced their efforts to assert control over Taiwan, and in the aftermath of the Sino-French War in 1885, the Qing government upgraded Taiwan's status to a province in order to exercise more direct control of the territory (Gardella 1999:187).

\section{The Japanese Colonial Era}

After the Qing Dynasty lost the Sino-Japanese War (August 1895 - April 1895) to Japan, the Qing Dynasty relinquished administrative control over Taiwan, and according 
to the terms of the Treaty of Shimonoseki it was ruled as a Japanese colony from 1895 to 1945 (Brown 2004:53). It was during this time period under Japanese administration that Taiwanese people's conceptions of their linguistic and ethnic identifications shifted towards being distinctively Taiwanese rather than Chinese. Furthermore, the Japanese colonial government's policies that were designed to administer and control the inhabitants of Taiwan also shaped the criterion for identifications that would later be adopted by nationalists when imagining a Taiwanese national community.

The ethnic affiliations of people who had previously identified themselves as belonging to separate groups changed due to the influence of administrative demographic categories put in place by the Japanese colonial administration; however, language use continued to be a key criterion for demographic identification. During the period of Japanese colonialism, the linguistic demographic category " $F u$ " or "Fujianese" encompassed speakers of both Zhangzhou and Quanzhou Hokkien language varieties living in Taiwan, while Hakka speakers constituted a separate linguistic category, known as "Guang" (Hsiau 2000:4; Brown 2001:156). Initially, the Japanese government continued the Qing practice of distinguishing mountain-dwelling aborigines from plains aborigines; however, by the 1930's most of the plains aborigines were physically, 
culturally, and linguistically indistinguishable from the Han majority and were consequently categorized together with speakers of the two Hokkien language varieties as members of the " $F u$ " Han linguistic group (Brown 2004:8-9). This development is significant because later in the twentieth century, Taiwanese nationalists would emphasize the intermixing of Han and plains aborigine populations as a means of redefining Taiwanese identification as being separate from Han Chinese populations on the Mainland.

The education system put in place by the Japanese administration also created opportunities for Taiwanese students to study abroad in both China and Japan, where they were influenced by Western intellectual ideas about modern social reforms (Hsiau 2000:30). Through the process of being educated abroad, they were also exposed to models of nationalism that had previously been developed in the Americas and in Europe, and they could later draw from these models to devise a nationalism that was indigenous to Taiwan (Hsiau 2000:30; Anderson 1991:116).

\section{Kuomintang Rule in the Post-War Era}

At the end of World War II, with the surrender of the Japanese colonial forces, Taiwan fell under the administrative jurisdiction of the Kuomintang-ruled Republic of China in accordance with the terms of the Cairo Declaration, which had been signed in 
1943 by United States President Franklin Roosevelt, United Kingdom Prime Minister

Winston Churchill, and Republic of China President Chaing Kai-shek (Philips 2007:280).

Taiwan's demographic population also abruptly shifted beginning in 1946 as two million

Han Chinese fled warfare in China between the Kuomintang (KMT) and the Chinese

Communist Part (CCP) and relocated to Taiwan. These refugees, known as Waishengren, accompanied the KMT forces as they took control of Taiwan (Hsiau 2000:50).

Many Taiwanese Benshengren, who made up the demographic majority and were comprised of the inhabitants of Taiwan prior to the influx of Waishengren refugees, initially welcomed the leadership change from the Japanese colonial government to the KMT administration (Philips 2007:281). However, they quickly became disillusioned with the KMT officials due to their rampant corruption and the inflation that resulted from the continuation of the Kuomintang's civil war with the Communist Party for control of Mainland China (Philips 2007:281). Elite Benshengren in particular had hoped that they would be entitled to share power under the new Kuomintang administration, and instead found themselves marginalized as they were excluded from positions of power and prestige (Philips 2007:282; Hsiao 1997:306).

As will be further described in Chapter III, the Kuomintang administration enacted a 
series of policies that institutionalized Waishengren social and political domination over the rest of the Benshengren population. Widespread discontent with the Kuomintang's administration of the island and their repression of the Benshengren majority led to mass unrest among the Benshengren population, and on February 28, 1947, the government responded to this unrest by killing thousands of critics of the KMT government and its territorial claims over Taiwan (Brown 2004:58-59). Known as the "2-28 Incident," this episode of overt state violence is considered a turning point in Taiwan's history because following this incident, KMT rule and Sinocization policies were strictly enforced and the Waishengren and the Benshengren social dichotomies became meaningful as oppositional categories (Philips 1999:296). In the aftermath, party leader and President, Chaing Kaishek declared martial law, which forbade the organization of rival political parties and transformed KMT rule in Taiwan into a de facto single-party totalitarian state that was politically and economically monopolized by the Waishengren Mainlanders (Hsiau 2000:64-65).

The KMT were completely defeated in Mainland China and retreated to Taiwan in 1949; however, due to the outbreak of the Korean War in 1950, the United States developed a policy of protecting the ROC government in Taiwan as a part of the Cold War 
containment strategy (Wang 1999:321). This military influence has enabled the ROC state in Taiwan to maintain de facto autonomy from the People's Republic of China in Mainland China for the past sixty years.

In the decades following the Kuomintang's consolidation of power in Taiwan, Taiwan experienced rapid industrialization and economic development. The KMT enacted land reforms during the early years of their administration in Taiwan, and Benshengren who were former landowners were compensated for land that was seized by the government. This allowed former landowners to both invest capital in industry and gain a degree of economic power over government-employed Mainlanders (Wang 1999:327). This capital was also instrumental in further developing Taiwan's infrastructure, and during the 1950s and 1960s textiles, electronics, and other industrial products were exported for sales in international markets (Wang 1999:329,331; Rubinstein 1999:370371). During the early 70s, this economic development continued, transforming Taiwan's economy into a key player in the global computer and information technology industries (Rubinstein 1999:374).

\section{Diplomatic Isolation and Political Democratization}

During the 1970s there were a series of foreign relations events that further 
influenced cultural developments in Taiwan. U.S. President Nixon's normalization of ties with the People's Republic of China (PRC) eventually led to the ROC's exclusion from UN representation (Hsiau 2000:68). In 1978, the Carter administration officially broke off diplomatic ties with the ROC, which had the effect of further weakening the KMT's credibility (Hsiau 2000:89). This lack of representation in the United Nations is still a contemporary facet of Taiwan's exclusion from the global community of nation-states, and it is a significant factor in forming Taiwan's condition as an aberration in the scheme of national categories. Through the course of these diplomatic developments, Taiwan became increasingly beyond categorization in the scheme of nation-states both in terms of its standing in the international community and in terms of the population's perception of the ROC's claims to legitimacy as a national entity with sovereignty over Taiwan.

In addition, due to a rise in international oil prices, Taiwan experienced a ten-year economic slowdown beginning in 1973, which accentuated discontent among Benshengren business owners who were forced to compete with government-affiliated and Waishengren-dominated monopolies (Rubinstein 1994:10,97) When Chiang Kaishek's son and successor, Chiang Ching-kuo, became president in 1975, he enacted policies designed to diffuse this tension by offering influential Benshengren greater 
degrees of access to positions of political power within the Kuomintang (Arrigo 1994:147-148). As older KMT legislators from Mainland China retired from office, more elections were held to fill their vacant positions at the local level, which enabled younger Benshengren to become KMT members (Wang 1999:334-335). These elections also had the effect of creating a forum for some politicians, who were not directly affiliated with the KMT party, known as Tangwai, to exert a degree of influence on local public affairs (Wang 1999:334-335).

In 1986, Tangwai activists capitalized on popular support that they had gradually built up since the late 1970s and announced the formation of an opposition party, called the Democratic Progressive Party (DPP) (Hsiau 2000:102). Although the formation of opposition parties was still illegal, the KMT did not actively move to suppress the DPP, and a few months later in 1987, martial law was lifted, effectively legalizing the DPP (Brown 2004:11).

After the death of President Chiang Ching-kuo in 1988, Vice-President Lee Denghui assumed the office of President and became the chairman of the KMT (Rubinstein 1999:447). As a Benshengren and secret supporter of Taiwanese independence, Lee actively promoted more Benshengren to influential positions in the government and set 
out to further Taiwanize the KMT (Rubinstein 1999:447). During the 1990s, Taiwan fully developed into a two-party political system, and the Taiwanese-independence-leaning Democratic Progressive Party gradually won more and more political power from the KMT. This transfer of power peaked in 2000 when DPP candidate Chen Shui-bian was elected ROC President, which effectively ended a half-century of KMT political dominance in Taiwan (Brown 2004:63). As will be discussed in further detail in Chapter 3, the Democratic Progressive Party's rise to power was accompanied by a shift in language domain norms, nationalist identifications, historical narratives, and education curricula.

\section{Contemporary Greater China Hegemony}

Despite the political gains of the DPP and the ideological realignment of much of the population towards Taiwanese identification, Taiwan's increasing economic integration into Greater China has been a factor influencing voters to continue to support the Kuomintang in political elections. Economic links with Mainland China developed in response to rising labor costs and land shortages in Taiwan, and these links were forged

during the same time period that the DPP rose to power during the 1990 s and early 2000s (Ash and Kueh 1993:711-12). Consequently, the DPP's position as the ruling political party only lasted for two presidential terms, and KMT President Ma Ying-jeou was 
elected in both 2008 and 2012. Ma's presidency has been characterized by the implementation of policies that favor increasing economic integration of Taiwan into Greater China.

Ever since martial law was lifted in the late 1980s, there have been increasing links between Mainland China and Taiwan. For example, by 1994, Taiwanese investment already comprised twenty percent of all foreign investment in China, and during the past two decades, Taiwanese companies have become increasingly integrated into the economy of "Greater China" (Hsing 1997:143). By 2003, an estimated 27\% of Taiwanese exports were sold in Mainland China, making it, by far, Taiwan's biggest export market (Chu 2004:492-493). In addition, as of 2004, Taiwanese companies had invested over US\$70 billion in Mainland China, and over half a million Taiwanese workers had relocated to Mainland China to seek employment and do business (Chu 2004 493). A 2003 statistical report issued by Human Resource Bank 101, a prominent job recruitment agency, indicating that a majority of Taiwanese applicants under age 35 were willing to work in Mainland China is further evidence that companies operating in the Greater China regional area are now a major source of employment for young university graduates (Chu 2004:509-510). 
The shifting military balance of power in favor of the People's Republic of China has also influenced voters to shy away from supporting pro-independence policies. Since the mid-1990s, the PRC has been allocating an increasingly high amount of resources towards creating a military build-up in Fujian Province that will enable the People's Republic of China to successfully invade Taiwan in the event that full-independence is declared (Chu 2004:489). In 1996, in response to the possibility of voters electing DPP candidates that favored the declaration of Taiwanese independence from China, the People's Republic of China (PRC) test-fired missiles into waters near Taiwan's most populated cities (Rubinstein 1999:492-493). This tactic was designed to intimidate the population of Taiwan and remind them that declaring independence would be tantamount to war because the PRC military would respond by invading Taiwan in order to bring it under the direct territorial control of the PRC (Rubinstein 1999:492-493). The Clinton administration reacted to the potential threat of a military confrontation between Taiwanese and Chinese nationalists by deploying US naval forces into the Taiwan Strait to prevent the PRC from invading Taiwan (Rubinstein 1999:492-3). In response, each year, the PRC has continued to develop its military capabilities to the point where Pentagon experts now feel that the PRC constitutes a credible military threat to Taiwan regardless of 
whether or not the United States decides to intervene in future incidences in the Taiwan Strait (Chu 2004:489).

Due to both this military build up and economic interdependence with business partners in Mainland China, the resolve has been weakened among much of the Taiwanese population to view the risk of war with the PRC and the threat of severing lucrative economic links as prices worth paying for attaining national Taiwanese independence. Therefore, although democratization of Taiwanese politics has been accompanied by a realignment of identification, with people increasingly identifying themselves as Taiwanese rather than Chinese, due to the military balance of power and Taiwan's increasing integration into the economy of Mainland China, these gains in autonomy have been muted by Taiwan's incorporation into a Greater China regional hegemony.

\section{Conclusion}

Taiwan's status as a nation-state is ambiguous; however, it is increasingly being incorporated into a Greater China regional hegemony through both threats of military coercion and the strengthening of economic links with Mainland China. These economic ties continue to play a significant role in the economic development of both contemporary Taiwan and Mainland China. Much of Taiwan's population now seeks out employment in 
occupations that involve doing business in the Greater China region. It is in this context that the people residing in Taiwan currently use language practice, literacy, and historical narratives as both forms of cultural, linguistic, and symbolic capital and as resources to create identification markers that position themselves and others in relation to different competing conceptions of Taiwan's national status. 


\section{Chapter III: A History of Language and Literacy in Taiwan}

Introduction

Language practice, literacy, and historical narratives have been key symbolic markers of different ethnic, national, and occupational groups in Taiwan; furthermore, these symbolic forms have been created and modified by people living in Taiwan in the context of shifting regional and global power structures. As illustrated in Chapter II, Taiwan's ambiguous status in the contemporary order of nation states has been shaped by both its role as a periphery territory in the sphere of Ming and Qing-era dynastic influence and its role as a contested territory in Dutch and Japanese colonial projects. The diverse groups living in Taiwan have made use of language and writing systems to create symbolic identifications against Taiwan's historical background as a coveted territory by larger regional and global power structures.

Since 1949, Taiwan has also been a contested territory between the rival People's Republic of China and Republic of China nations. In addition, the Taiwanese independence movement has sought to establish The Republic of Taiwan as an independent nation since the 1970s. The languages spoken by the inhabitants of Taiwan and their economic means of sustenance have been salient factors in the construction and 
modification of group identifications in relation to these competing conceptions of Taiwan's status as a territorial entity.

In the mid-twentieth century, the ruling Kuomintang Party instituted Mandarin dominance in official public language domains, with Han-character-based literacy, and a Sino-centric historical narrative as symbolic components of a Chinese nationalism that justified their rule over Taiwan. Since the lifting of martial law in 1988, people in Taiwan who have been affiliated with the Democratic Progressive Party have resisted this hegemony by creating and promoting alternative language norms and an alternative historical narrative in order to create a rival Taiwanese nationalism.

The establishment and promotion of official languages is a key symbolic component of nation building (Anderson 1991:44-46). For national citizens, proficiency in an officially recognized national language is both a mark of national identification and a gateway to occupations of status and influence. The participants in the colonial Empire of Japan and the Kuomintang's Republic of China nation building projects in Taiwan implemented policies designed to symbolically identify inhabitants of Taiwan with different national constructs. This was accomplished through the enactment of language policies that created linguistic hegemonies establishing the dominance of officially- 
recognized national languages over other alternative language varieties. Contemporary Taiwanese nationalists resist identification with Chinese nationalism by rejecting these symbolic forms and instead creating alternative language domain norms, an alternative literacy format, and an alternative historical narrative that ideologically supports the legitimacy of a rival Taiwanese nationalism.

Creating language domain norms that establish the national language as the dominant standard over other language varieties has served as both a means of disassociating people's identifications from rival power structures and making proficiency in the national language a prerequisite for success in academic institutions and access to employment. In addition, the people in Taiwan who have engaged in nation building projects have typically filled specific occupational niches, and they have taken the forms of linguistic capital that are valued in their professional lives and made them the standard language varieties for the national constructs they wish to champion. As will be illustrated later in this chapter, the Taiwanese language variety that has been appropriated by contemporary Taiwanese nationalists as a mark of nationalist identification was also a mark of identification for workers in the middle-class occupational spheres that formed the support base for the Democratic Progressive Party during the 1980s. 
Writing systems have also been salient as symbolic identification markers, particularly with the rise of nationalism and public education in the twentieth century. Writing systems were first used by a minority of the population during the Dutch and Qing eras as instruments in the administration of peripheral regions and missionary work, and later they were taught to the larger public and used as means of indoctrination into nation building projects by the Japanese and the Kuomintang administrations (Wei: 2006:96). Literacy plays a key role in the creation of texts that become the raw material of narrative, and it therefore implicitly bestows the power to document events and depict group identifications on some people and not on others. Literacy empowers people to create symbolic depictions and group identifications that can later be used in the construction of nationalist narratives. When a colonial regime or nationalist power structure makes use of a writing system for administrative purposes, the writing system fulfills the dual function of both documenting information and marking territories and inhabitants of those territories as having been subjects of the power structures associated with specific writing systems in the past.

This chapter begins with an overview of the literacy practices that were created and utilized by the Dutch, Qing, and Japanese administrations in Taiwan. It then describes 
how language practices, literacy, and historical narratives were created and utilized by the Kuomintang to foster an identification with a Chinese nationalist hegemony among the Taiwanese public and to establish their dominance over access to occupational positions of economic and political prestige and influence. The following section illustrates how Taiwanese nationalists have sought to resist this hegemony by creating alternative language domain norms, an alternative literacy format, and an alternative historical narrative in order to contest the KMT's Chinese nationalism and legitimate a rival nationalism. The occupational backgrounds of the people involved in this resistance are also explored in order to illustrate how the language variety that functioned as a form of linguistic capital in the Taiwanese nationalists' occupational spheres was also appropriated and used as the national language that became the counterpart to Taiwanese nationalism. Finally, this chapter concludes by providing an overview of the language situation in contemporary Taiwanese society.

\section{Authentication and Denaturalization}

The process of constructing symbolic markers of identification for different groups entails determining sets of criteria for what qualifies as "authentic" traits of members of a given social group. Mary Bucholtz states that, like identity, the creation of authenticity is 
also an active process, and she therefore advocates using the term "authentication," which is "the outcome of constantly negotiated social practices" (Bucholtz 2003:408). Bucholtz and Hall hold that constructing official histories of social and linguistic groups and standardizing officially recognized languages are frequently-practiced tactics in the authentication of criteria for group membership, especially national citizenship (Bucholtz and Hall 2004:385).

In contrast to engaging in symbolic acts that serve to bolster the legitimacy of a nationalism, people can instead engage in symbolic activities that are designed to undermine the credibility of nationalist constructs over time. Bucholtz and Hall use the term "denaturalization" to refer to processes in which social actors contest the validity of symbolic criteria for group membership by undermining claims to the validity or "realness" of evidence used to support efforts of authentication on the part of other rival social groups (Bucholtz and Hall 2004:386). "Denaturalization" can be an effective tactic on the part of those who wish to reject the validity of one form of national identification and instead propose to replace it with an alternative rival form of national identification.

The first means of challenging a nationalist construct involves refuting the authenticity of its symbolic components by denaturalizing them. This is done by 
invalidating the dominant symbolic forms and instead promoting alternative symbolic practices which are associated with alternative national identities. Buchultz and Hall espouse the view that the creation of sets of criteria for the authentication of different symbolic traits of group membership commonly involves selectively emphasizing the similarity of some traits and difference of other traits when constructing notions of similarity to and difference from other social groups (Bucholtz and Hall 2004:371; 2005:599). Therefore, categories of group membership are typically constructed in relation to conceptions of other groups that are in existence at the time that processes of identification and authentication are being carried out (Bucholtz and Hall 2005:598). Furthermore, Bucholtz and Hall state that people often frame identification as being a member of a given social group in terms of what groups they are not identified with - by either themselves or by others (Bucholtz and Hall 2004:180). Therefore, creating rival identifications that disassociate people from the commonly recognized symbolic markers of national identifications can be an effective tactic of contesting a nationalist hegemony.

\section{The Dutch Colonial Era}

The roots of modern Taiwanese nationalism extend back prior to the Dutch colonial era when ethnic Han migrants from southern China began to interact with the aboriginal 
inhabitants of Taiwan. As was described in Chapter II, group membership was centered around language use, economic sustenance patterns, and lineage decent systems. During the Dutch colonial era, people living in Taiwan were introduced to colonial trade networks and writing systems that served as resources for them to further create and modify ethnic identifications.

The Dutch colonial forces were accompanied by missionaries who devised a writing system using Roman letters to write one of the indigenous languages, Siraya, in the south in order to facilitate conversion of its speakers to Christianity (Tsao 1999:329-330). In addition to religious purposes, this Romanized writing system for Siraya was also used for record keeping and commerce by a small number of officials; however, it receded from use as Qing Dynasty officials replaced it with the use of Han characters after the Dutch withdrew from Taiwan (Tsao 1999:329-330). Later, documentation of the use of a Roman alphabet to write an aboriginal language during this era would be incorporated into historical narratives created by contemporary Taiwanese nationalists seeking to promote a Roman-script-based writing system as a symbol of Taiwanese nationalist identification.

\section{Dynastic Rule}

Taiwan was administered as a fringe territory on the periphery of dynastic control of 
the Ming and Qing Dynasties from 1661-1895 (Wei 2006:95-96). These administrations viewed Taiwan as a territory that should be controlled by Chinese regimes as a defense against rival colonial and Han power structures. During this time period, Han characters were used for administrative purposes, but because education was geared towards training an elite minority of administrators and officials, literacy was not widespread among the general population (Woodside1983:11-12; Wei 2006:96). Providing the public with mass education was not a priority as long as there was a minority of literate administrators who were loyal to the dynastic regimes in Mainland China (Wei 2006:96). However, literacy in Han characters served as both a gateway to employment in occupations of prestige that were affiliated with the dynastic administration structures and as a symbolic marker of Taiwan's incorporation into the territorial jurisdiction of dynastic power structures (Woodside1983:11-12; Wei 2006:96).

As noted in Chapter II, the majority of inhabitants of Taiwan shaped and modified their group identifications though adopting different ways of conceptualizing lineage decent and through different patterns of language use. In particular, children of mixed aboriginal and Han parentage frequently made use of their patrilineal decent in order to claim Han ethnicity (Brown 2004:138-139). In addition, people in Taiwan identified 
themselves as members of Zhangzhou, Quanzhou, and Hakka groups through speaking the different respective language varieties (Vermeer 1999:80). Ethnic identification was also shaped by different people's economic roles and occupations. Therefore, as illustrated in Chapter II, some members of plains aborigines groups maintained their distinctive nonHan ethnic identifications due to their occupational niche as landowners (Shepherd 1999:116).

\section{Literacy and Missionary Work during the Qing Dynasty}

During the second half of the nineteenth century, Taiwan became increasingly integrated into global trade and involved in power struggles between the Qing Dynasty and foreign colonial powers. As a part of the Opium War settlement between China and western colonial powers, under the Treaty of Tianjin in 1858, western powers were permitted to conduct trade in Taiwanese ports, and Christian groups were permitted to engage in missionary activities (Brown 2004:51). Missionaries during the later half of the nineteenth century were especially influential to the subjects of this study because they reintroduced the use of Roman letters for use as a writing system for the Taiwanese language.

As will be further detailed in Chapters 4 and 5, texts in this writing system would 
later be used as the foundations for the Romanized writing system that would be championed by Taiwanese nationalists a century later when constructing a post-martial law Taiwanese nationalist identification. Therefore, the writing system used by western missionaries served the function of both documenting information and constituting an identifying mark for people and territories who had been influenced by missionaries in the past. As will be further discussed in Chapters IV and V, in modern contexts, Taiwanese nationalists incorporate the documented existence of Romanized Taiwanese texts during the nineteenth century into nationalist narratives to demonstrate that a writing system other than Han characters existed in Taiwan prior to the establishment of the ROC education system by the KMT. This is used as evidence to authenticate claims that literacy in Romanized Taiwanese texts is a desirable component of Taiwanese nationalism that should be used to symbolically distinguish Taiwanese people from Chinese nationals.

\section{The Japanese Colonial Era}

During the Japanese colonial era, literacy and spoken proficiency in the official national Japanese language served as a means of identifying Taiwanese people as colonial subjects of the Japanese nation (Wu and Chen 1989: 118). The Japanese colonial administration was distinctive from the Qing colonial regime because, rather than viewing 
Taiwan as a fringe territory, the Japanese administration actively governed Taiwan and attempted to mold Taiwan into a model colony to be incorporated into the Japanese nation (Cummings 1984:8). Therefore, the Japanese colonial administration introduced traits of nationalism, such as mass literacy at the primary school level and standardized education in an official national language, into the administration of Taiwan (Wu and Chen 1989: 118). This resulted in language domain norms that privileged the national language over other language varieties in the domain of public discourse.

In an effort to eradicate loyalty to the Qing Dynasty, the Japanese government actively discouraged cultural ties to China, and a series of policies were designed to instill Japanese culture and values into the colonial subjects through the promotion of language practices that privileged the use of Japanese over other language varieties (Hsiau 2000:29). This had the effect of making Japanese language skills and literacy a mark of identification for those who were eligible for high-status employment opportunities (Chang and Myers 1963:440; Hsiau 2000:36). These policies were primarily carried out through making the Japanese language the medium of instruction in educational institutions (Hsiau 2000: 35,151). In addition, it also became the norm to use Japanese instead of Taiwanese, Hakka, and aboriginal languages in official public discourse (Hsiau 
2000:36; Brown: 2004:54). This policy was instrumental in creating a class of educated bilingual Taiwanese, who used Japanese in the public sphere, while other language varieties continued to be used in everyday life by much of the rest of the population (Hsiau 2000:36).

\section{Kuomintang Dominance During the Martial Law Era}

During the Kuomintang's rule of Taiwan following the defeat of Japan in World War II, historical narrative, language domain norms, and Han-character literacy were all utilized as symbolic components of a Chinese nationalist hegemony to legitimate the Kuomintang's administrative dominance. This was accomplished through the introduction of language policies in Taiwan that had previously been used by the Republic of China government in Mainland China as part of the movement to establish the Chinese nation in Mainland China after 1911 (Anderson 1991:67; Tsao 1999:333-5).

James Townsend states that the Chinese nationalism that developed in the early twentieth century was influenced by a form of "culturalism," that is, a "belief that China was a cultural community whose boundaries were determined by the knowledge and practice of principles expressed through China's elite cultural tradition" (1992:112). According to Townsend, this enabled Chinese nationalists to construct a Chinese national identity that 
allowed for the inclusion of people from different ethnic groups, such as Tibetans,

Manchurians, and Turks, into the Chinese nation as long as they adopted the forms of this

"Chinese cultural tradition" (1992:114). In practice, however, these cultural forms were also index markers of Han ethnicity; therefore, cultural traits of "Han-ness" became the de facto standards that symbolically identified people with Chinese nationalism (Townsend 1992:114).

Both the PRC and the ROC's Chinese nationalisms were subsequently influenced by this culturalism, and Mandarin language skills and literacy in Han characters have served as key cultural practices identifying people with this Chinese cultural tradition. The Kuomintang language policies in post-war Taiwan drew on this culturalism, and this had the effect of linking people's economic positions to their linguistic practices and ethnic identifications. Consequently, on the basis of their ability to conform to the language practices of this culturalism, Mandarin-speaking Waishengren enjoyed a higher status than Benshengren, who spoke other language varieties.

During the martial law era from 1949 to 1988, language practice, Han ethnic identity, and Chinese national identity were closely interrelated as valued resources to gain power and prestige in a Chinese nationalist hegemony, which closely overlapped with the power and authority of the Republic of China nation-state. As illustrated in Chapter II, the 
unequal distribution of power on the basis of ethnic identifications created interethnic conflicts that led to the 228 Massacre in 1947 and the subsequent declaration of martial law by the KMT. The repressive Sinocization policies put in place during the martial law era were instrumental in establishing a Chinese nationalist hegemony, where in addition to acting out of fear of coercion, people were also motivated to conform to the dominant language domain norms and nationalist ideology as a means of gaining access to occupational opportunities. Therefore, the language situation in Taiwan came to exemplify Raymond Williams's statement that:

"The true condition of hegemony is effective self-identification with the hegemonic forms: a specific and internalized 'socialization' which is expected to be positive but which, if that is not possible, will rest on a resigned recognition of the inevitable and necessary" (1977:118).

In order to justify the KMT's rule over Taiwan, a historical narrative that emphasized common links between Taiwan and China was disseminated through the media and the education system as the ideological counterpart to the KMT's Chinese nationalist ideology (Hsiau 2000:151). Han culture was emphasized by portraying Zheng Cheng-gong as a Chinese national hero, who liberated Taiwan from Dutch colonial rule (Hsiau 2000:151-152). The KMT struggle to liberate Taiwan from Japanese colonial rule and reclaim mainland China was also framed in terms of a historical continuity of Chinese 
history that analogized Zheng Cheng-gong's attempts to challenge the Manchu Qing regime, which was depicted as "foreign" because it was not dominated by ethnic Han Chinese, with KMT efforts to challenge the communist regime, which was similarly portrayed as being polluted by foreign Marxist ideologies (Hsiau 2000:152-153).

The KMT implemented policies designed to identify Taiwan as being a part of the Republic of China (ROC) and strove to erase both the influence of Japanese culture and other localized identifications from Taiwanese society by introducing language policies that excluded people who were not fluent in Mandarin from government posts (Hsiau 2000:54). By promoting Mandarin as a national language, the KMT hoped to create a homogeneous sense of Chinese identity that transcended the subethnic identities that were marked by the speaking of other language varieties, such as Taiwanese, Hakka, and aboriginal languages (Wei 2006:98-9). The majority of the Mainlanders who had retreated with the KMT to Taiwan were fluent in Mandarin; therefore, aside from being the administrative language, Mandarin also served as a lingua franca for KMT settlers in Taiwan (Tsao 1999:332). Fluency in Mandarin was a prerequisite for securing employment in dominant administrative and economic institutions. Consequently, during the first few decades of KMT rule in Taiwan, thanks to their ability to speak Mandarin, the 
Mainlanders, known as Waihengren, or "non-native residents of Taiwan province," occupied higher status social positions than the local Taiwanese, who were collectively labeled as Benshengren, or "native residents of Taiwan province" (Tsao 1999:365).

These language policies had the effect of making access to positions of power and employment in prestigious occupational spheres contingent on conforming to Mandarindominant language domain norms and Han-character-based literacy norms. Therefore, Mandarin served as the dominant language for use in official institutions, and it was employed in both spoken and written contexts (Tsao 1999:350). Other widely spoken language varieties, such as Taiwanese and Hakka, were labeled "dialects" and were reserved for informal and non-written occasions, and they therefore took on the status of less prestigious language varieties in Taiwanese society (Tsao 1999:350). As a result of these language policies, Benshengren, who were either uneducated or had been educated during the Japanese colonial period, were excluded from prestigious occupations and positions of power (Hsiau 2000:50,54). Mandarin language hegemony was also promoted by punishing students for speaking "dialects" and aboriginal languages in schools (Hsiau 2000:129). Similarly, the speaking of non-Mandarin language varieties was also restricted in the mass media, and when speakers of Taiwanese did appear in the media, they tended 
to be portrayed as being lower class, criminals, and socially backwards (Hsiau 2000:130).

As will be illustrated later in this study, the overall dominance of Mandarin in the sphere

of official institutions remains largely intact in contemporary Taiwan.

\section{Language Use and Occupation}

Due to the influence of the KMT's language policies, the majority of the population had restricted access to high-status positions because of their inability to conform to language domain norms that privileged Mandarin in prestigious spheres of discourse.

However, as Taiwan industrialized, the changing economy provided niche occupations for people who did not have the Mandarin language skills needed for employment in public administration positions. Taiwan's increasing integration into the global market brought about changes in the local job market, and ethnicity and language use became identification markers that symbolized association with different types of employment.

According to Hill Gates, during the 1970s, two middle classes developed that were distinguished from one another by ethnic affiliations, linguistic habits, and occupational tendencies (1981:273). One of the middle classes was comprised of mostly Mainlanders and a minority of highly educated Benshengren, and members of this Waishengren middle class tended to occupy positions in government bureaucracies, schools, and large state-run 
corporations. A key identification marker of this Waishengren middle class was the ability to speak Mandarin, and this ability was closely correlated with academic achievement in state-run educational institutions (Gates 1981:264-5,274,277). Therefore, the acquisition of Mandarin language skills and Han character literacy greatly facilitated upward social mobility for Benshenren hoping to enter this Waishengren middle class.

The other middle class tended to be owners or employees of small and mediumsized businesses and factories, and they were comprised of Benshengren who spoke language varieties other than Mandarin, especially Taiwanese (Gates 1981:273,279). Although the second middle class of Benshengren had achieved a degree of economic power, during the 1960s and 1970s, they were still excluded from positions of political power because in local elections any elected leaders had to be approved by the Waishengren-dominated KMT party (Wang: 1999:322). They were also repressed by the continuation of the legislative restrictions that maintained the linguistic dominance of Mandarin in the public sphere (Tsao 1999:344,349). Although participants in these occupational fields had limited access to political power during the 1960s and 1970s, their growing economic strength would later enable them to constitute a political challenge to KMT dominance in Taiwan in the late 1970s. In addition, the linguistic practices that 
identified members of this middle class as participants in these occupational spheres

would also function as identification markers for those seeking to challenge the KMT's

Chinese nationalist hegemony.

\section{The Rise of Taiwanese Nationalism}

During the martial-law era of Kuomintang rule, the national education system

promoted Han character based literacy in Mandarin and a Sino-centric historical narrative that identified the inhabitants of Taiwan as Chinese according to symbolic criteria that were components of a Chinese nationalist hegemony. However, economic development and political liberalization provided some people with leeway to resist this hegemony through the creation of an alternative Taiwanese nationalism that was associated with the Tangwai political activities described in Chapter II. The practice of alternative language domain norms associated with Benshengren middle class occupations and the promotion of an alternative historical narrative were salient symbolic traits of association with this alternative Taiwanese nationalism, and some gains were accomplished in resisting KMT's Chinese nationalist hegemony through the promotion of Taiwanese nationalism.

As people gained greater economic power through employment in occupational spheres that were associated with their Benshengren ethnic and linguistic identifications, 
they created an alternative nationalism with a different historical narrative, language domain norms, and literary texts. This alternative Taiwanese nationalism was highly influenced by the ideological template that the Kuomintang had used to construct its Chinese nationalism. Therefore, not unlike the Chinese nationalism of the Kuomintang's Republic of China, in this alternative Taiwanese nationalism, Taiwanese language fluency, Taiwanese ethnicity, and national identity were closely associated with one another. In addition, due to the influence of a form of Taiwanese "culturalism," although Taiwanese nationalism was ideologically conceived as being inclusive of other ethnic and linguistic groups, such as Hakka and Aboriginal people, the linguistic and cultural traits of the Taiwanese-speaking majority served as the de facto cultural index markers for Taiwanese national identification. In the late 1970 s, these symbolic resources were utilized by Tangwai activists to pose a challenge to and resistance against the KMT's Chinese nationalist hegemony. In addition, these acts of resistance were carried out in the context of Taiwan's increasingly ambiguous national status in relation to other nation-states due to its diplomatic isolation.

During the late 1970s, a new magazine called Formosa, or Mei-li-tao, was founded as means of disseminating ideas that challenged KMT hegemony (Hsiau 2000:89). 
Activists associated with the magazine organized a human rights rally that resulted in the arrest of several activists. This confrontation in 1979 came to be known as the Kaohsiung Incident (Hsiau 2000:89). In its aftermath, Tangwai supporters became increasingly radical in their anti-KMT views. Meanwhile, other publications began to construct an alternative historical narrative that supported a vision of Taiwan as an independent nation (Hsiau 2000:90). According to the Tangwai activists, the past was defined as a struggle of Han settlers and Taiwanese aborigines against foreign invaders, such as the Dutch, the Japanese, and the Qing Dynasty (Hsiau 2000:91). A key tenet of this narrative was that the diverse groups that comprised Benshengren Taiwanese culture had been altered and unified by the collective experience of being colonized by the Japanese and that they therefore constituted a cultural entity that was distinct from the Chinese nation (Hsiau 2000:91). Furthermore, there was a moralistic component of this narrative that framed the KMT's domination of Taiwan under the moniker of the ROC as being a continuation of past hardships suffered under foreign domination. Both the 2-28 Incident and the Kaohsiung Incident were portrayed as events in which Taiwanese were victimized by an occupying power. (Hsiau 2000:103,150-151).

The Tangwai activists who founded the Democratic Progressive Party in 1986 
promoted both the use of Taiwanese as an alternative national language and an alternative historical narrative to legitimate a rival nationalism to the Kuomintang's Chinese nationalism. The support base for the DPP was comprised of members of the predominantly Taiwanese-speaking Benshengren middle class. The DPP's original platform included seeking independence from China by establishing a "Republic of Taiwan," and as a component of this alternative nationalism, they promoted Taiwanese as the national language (Hsiau 2000:103). Therefore, the new language of prestige among supporters of this alternative Taiwanese nationalism was also the language variety that served as an identification mark for participants in the occupational spheres that comprised the main support base of the DPP.

\section{Challenging the Kuomintang's Chinese Nationalism}

When Lee Deng-hui assumed the office of president in 1988, he enacted a series of policies designed to dismantle symbolic components of the Chinese nationalism created through the post-war KMT administration and instead realign the population with an alternative Taiwanese identification. Lee was a Taiwanese Benshengren, but he occupied a top position in the KMT leadership. Although Lee was a KMT official, he had also secretly been a supporter of Taiwanese nationalism, and once he became president, he 
used his position and influence to promote this cause (Chu 2004:499). Lee adopted the Tangwai's and the DPP's alternative historical narrative and promoted alternative language domain use in order to denaturalize some of the symbolic foundations of the KMT's Chinese nationalism and replace them with symbolic markers of an alternative Taiwanese nationalism.

President Lee's policies constituted a shift away from the Chinese nationalist narrative that had been employed by the KMT during the martial law era by encouraging a greater recognition of components of the alternative Taiwanese nationalist narrative. Most significantly, in 1992 Lee sponsored an official inquiry into the 2-28 Incident, issued an official apology to the victims of the state violence, and sponsored the construction of a memorial to the people who were killed in the aftermath of the 2-28 Incident (Rubinstein 1999:456). In doing so, President Lee modified the KMT's position of not discussing the 2-28 Incident and recognized the legitimacy and importance of this incident in the historical narratives of Taiwanese nationalists. Recognizing the relevancy of the 2-28 Incident had the effect of authenticating an important component of the Taiwanese nationalist historical narrative.

Lee was also instrumental in diminishing the linguistic hegemony of 
Mandarinization put in place by the KMT, and his policies had the effect of undermining part of the structural and symbolic coercion that supported ROC nationalism. Policies carried out during Lee's term lifted censorship in the media and permitting the use of languages other than Mandarin in the media and education systems (Rubinstein 1999:456; Hsiau 2000:133). In addition, language-planning measures were enacted to preserve and revitalize local languages; these included legal requirements for mother-tongue education in public schools, and the National Language Development Law (NLDL), which granted equal legal status to all languages and dialects (Tsao 1999:352; Wei 2006:101). This created a symbolic niche for the use of alternative Taiwanese language varieties in the public sphere, which became instrumental in strengthening the legitimacy of Taiwanese nationalism.

These legislative measures coincided with a vision of what President Lee Deng-hui referred to as the "New Taiwanese" identity, which aimed to equally include all of the ethnic groups living in contemporary Taiwan (Wei 2006:100). This conception of Taiwanese identification was also adopted by the Democratic Progressive Party and incorporated into their political platform. Therefore, this ideological conception of Taiwanese nationalism envisioned an inclusive form of Taiwanese nationalism that 
allowed Benshengren speakers of Taiwanese, Hakka, and Aboriginal languages and

Waishengren Mainlanders to be identified as equal members of this vision of the

Taiwanese nation.

Throughout the 1990s, the DPP built up its power base by promoting this inclusive vision of Taiwaneseness in order to attract voters belonging to all of the ethnic groups in Taiwan (Hsiau 2000:105). This Taiwanese identification involved creating a unity of the "four great ethnic groups," which included Taiwanese, Hakkanese, Mainlanders (formerly known as Waishengren), and aborigines, and this view of Taiwanese identity is now predominant in both KMT and DPP political discourse (Hsiau 2000:105). Aborigine contributions to Taiwanese identification were also increasingly emphasized as a means

of distinguishing Taiwanese culture from Chinese culture (Hsiau 2000:107-108).

\section{Multilingualism in Political Discourse}

The lifting of official language restrictions has brought about a trend towards the legitimization of multilingualism in political discourse (Wei 2006:99). After the lifting of martial law, in the sphere of political discourse the practice of speaking Taiwanese came to be associated with the anti-KMT democratization movement led by the Democratic People's Party (DPP) and the often-overlapping movement in support of Taiwanese 
independence (DeBernardi 1991:1991:17). This later association, was related to a

movement among Taiwanese-speaking pro-independence advocates to replace Mandarin with Taiwanese as the national language (Wei 2003:146).

Due to the popularity of Taiwanese as an index of local identification, during the past two decades, politicians associated with both the DPP and the KMT have increasingly used Taiwanese in public speeches as a means of securing popular support (Wei 2003:146). For example, even politicians who are neither native speakers of Taiwanese nor members of the DPP, such as current President Ma Ying-jeou, have found it necessary to demonstrate their linguistic competence in Taiwanese in order to secure and maintain political power (Wei 2003:146). The speaking of Taiwanese in public has been further legitimated by the fact that people who are from Taiwanese-speaking family backgrounds comprise the demographic majority (Wei 2003:14). In addition, due to the increasing upward social mobility of people from Taiwanese-speaking family backgrounds since the 1970s, the Taiwanese language now has less of a negative association with lower socioeconomic status than during the early post-war period of economic development (Wei 2003:14). 


\section{Language, Literacy, and Education in Taiwan}

Taiwan enjoys a high literacy rate, with $96.1 \%$ of the population being able to read and write (CIA 2012). Since 1968, nine years of compulsory education has been required for all citizens in state-approved education institutions (Law 2002:66). The vast majority of curriculum is taught using spoken Mandarin and Han characters as the officially approved medium for reading and writing, with the exception of foreign language and mother language curriculum, which will be further described in the following section. In early elementary school, students are taught how to read Han characters using a system of pronunciation symbols called Zhuyinfuhao, which correspond to Mandarin speech and are derived from Chinese radicals (Chiung 2001:26). The Zhyinfuhao system is not considered to be an independent writing system, but rather a learning tool to facilitate students' understanding of how Han characters should be read to correspond with standard Mandarin pronunciation in Taiwan. However, as a learning tool, the Zhuyinfuhao system is very useful because in addition to pronunciation, it also instructs learners the proper tone for each character. Because Mandarin is a tonal language, with four possible tones for each character, speaking in the correct tone is crucial for comprehension.

In the figures below are samples of both traditional Han characters taught in 
Taiwan, and Han characters accompanied by Zhuyinfuhao symbols for elementary school students.
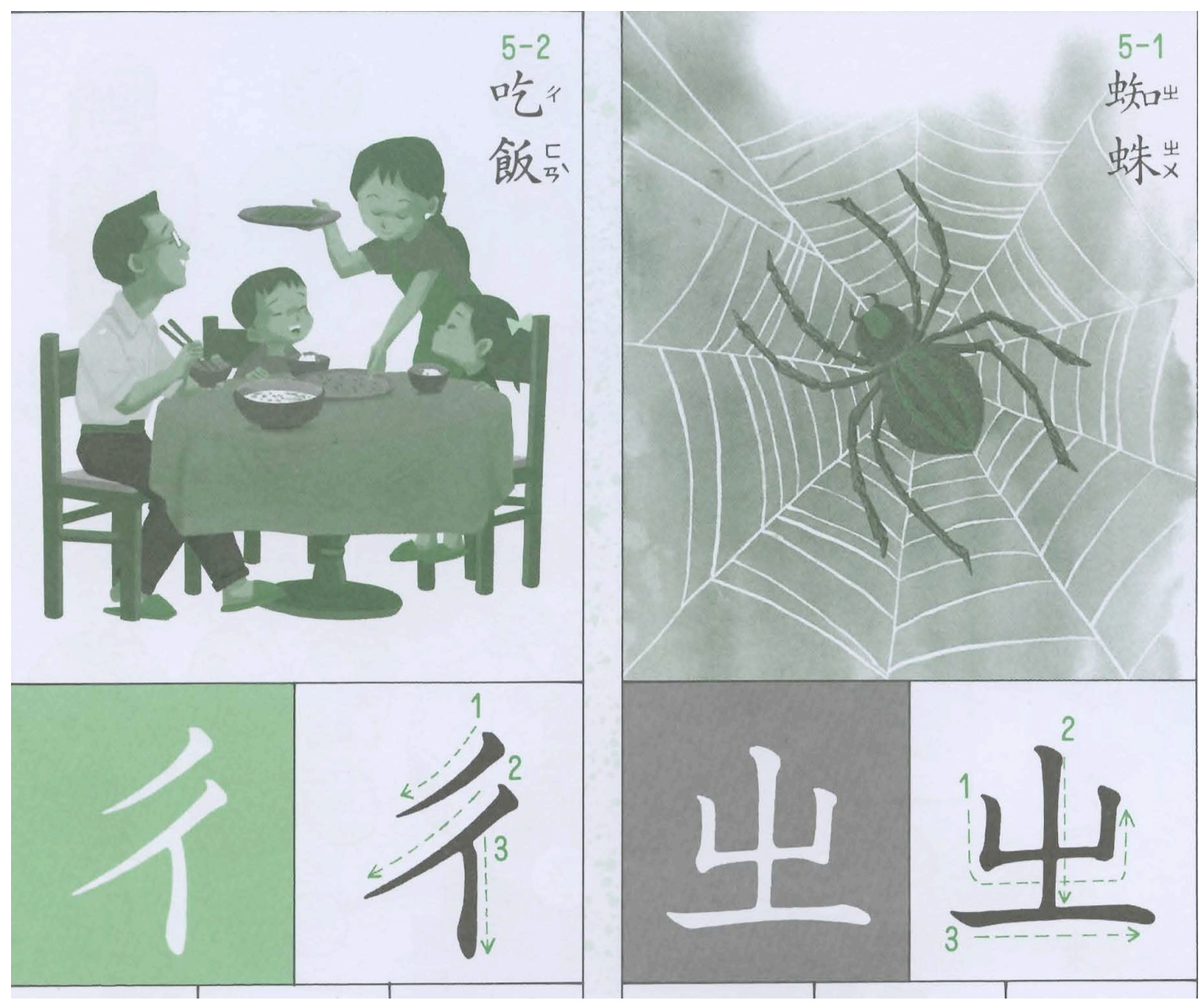

Figure 3.1 Han characters with Zhuyinfuhao (Source: 認識々タワ 2009)

The writing system taught in Taiwan through the Republic of China education system is distinct from the system used in the People's Republic of China is two ways.

First, in Mainland China, simplified Han characters function as the accepted way of writing and printing characters, whereas in Taiwan, people continue to use traditional 
complex characters. Second, students are taught how to read and write using a Romanized pronunciation system, which like Zhuyinfuhao is taught to young students and is meant to be used as a learning tool rather than an independent orthography (Chiung 2001:26). In the figure below are samples of simplified Han characters used in the People's Republic of China accompanied by Romanized writing for young learners.

\author{
我姓王。 \\ Wǒ xìng Wáng. \\ 我说法语。 \\ Wŏ shuō Făyŭ. \\ 我们都是中国人。 \\ Wǒmen dōu shì Zhōngguó rén. \\ 我不姓王。 \\ Wǒ bú xìng Wáng. \\ 我不说法语。 \\ Wŏ bù shuō Făyŭ. \\ 我们都不是中国人。 \\ Wǒmen dōu bú shì Zhōngguó rén.
}

Figure 3.2 Simplified Han characters with Romanized writing (Source: Wu 2002)

\section{Academic Credentials and Employment}

Academic credentials in the form of a university degree is also a crucial form of what Pierre Bourdieu refers to as the "cultural capital" needed to obtain employment in positions of prestige (Bourdieu 1977:187). Because linguistic capital in the form of Mandarin language skills and Han character based literacy are, in turn, components of the cultural capital that serves as a symbolic mark of qualification for employment this influences students to voluntarily act in conformity with the hegemonic forms of language 
domain norms on school campuses as Bourdieu predicted (1977:187).

Taiwan's increasing economic development has been accompanied by a shift from an industrial economy to a service sector economy, and educational degrees are crucial prerequisites for employment in these enterprises. For instance, since the 1980s, service sector enterprises, such as legal, financial, accounting, engineering, design, and advertising services and knowledge based information technology enterprises have come to play a greater role in Taiwan's economy, and the majority of university graduates seek out employment in these fields (Cooper 2003:168-9; McBeath 1998:124). As of 2000, 55 percent of the workforce was employed in the service sector, and the information technology sector experienced at least a $25 \%$ yearly growth rate throughout the $1990 \mathrm{~s}$ (Cooper 2003:168-9; McBeath 1998:124).

Employment in service and information technology industries requires increasing levels of education, and between 1993 and 2000 the ratio of exports from Taiwan that were manufactured in "high skilled labor intensive" industries rose from $20 \%$ to $50 \%$ (Chu 2004:107). A number of firms have adapted to the service-oriented economy by increasing their research and development, and the ability to carry out these activities is also dependent on having a work force that has undergone formal education (Chu 
2004:110; Chou 1995:4). Therefore, the linguistic behavior of students on campus is

highly influenced by conforming to practices that will symbolically mark them as

desirable educated candidates for employment in service sector enterprises.

\section{Resistance Through Mother Language Education}

Taiwanese nationalists recognized the role of Mandarin language domination in

the creation and continuation of the Kuomintang's Chinese nationalist hegemony;

therefore, the Democratic Progressive party acted to resist this hegemony through policies

designed to preserve and revitalize the Taiwanese language. Beginning in the 2001-2002

school year, it became a requirement for all elementary school students to undergo one

hour of mother language education instruction a week, and elective mother language

education courses were instituted for middle school students (Law 2002:74).

The current system of teaching Taiwanese is derived from the Romanized Beiweiji

writing system, which was first developed and used by Presbyterian missionaries during

the nineteenth century (Chiung 2001 33). In contrast to Zhuyinfuhao and the Romanized

writing system used for Mandarin language education in Mainland China, the proponents

of Romanized Taiwanese writing view it as an independent writing system, rather than a

learning tool to assist learners to read Han characters (Chiung 2001:34). The strong point 
of this system is that the Romanized orthographic symbols directly correspond to how the phonemes are spoken in the langugage (Chiung 2001 24). In addition, because there are seven tones with a complex sandhi, the Romanized writing system is taught in a way that clearly represents the tones and how they change when spoken in conjunction with other tones (Chiung 2001 24). Due to the complexity of the intonation, learning how to speak Taiwanese using only Han characters without a system to indicate the proper intonation and pronunciation would be extremely difficult, if not impossible. In the figure below is a sample of the Romanized Taiwanese writing currently used in mother language course

materials.

\section{( Sōai ${ }^{\mathrm{n}}$-á Sōai ${ }^{\mathrm{n}}$-á sè-liàp phôe chhe ${ }^{\mathrm{n}}$-chhe ${ }^{\mathrm{n}}$ Théng-hó bán lâi chò sōai ${ }^{\mathrm{n}}$-á-chhe $^{\mathrm{n}}$ Sōain ${ }^{n}$-á tōa-liàp thng-chiap chē Théng-hó bán lâi chhián lâng-kheh}

Figure 3.3 Roman Beiweiji Taiwanese Text (Source: Peh-oe-ji ki-chho kau-chai 2008)

Despite the usefulness of the Romanized Taiwanese literacy format for young

learners, most university students and adults are unfamiliar with this writing system, and 
they still identify themselves as educated and literate through the use of Han characters.

Consequently, the standard Romanized Taiwanese system is commonly written in conjunction with Han characters in textbooks for elementary school students in order to make the learning materials accessible to students' parents. This is related to a strongly ingrained linguistic ideology that views non-Han character based writing systems as improper literacy forms for use in education institutions (Chiung 2001 35). In addition, if students are not educated in the Romanized writing format, they will not be able to read it, even if they are proficient in spoken Taiwanese. Consequently, most university students and adults find texts written solely in Romanized Taiwanese to be incomprehensible unless they are accompanied by Han characters that students can use as a reference point to infer the meaning of the texts.

Prior to the official recognition of the Romanized Taiwanese system, some learning materials were also produced using mostly Han characters, with some isolated syllables that were written in Roman letters if there was not a corresponding Han character (Chiung 2001 32-33). Some students have seen these texts, and because Han characters are based on meaning more than sound, they can generally understand the basic meaning of these texts, even if they are not sure how to read the text aloud in Taiwanese. 
In the figure below is a sample of this writing system.

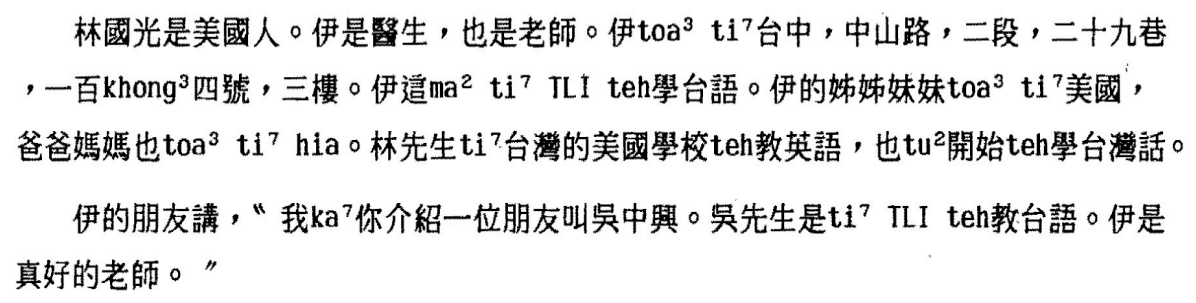

Figure 3.4 Romanized Taiwanese mixed with Han characters (Source: 生活台語 1990)

Conclusion: Language Use and Contemporary Greater China Hegemony

Although political democratization has been accompanied by the lifting of

restrictions against the use of non-Mandarin language varieties, the construction of alternative views of nationality, ethnicity, and historical narratives through the use of alternative linguistic practices is still constrained by Taiwan's increasing incorporation into the contemporary Greater China regional hegemony. Although Taiwan is still governed by the Republic of China state apparatus, most people now identify more with Taiwan than with the Chinese nationalist ideology of the Republic of China. Therefore, for people living in Taiwan, national identity has become disjointed from the state power of the Republic of China.

In spite of the inhabitants of Taiwan's ideological shift away from the Chinese national identification, they still embrace many aspects of the Chinese culturalism that 
previously functioned as ideological components of the Kuomintang's Chinese nationalism. This is because symbolic traits of that culturalism, such as Mandarin language fluency and Han-character-based literacy still function as valued forms of cultural and linguistic capital in the Greater China regional economy. In everyday life, then, most people in Taiwan still act in accordance with many of the symbolic components of the Chinese culturalism that was first used by the KMT to establish administrative control over Taiwan, and is now being used to incorporate Taiwan into the Greater China regional hegemony. Even though a formal electoral democracy is in place, restrictions on language use have been rescinded, and mother language education has been introduced into public school curriculum, Mandarin dominance continues in most spheres of public discourse in everyday life. Furthermore, workers in international companies operating in the Greater China region speak predominantly in Mandarin in public discourse and use Han characters as symbolic markers of identification with this Greater China nationalist hegemony (Zhang 2005:434).

Taiwan's position in the international arena of nation-states still defies categorization according to the predominant conceptual categories for defining national power structures and identities because neither a consistent national consciousness nor a 
sense of how to place Taiwan under the stable sovereignty of a legitimately-recognized national power structure have solidified. It is in this context that the contemporary inhabitants of Taiwan create identifications in relation to conceptions of Taiwanese and Chinese nationalisms through the creative use of language and literacy. The following chapter will provide an ethnographic description of a group of medical care professionals and language instructors who are resisting Chinese cultural and economic hegemony through the creation and promotion of Taiwanese-language medical school curriculum and testing materials. 


\section{Chapter IV: The Sunday Study Group}

Introduction

In Kaohsiung City, there is a group of medical doctors and language instructors

who meet two Sundays a month to edit Taiwanese language textbook curriculum and

testing materials. The study group members are involved in the promotion of an

alternative writing system, alternative language domain norms, and an alternative

historical narrative to that promoted in mainstream education institutions since the end of

World War II. The study group participants use these alternative identification markers to

position themselves in opposition to the Kuomintang's Chinese nationalist hegemony and

create an alternative Taiwanese national identification.

The members of this group are doctors and Taiwanese language instructors, and

many of them first learned about Romanized Taiwanese writing through the influence of

Presbyterian church activities when they were growing up. The nine key members are two

medical doctors, Dr. Tenn Si-chong, and Tiu Hok-chu; Dr. Tenn's office assistant, I Giok-

ngo; a computer science professor, Lim Chheng Siang; a hospital administrator, Ng Kheng

Goan; a medical student, Huang Jyh-Min; a literary magazine editor, Tan Hong-hui; and

three language instructors, Huang Wen-zhang, Chen Jin-hua, and Jason Jiang. These core 
participants all gave their informed consent to have their names used in this study. The study group began meeting to edit Taiwanese language medical school curriculum in the spring of 2010, and I began attending meetings in December 2010.

I was welcomed by all of the participants, who I believe liked having a western participant in their meetings because I represented a link with the outside world and they felt that by being the subject of an academic paper, their nationalist ideology could gain publicity and legitimacy in international academic circles. This aspiration of gaining greater international recognition is a result of Taiwan's diplomatic isolation due to its lack of independent representation in international organizations such as the United Nations

\section{Language in Interviews}

During interviews and study group meetings, the study group participants utilized

alternative language domain norms to those practiced by most speakers in mainstream Taiwanese society. These linguistic choices are symbolic of their rejection of the Chinese cultural hegemony that currently dominates Taiwanese society. I discovered that being able to draw from my personal experience of how most other Taiwanese people generally act in accordance with mainstream language domain norms when speaking with me to be useful in perceiving how the study group members departed from those norms during my 
interactions with them.

Usually when I had conversations with people living in Kaohsiung, speakers prefered to speak with me using Mandarin. When I spoke with them in Taiwanese, they usually only spoke Taiwanese with me for a short time before switching to Mandarin. This is because mainstream language domain norms typically allocate speaking Taiwanese to informal contexts where speakers are interacting with local Taiwanese people who are either elderly, from lower socioeconomic backgrounds, or are from rural areas where Mandarin is not the unmarked language for communication. Consequently, most people in Taiwan consider English or Mandarin to be the proper languages for communicating with a graduate student from a western country, and they consider the act of speaking Taiwanese with someone who is not from Taiwan to be unusual.

In contrast with other people in Taiwan who act in accordance with mainstream language domain norms, study group members preferred to speak with me using either Taiwanese or English, instead of Mandarin. For example, during the recorded interviews, study group members felt that Taiwanese would have been the ideal medium of communication; however, my Taiwanese level was too low to have successfully conducted the interviews in Taiwanese. Therefore, if the group members were fluent in 
English, we spoke primarily in English, but occasionally switched to Mandarin if I needed to clarify the meaning of some of the interviewees' statements. When interviewing study group members who were not proficient in English, we communicated in Mandarin; however, they ideally would have preferred that I conduct the interviews in either Taiwanese or English. Therefore, study group members spoke Mandarin with me in interviews only when it was necessary for communication.

Similarly, during study group meetings, the unmarked language was Taiwanese, rather than Mandarin. The study group members would also sometimes switch to English to clarify points if they felt that I may not have understood what they had said in Taiwanese; however, they avoided switching to Mandarin for the same purpose. Furthermore, in contrast to most other people that I have interacted with in Taiwan, any time I made an attempt to speak Taiwanese with study group members, they would try to continue the conversation in Taiwanese for as long as possible. The study group members' choice to speak Taiwanese as their unmarked language is significant because study group members do not engage in these linguistic practices due to a lack of proficiency in Mandarin. Instead, the study group members' use of Taiwanese during meetings and interviews was an intentional choice that they made to strategically identify themselves as 
Taiwanese nationalists.

The Socioeconomic Position of Doctors

In contrast to most other professional fields in Taiwan, in occupations related to medical care, Taiwanese language skills continue to serve as a form of linguistic capital. The linguistic habits of doctors are unusual because although they enjoy high socioeconomic positions, they still frequently interact with people who speak Taiwanese as a part of their regular work routines. Whereas workers in most other high-status occupations are expected to conform to the norm of speaking Mandarin in the workplace, doctors regularly speak with elderly and lower-class patients who are better able to articulate the state of their physical conditions by speaking Taiwanese than by speaking Mandarin. Therefore, linguistic proficiency in Taiwanese is an asset for doctors, and in contrast to most other high-status professions, doctors are under little pressure to integrate into the linguistic norms of what Zhang Qing refers to as the "Greater Chinese linguistic market" (Zhang 2005:454).

In addition to occupying a professional niche where the ability to speak Taiwanese is valued, doctors are also able to create convincing narratives that link themselves historically to the education system that was established by the Japanese colonial 
government and to the promotion of literacy and western medicine by western

missionaries during the first half of the twentieth century. For instance, the study group members identify with the British Presbyterian doctor, James Maxwell, who arrived in Taiwan in 1865 and established the first hospital in collaboration with the Women's Missionary Association (Liu 1998:6). Other western missionaries who established hospitals in Taiwan include Rev. C.L. Mackay and Dr. David Landsborough, who set up hospitals in 1871 in Tanshui and 1906 in Changhua respectively (Liu 1998:6). These missionary groups also authored the Romanized Taiwanese medical textbooks that form the basis for the study group members' Taiwanese-language medical studies curriculum. During the Japanese colonial era, the Taiwanese people who received the best educations were also frequently employed in the field of medical care. The Japanese colonial government was responsible for the founding of the provincial and city hospitals in Taiwan, and some of the Japanese-educated doctors continued to practice medicine in these hospitals when they were administered by the KMT government after they gained political control over Taiwan (Liu 1998:6). Therefore, in addition to creating ethnic identifications through census categories, the Japanese administration was also instrumental in creating what Benedict Anderson calls an "imagined community" by 
creating a class of educated bilingual professionals, which was partially comprised of medical doctors who were fluent in Taiwanese and Japanese (1991:57-58).

The national health insurance system that is currently in place in Taiwan was originally instituted through the efforts of the DPP, and as a political platform, they emphasized the need to develop an egalitarian health care system that provided all elderly patients with the same standard of care as retired KMT government workers and veterans (Liu 1998:6). Because many doctors were also early supporters of anti-KMT political activities, the medical profession has been associated with the cause of championing Taiwanese political autonomy since the rise of Tangwai political activism in the 1970s (Ho 2010:6). The study group members emphasize the association between the development of health care in Taiwan, the promotion of the Taiwanese language literacy, and the promotion of Taiwanese political autonomy through their accounts of Taiwanese history, and this narrative portrays their current activities as a part of a historical tradition of doctors working to promote Taiwanese nationalism.

The assertion that doctors should be able to speak Taiwanese in order to effectively treat patients is supported in practice by the fact that language skills and the ability to clearly communicate with patients is genuinely important for doctors. As Anne Fadiman 
noted in her ethnographic account of medical care for Lao refugees in the United States, language barriers are a significant obstacle that physicians must face when trying to convey health related information to patients $(1997: 38,47)$. Fadiman notes that language and cultural barriers frequently negatively influence doctors' abilities to understand patients' descriptions of physical sensations and therefore also impede their abilities to accurately diagnose patients' health conditions $(1997: 47,69)$. Similarly, patients in the United States who are not native speakers of English frequently find the meaning of medical information conveyed by doctors to be confusing due to the complexity of English language tenses (Fadiman 1997:178). In the case of Taiwanese, because subtle differences in intonation can also influence the meaning and emotional connotations of terms, there is a risk that doctors may convey medical information to patients that is inaccurate or convey it in a culturally inappropriate manner if they lack Taiwanese language skills.

The genuine practical utility of doctors having Taiwanese language skills when carrying out their professional duties lends credibility to the claims of study group members that Taiwanese language literacy should be promoted among medical care workers. Hence, it is unsurprising that the drive to promote Taiwanese language literacy 
as a component of Taiwanese nationalism would be initiated by medical care

professionals.

Personal and Professional Backgrounds and Language Ideology

There is a close relationship between the language varieties and literacy formats that are valued in the study group members' personal and professional lives and the linguistic resources that they have chosen to appropriate as symbolic markers of their Taiwanese national identification. Study group members typically first became exposed to the format of Taiwanese language literacy promoted through the medical school curriculum during the course of their family upbringing and professional development. For instance, the Romanized Taiwanese was familiar to Dr. Tiu because his father had learned to read some Romanized Taiwanese texts in Taipei county during the Japanese colonial era. Dr. Tiu described the state of medical textbooks in the 1970s in the following quotation:

When I was in medical school, it was interesting. We began reading the medical textbooks in English text, but English is very had for us. Anyways, when we entered medical school, most of us went to get Mandarin medical books - a translation. But it was very ridiculous. When we read the textbook in Mandarin, we knew every single character in the text, but we didn't know what it meant. So finally, we had to come back to the English textbook. 
He also found that in practice many patients were not fluent enough in Mandarin to understand the medical terms because they were more proficient in Taiwanese. These experiences contributed to his developing a preference against using Mandarin in his professional work; however, this preference was also largely driven by an ideological commitment to promoting Taiwanese nationalism.

During the time that Dr. Tiu was in medical school, the underground Tangwai activities of the 1970s were taking place, and during his first few years working as a doctor he found that many of his colleagues at the hospital read underground Tangwai publications. It was through these publications that Dr. Tiu became a supporter first of anti-KMT activities and later of Taiwanese independence. Dr. Tiu had this to say about his experiences reading Tangwai literature:

When I came to read the Tangwai magazines, I became another person. I did not actually participate in politics, but I donated a lot. And later, in about 1989 or 90, I came to believe that politics can overthrow the regime. But politics alone cannot build a nation. If you want to build a nation, you will want to build a nation quite different from the present one. So you have to have some other elements. For example, culture, and languages ... especially language is a good way to show identity. Especially, if I speak Taiwanese and I write Roman letters.

In the 1990s, Dr. Tiu became involved in lobbying for mother language education and was 
appointed to a post in the Ministry of Education, where he was an active in supporter for the adoption of the Beiweiji system of Romanized Taiwanese in Taiwanese language teaching curriculum. He also went on to develop Taiwanese teacher training education at Taiwanese Theological College and Seminary and is currently one of the teachers in the Taiwanese language classes at KMU. Dr. Tiu emphasizes the social role of the doctor as both a healer and as a leader of social reform, and he feels that his work in developing Taiwanese-language medical school curriculum is a continuation of the role that doctors have played in anti-colonial movements in Taiwan during the past one hundred years.

According to Dr. Tiu:

Doctors have always been leaders fighting the colonial regimes for the past 100 years. Did you see the history of our opposition in the past 100 years? You will see that 50 or even 70 events are done or initiated or inspired by doctors. And doctors, they are more well-educated. They are respected. So doctors do this job for the promotion, revitalizaton, and protection of the language.

Dr. Tenn similarly sees the influence of doctors and missionaries as part of a modern tradition in movements to promote Taiwanese sovereignty. Having become literate in both Romanized Taiwanese and Hakka through the influence of Presbyterian Church activities, he sees the promotion of the Taiwanese language as an important 
symbolic component of anti-colonialism. Dr. Tenn refutes the view that since the end of Japanese colonialism, Taiwan has been a post-colonial society, and instead espouses the view that the Republic of China's and the People's Republic of China's claims to rule over Taiwan are also forms of modern colonialism and should, therefore, be rejected by the Taiwanese people. Dr. Tenn expressed his viewpoint in the following quotation:

This piece of land was colonized by the Dutch, the Spanish, the Japanese, and the Chinese. We long for one day when we can stand up and rule ourselves. We don't want to be ruled by other people. Actually, this is our dream. So we always keep the Meili dream alive.

Both Dr. Tiu and Dr. Tenn feel that writing Taiwanese using Roman letters is an important symbolic act because by rejecting Han characters, they are promoting a general movement towards "Desinicization" in Taiwan. They both cite the development of medical texts by Presbyterian missionaries as important events in the promotion of education and literacy in Taiwan. Dr. Tenn believes that speaking the Taiwanese language is an important component of Taiwanese identity, and as such it is important to promote the use of Taiwanese in spheres of interaction outside the informal private sphere. Hence, he uses his role as a doctor to promote the use of Taiwanese in science and medicine. For example, in collaboration with his wife, who works as a doctor in the psychiatry 
department of KMU Hospital, Dr. Tenn is researching the influence of schizophrenia on the ability to speak tonal languages. He believes that the Taiwanese language is valuable for linguistic research because of the richness of its tonal system, which is more complex than Mandarin.

Another study group participant, Professor Lim also shares this view that the promotion of Taiwanese in spheres outside the private informal sphere is important to promoting Taiwanese nationalism. The now-Professor emeritus broke ground in the mid90s by teaching software classes at Tonghai University in Taichung lecturing entirely in Taiwanese. Professor Lim feels that the pervasive belief that Han characters are the only legitimate form of writing in Taiwanese society is part of a hegemonic belief in Chinese cultural superiority that should be contested. Lin had this to say about his teaching experiences:

During class, I would often speak Taiwanese. This was unheard of. But they gradually came to understand ... "eh, Taiwanese can be used to talk about computer languages". It's a normal thing. Let me ask you: In Russia, do they use English to teach computer languages? Of course not. In Italy, to teach computer science, do they use English?

Professor Lim claims that although students and coworkers initially found the teaching of computer software in Taiwanese unconventional, they were able to adjust to 
the class and realize that there was no reason that Taiwanese could not be used as a language to discuss modern science and technology. Professor Lim also became involved in teaching medical Taiwanese classes at Chung Shan Medical University when the original instructor became ill and passed away. In addition to having experience teaching software classes at Tonghai University, he also had experience working for the family planning bureau at the Department of Health from 1965 to 1979. During this time, Professor Lim frequently traveled throughout Taiwan to collect health data and provide information about family planning to people in rural areas. This position required that he frequently talk about health-related topics with people using Taiwanese. In addition, he worked in one of the first government bureaus to use computers to process statistical health-related data, and as a result, he acquired a strong command of medical terminology in Mandarin. It was because of these experiences that he felt that he would be qualified to teach the Taiwanese medical course, and he began driving down from central Taiwan to the study group meetings in Kaohsiung on Sundays after he learned about its existence on the Internet.

\section{The Influence of Christian Missionaries}

Most of the study group participants were first educated in the Beiweiji Romanized 
Taiwanese writing format through the influence of missionary activities in Taiwan. Furthermore, much of the terminology used in the Taiwanese-language medical curriculum is drawn from Taiwanese language medical texts that were originally published in the 1920 s by Presbyterian missionaries. Hospital administrator and study group participant $\mathrm{Ng}$ Keng Guan was first exposed to Romanized Taiwanese texts by attending Presbyterian Church services as a child. Born in 1956, he cites his mother as an example of someone who was already an adult by the time the Kuomintang instituted Mandarin-language education. Although she never became literate in Han characters, she had learned to read some Romanized Taiwanese as a child through Presbyterian-churchsponsored education. In the recorded interview $\mathrm{Ng}$ Keng Guan described his feelings about the influence of missionaries as follows:

Missionaries came to spread Christianity, and they wrote Taiwanese with Roman letters and taught the local people. For example, my mother never went through the KMT education, so she never formerly studied, but she can understand Roman letters. But she speaks Taiwanese. Missionaries have had a big influence on Taiwanese culture. Many of them were well-educated and many were medical doctors. They were extremely charitable and did a lot for the local people.

Along with the other study group participants who I interviewed, Ng Keng Guan emphasizes that literacy existed in Taiwan before the KMT's arrival, and rather than 
viewing the study group's current activities as creating a new form of literacy, they see it as a rekindling of an old traditional link to previous generations that was broken by the repressive language policies of the KMT. Similarly, Taiwanese instructor and "Bong" Taiwanese Literary Magazine editor Tan Hong-hui was also informally educated in Romanized Taiwanese as a child in the late 1970s and 1980s at the Presbyterian Church that she attended in Kaohsiung. During the interview, she showed me a Romanized Taiwanese book that her grandfather had owned in the 1930s and told me that she had practiced reading Taiwanese language texts at home with her father and grandfather as a child.

Nationalism, Practicality, and Taiwanese Language Literacy

There is a strong relationship between ideological support for Taiwanese political and cultural autonomy and participation in activities to promote literacy in Romanized Taiwanese. For example, all of the participants expressed a desire to have Han characters entirely replaced by Romanized Taiwanese writing in all mainstream literacy domains as an ideal goal. They are pursuing this goal in order to contest the dominant language ideologies that grant preferential status to spoken Mandarin and Han-character based literacy. Jason Jiang summed up this ideology in the following quotation, expressing his 
desire to have Taiwanese adopted as the full-time medium of instruction in public schools:

We hope that it (the Taiwanese language) can gradually become the way that Mandarin is now. We hope that people can speak it in regular classes and talk about English, history, and physics in it - just like we do with Mandarin now. Of course there's no way to do that right away. One step at a time.

Study group members also uniformly espoused the belief that Romanized Taiwanese is a more practical literacy format than Chinese characters because Roman letters are easier to teach to young students than Han characters. They also believe that because the Roman alphabet is used to write the official national languages of most developed countries, if Taiwanese students learn Romanized Taiwanese writing as young children, it will be easier for them to learn foreign languages. Study group members similarly believe that foreign students will find Taiwanese easier to learn if it is written in the Romanized script instead of Han characters. In the words of Professor Lim:
I believe it (learning Romanized writing) can be done faster. It will help students learn English too. I believe that Romanized characters will improve their ability to learn language. It's efficient. There are so many Han characters, and people can't use them because there are so many words that can't be written with Han characters. And you have to be able to write, not just speak. Be an educated person, and intellectual. You have to find a way to write things that you've never heard of, otherwise, how will you have your mental development? 
Study group members also seek to promote the status of Taiwanese as a language rather than a dialect, and the language name "Taiwanese" instead of "Minnan." The act of conferring a language variety with the status of being a "language" as opposed to a "dialect" is significant because the term "language" carries the connotation of being an officially recognized standard by the state, whereas "dialects" are less-prestigious deviations from the standard. The term "Taiwanese" signifies a definition of the language variety as a full-fledged language that is unique to Taiwan, whereas, "Minnan" signifies a conception that the language variety is a dialect of Hokkien, which is spoken in other locations in the Greater China. Study group members feel that by labeling Taiwanese as a "dialect" the KMT language policy planners have demoted the status of the language variety to a substandard deviation from proper linguistic norms.

The study group members seek to elevate Taiwanese to the status of an official language that is unique to Taiwan and fit to be used in all linguistic domains. Consequently, they always refer to it by using the word Taiwanese and they also refer to it as a language instead of a dialect. Study group members reject the title Minnan. According to Dr. Tenn, the term Minnan was invented by the KMT during the 1960 s in order to create the illusion that the Taiwanese language is the same as the Hokkien 
language spoken in Fujian province and among other Hokkien ethnic-Chinese immigrant

communities living in Southeast Asia. In his own words:

Min-nan wasn't invented until the 1960s. They want to make it seem like we are more related to China, but originally there was no such thing as this language Minnan. It was later that they told us that we speak this language. They say it's a language from the south of Fujian Province, and if we speak it, it means that we are their descendants.

Study group member Tan Hong Hui has been involved in protests and spoken out in the mainstream media against using the term Minnan instead of Taiwanese in mother language education materials. The study group members also generally use the term Huayu to refer to Mandarin, and they never used the term Guoyu, which translates as "national language" and is the most commonly used term for Mandarin in mainstream discourse.

The study group members' emphasis on the uniqueness of the Taiwanese language and its distinctiveness is further reinforced by their choices to avoid using translations from Mandarin terms that are written using Han characters when standardizing medical terms. Interestingly, they are less opposed to using translations from Japanese terms that were in use during the Japanese colonial era. This stylistic choice underscores the point that Taiwanese is distinct from other varieties of Hokkien and part of this distinctiveness 
is due to having incorporated influences from the Japanese language during the colonial era. Therefore, some stylistic aspects of the Taiwanese language literacy promoted by the study group members are, as with many other standardized language varieties, such as Hebrew in Israel and Flemish in Belgium, recent creations with specific stylistic choices that are ideologically motivated (Spolsky and Shohamy 1999:15; Hobsbawm 1983:14).

\section{Language, Identification, and Historical Narrative}

The promotion of Romanized Taiwanese is ideologically linked to a historical narrative that portrays a tradition of literacy in Romanized writing as having a longer history in Taiwan than Han characters. The study group members' historical narrative about Taiwan emphasizes the influence of aboriginal, Dutch, Spanish, and Japanese linguistic and cultural traits in forming their identity and qualifying them as being a distinct nationality from the people of Fujian Province and Greater China. This narrative also associates Romanized writing with the influence of outside powers that have been more benevolent and more genuinely concerned with the well-being of Taiwanese people than has been characteristic of what they consider the Chinese colonialism of the KMT. By promoting this historical narrative, study group members seek to authenticate Romanized Taiwanese language literacy and denaturalize the Han-character based format 
of Mandarin language literacy that is a symbolic mark of the Kuomintang's Chinese nationalism.

For example, Dr. Tiu stated that he considers himself unlucky to be a part of the generation that was educated by the KMT after World War II, and according to him, his parents' generation were more fortunate to have been educated by missionaries and the Japanese colonial government:

Fortunately, Taigi (Taiwanese) has been used by the missionaries in the past 100 years. They have used Taigi and Romaji (Roman letters) to write about religion, culture, and medicine. The older generation was educated by Japan. They are made in Japan, and the younger generation (Dr. Tiu's generation) is made mixed ... the KMT, democracy, western-especially the US, and we, the mixed generation, between 50 and 70 are made mainly by the KMT, made in China. So this generation is the worst. It was very unfortunate to be in the mainstream of this generation, age 50 to 70.

Huang Wen-zhang similarly expressed the view that in many respects, the literacy promoted by missionaries through Romanized Taiwanese texts was of a higher standard than the education that students have received through Han character texts in post-war Taiwan. He feels that the mainstream viewpoint that Taiwanese is only a spoken language that is appropriate for informal and private situations is a misconception that has been brought about by the KMT language policies that repressed the distribution of texts not 
written in Han characters. In the interview, Huang Wen-zhang remarked:

When the KMT came to Taiwan, there was the 228 Incident, and they repressed everything that was Taiwanese. They did away with Taiwanese writing, and put their writing above it. The people who weren't killed didn't dare speak out against them. That was the goal of their rule. They did away with the Taiwanese people's writing, and put their writing above it. People don't talk about philosophy in Taiwanese, like you said, because there is no way for them to write it. Before, there was a way to write about it and to write about it at a higher level than them.

The view that the contemporary inhabitants in Taiwan are the mixed offspring of both aboriginal and ethnic Chinese ancestors is also a key component of the historical narrative espoused by the study group members. According to this narrative, it was mostly men who came to Taiwan during the Qing Dynasty, originally as temporary migrants. Huang Wen-zhang and Tan Hong-hui both claim that at the time, the lowlands aborigines inherited land matrilineally; therefore, by marrying lowland aboriginal women, migrant workers from Fujian Province became landowners in Taiwan. Because this left the families with a higher social status and better economic opportunities, the descendants of the Han men and lowland aboriginal women stayed in Taiwan.

Although according to mainstream Chinese ideology, the descendants of Han Chinese men and aboriginal women are considered Han Chinese, all of the study group 
members see themselves as being of mixed descent, and therefore not of Han Chinese descent. The study group members, therefore, reject the ideology that Han ethnicity is inherited patrilineally, and they instead believe that the matrilineal side of their ancestry is a significant aspect of their Taiwanese identity as opposed to being Han Chinese. Dr. Tiu states that although during the Qing Dynasty, speakers of Zhangzhou Hokkien and Quanzhou Hokkien were considered two separate groups and were frequently in conflict, it was the common experience of being colonized by the Japanese and being considered as one demographic category as "Fujianese" by the Japanese colonial administration that caused the two groups to merge into one group. According to this historical narrative, this hybrid group of Taiwanese speakers is different from other Hokkien speakers because besides being a unique mixture of Zhangzhou and Quanzhou Hokkien, the Taiwanese language has also absorbed vocabulary from aboriginal, Dutch, Spanish, and Japanese languages.

\section{Ethnicity and Nationalism}

The template for the Taiwanese nationalism promoted by the study group participants is very similar to the ethnic nationalism of the Republic of China described in Chapter III in the sense that it is a nationalism based on a "culturalism" that implicitly 
emphasizes ethnicity (Fei 1980:94; Chun 1994:50,66; Townsend 1992:112). The study group members use this nationalist template as a symbolic resource in their efforts to promote Taiwanese nationalism and contest Chinese nationalism. Changing ethnic identification is important to Taiwanese nationalism because in this type of nationalism, ethnicity is closely tied to national identification. This is in contrast to the civic nationalism of Singapore, where although much of the population is considered ethnically Han, they are still considered citizens of Singapore rather than Chinese nationals (Chun 1994:50). The reason that the study group participants are creating a nationalism that emphasizes ethnicity instead of a civic nationalism is because both the ROC model of nationalism and the symbolic identification markers for "Taiwaneseness" and "Chineseness" are already available as pre-existing resources due to the influence of the post-war KMT policies.

During interviews, Dr. Tenn and Tan Hong Hui expressed interest in genetic studies that trace the bloodlines of the contemporary inhabitants of Taiwan because they provide empirical scientific evidence that Taiwanese people are of largely non-Han and aboriginal descent. When I visited her home for the interview, Tan Hong Hui had a map of Taiwan prominently displayed on her living room wall showing the prevalence of 
different non-Han genetic markers among the populations of residents in different regions

of Taiwan and stated:

When people here know more about this, they see that we are more related to Pacific Islanders and people in Southeast Asia than we are to northern people in Beijing in terms of language and bloodlines. This is the actual truth, but the question is whether or not people want to recognize it. That is another matter.

In a recorded interview, Chen Jin Hua and Jason Jiang also referenced a genetic

study showing that the population of Fujian Province, which is the source area for most of the Han migrants who were ancestors of the contemporary population in Taiwan, is more closely related by bloodlines to the people of Vietnam than to the Han population in the Yellow River region and Beijing. Jason Jiang had this to say about the issue:

Chinese people gave men a higher status, so even though the bloodlines are from both men and women, they recognized the bloodlines inherited through the male lineage. So because of this, it came to be thought that everyone was Han.

Chen Jin Hua went a step further, stating:

I think of myself as a plains aboriginal person from my mother's side. I'm not a Han person.

For other group members, such as Ng Keng Goan and Dr. Tiu, however, the degree 
of genetic similarity or difference from people living in Fujian Province is not as important as the shared history and experience of living in Taiwan as a criterion for molding the people of Taiwan into a distinct nationality. For instance, $\mathrm{Ng}$ Keng Goan states that he feels the Taiwanese nation is comprised of four ethnic groups: Taiwanese speakers, Hakka speakers, the Mainlanders, and the aboriginal people, and members of all four groups should enjoy equal rights as Taiwanese people. Therefore, his view of Taiwanese nationalism is derived from the more inclusive "New Taiwanese" form of nationality described in Chapter III, even though the linguistic practices of the study group as a whole are more influenced by the earlier Tangwai-era Taiwanese nationalism from the 1970s and 1980s.

\section{Authentication and Identification}

A part of the promotion of Taiwanese language literacy and language domain norms, which favors the use of Taiwanese as the dominant language variety in public discourse, entails authenticating the use of Taiwanese in some contexts, but criticizing the use of Taiwanese in other circumstances on the grounds that it is inauthentic. Therefore, while the study group participants hope to expand the use of Taiwanese in the public sphere, there are also some cases where they consider the use of Taiwanese in political 
dialog to be exploitive. For example, several study group participants specifically singled out the Hong Kong-born KMT President Ma Ying-jiu's use of Taiwanese in his public appearances as a dishonest and manipulative way of attracting votes from Taiwanese speakers. Dr. Tenn believes that when President Ma speaks Taiwanese in order to promote policies that favor greater integration of Taiwan into Greater China, he is exploiting the language to feed voters a "poison pill."

The fact that President Ma is not a native speaker of Taiwanese and does not usually speak Taiwanese during his daily life is another reason that study group members criticize his use of Taiwanese as being inauthentic. For example, Ng Kheng Guan espouses the belief that the President is able to deliver speeches in Taiwanese only because he has memorized a script provided by accent coaches and he only speaks in Taiwanese at public events for show. According to Ng:

It is a manipulative tactic to get votes. For example when President Ma Ying-jiu wants to get votes, he'll speak Taiwanese. When he goes to a Hakka village, he'll speak Hakka. But really, if you speak to him face to face, he doesn't speak it. He just memorizes a script. He uses this as a way to cheat people.

Therefore, the study group participants hope not only to promote the use of the Taiwanese language in the public sphere but also to authenticate certain ways of using the 
Taiwanese language in contrast to others. For example, Tan Hong-hui states that much of the Taiwanese-language broadcasting on television does not sound like authentic Taiwanese because many terms are phrased in such a manner that it sounds like the script was first written in Mandarin using Han characters and then translated into Taiwanese according to how terms would be phrased using Han characters.

\section{Language Domain Ideology}

The language habits of study group members in their professional and personal lives were also different from the mainstream language practices in urban Taiwan, which privilege Mandarin as the appropriate language for public interactions and allocate Taiwanese to less-prestigious language domains, such as private discourse and communication with elderly family members. All of the study group participants claimed to speak Taiwanese predominantly in their homes, and they also claimed to make a point of speaking it as the unmarked language with their children instead of Mandarin.

Jason Jiang states that in his daily life, he speaks Taiwanese as often as possible, and he uses it as his unmarked language when he goes to the bank or takes public transportation. When Chen Jin-hua teaches Taiwanese classes in public middle schools or delivers presentations for her graduate studies, she speaks entirely in Taiwanese. When 
students or classmates complain that they cannot understand her, she still insists on speaking Taiwanese, and tells other people that it will be good for them because she is giving them an opportunity to learn a new language. Professor Lim also uses Taiwanese as his default language when he teaches both Taiwanese classes and university-level software classes. In addition, when he communicates by email or text message, he writes entirely in Romanized Taiwanese. Dr. Tenn and Dr. Tiu both prefer to speak in Taiwanese and claim to speak to patients in Taiwanese whenever they think that patients will be able to understand them. In one interview, Dr. Tiu expressed frustration that because of his higher status as a doctor, patients would often try to speak back to him using Mandarin, and he would have to encourage patients to speak to him using Taiwanese to get them to respond to him in Taiwanese.

According to Jason Jiang, employees at large companies typically have to take tests as a part of the application process; therefore, proficiency in Mandarin is crucial in obtaining employment in these companies. Jason Jiang believes that it is not uncommon for people with high occupational statuses to look down on people who speak Taiwanese in the workplace, because they view it as a sign of not being able to score well on employment-screening examinations. Therefore, the fact that study group members 
predominantly speak Taiwanese in their professional lives is most striking because they are all well-educated and speak Taiwanese in the professional sphere as a lifestyle choice rather than because they do not have the resources or opportunity to become proficient in Mandarin.

In addition to editing medical school curriculum in the study group, the majority of the study group members are also involved in other activities to promote the Taiwanese language. For example, Tan Hong-hui is both the editor of the literary newspaper "Bong" and collaborates with her sister in promoting Taiwanese-language programming on public television. She also is a member of another study group that regularly meets at her apartment in Kaohsiung to read and discuss contemporary Taiwanese-language literature. Similarly, Chen Jin-hua and Jason Jiang offer Taiwanese-language classes at a private language school that they opened in Kaohsiung City. In addition to teaching students from a variety of social backgrounds and age groups, they also prepare the students to successfully take part in the General Taiwanese Proficiency Test, which was introduced in 2008 at National Cheng Kung University in Tainan. Chen Jin-hua is also currently working on a graduate thesis about Taiwanese-language pedagogy through Taiwanese Theological College and Seminary. 
Many of the study group participants are also interested in developing Taiwaneselanguage computer applications, and during breaks, the study group members often talked about language and technological issues. For example, study group participant Huang Wen-zhang's interest in computers and technology is closely related to his interest in Taiwanese language studies, and he is active in assisting the instructors at KMU in making Taiwanese-language computer displays for the lectures. Huang Wen-zhang also teaches Taiwanese-language courses at a public elementary school and along with other study group members enjoys participating in the development of Unicode writing and internet resources for the Taiwanese language. This interest in promoting Taiwanese on the Internet and in science and technology is a part of a more general commitment shared by all of the group members to strive to encourage the use of Taiwanese in spheres outside the narrow confines of the private informal sphere, as it was allocated to by the restrictive language policies of the Japanese colonial regime and the KMT during the past century.

\section{Gender and Language Ideology}

When asked whether they thought it was considered more acceptable in mainstream discourse for men to speak Taiwanese than women, female group members Tan Hong-hui and Chen Jin-hua both felt that there are more restrictions on women 
speaking Taiwanese. They both stated that the speaking of Taiwanese among women is more frowned upon than men in the same way that other behaviors that are considered "crude" or "lower-class," such as smoking and cursing, are considered relatively more acceptable among men than women. In the interview with Tan Hong-hui, I mentioned both the recognition of matrilineal descent in the study group members' identity formation and the tendency for women to be high-level political figures in the DPP. When I asked her if she felt that there was a connection between feminism and Taiwanese nationalism, she replied that for her, there was a clear relationship between the two issues.

In another interview, Chen Jin-hua stated that she feels that negative public opinion towards women speaking Taiwanese is largely a result of the language policy where the speaking of Taiwanese was forbidden in schools, and speakers of Taiwanese were portrayed as being lower class and criminals in mainstream media. She hopes that her activism in promoting the greater acceptance of the Taiwanese language in the public sphere contributes to the development of a social atmosphere that is less restrictive and judgmental towards women's behavior in general.

\section{Likely Accomplishments}

The study group members' language preservation and revitalization efforts are 
likely to influence public opinion in the sense that their activism encourages Taiwanese people to develop a more positive association between the speaking of Taiwanese in public and Taiwanese identification. However, the effectiveness of their activism will most likely be limited due to structural factors that have firmly established a link between Mandarin language achievement, Han character literacy, and access to prestigious employment opportunities. As a result of these structural conditions, most families are more supportive of educational initiatives that will ensure that their children acquire forms of linguistic capital that will enable them to successfully attain employment in mainstream job markets than initiatives to promote Taiwanese identification.

The degree of success that study group members are able to achieve in contesting Mandarin-language dominance and replacing it with Taiwanese language literacy most likely depends on the extent to which study group members are able to influence public policy. Evidence from other studies suggests that government intervention in the form of language policy measures is crucial to the success of language preservation and revitalization movements. For example, Sue Wright states that "hands-off" language policies that do not actively implement measures to protect non-dominant languages create the conditions for dominant languages to retain their uncontested positions because 
most social and economic institutions encourage the use of the dominant language varieties as default languages (Wright 2004:187). Wright also states that language preservation and revitalization initiatives are often ineffective because the structural status quo conditions are so firmly entrenched that the language policy measures have little chance of constituting a genuine threat to the prevailing power relations (Wright 2004:187,242).

According to Wright, in some cases, language preservation and revitalization measures may in practice be little more than token gestures that serve to deflect public criticism away from the dominance of one group by another $(2004: 187,242)$. Study group members advocate increasing the scope of mother language education in Taiwan for this very reason. For example, Tan Hong-hui argues that requiring students to attend only one hour a week of mother language instruction a week is harmful because the instruction time is both insufficient for students to develop linguistic competence in Taiwanese and it gives the public the illusion that the language is already being protected and is, therefore, not in danger of continuing to decline in use,

If there's no change in the government policy in the short-term future, the complete use of Mandarin will become more and more normalized because long-term, some people say the DPP has power, so there's no repression, and it's open and free. So there's not as much of an environment that's 
conducive to protesting. There's a feeling that everybody can live well and speak Mandarin, and there's nothing wrong with that. So it's a great danger.

In spite of this danger of being co-opted and used for token purposes, Dr. Tenn feels that the establishment of mother language education has accomplished the goal of reversing the negative stigma that associates the speaking of Taiwanese with low-class and criminal behavior. Dr. Tiu also feels that even if mother language education does not accomplish the more ambitious goal of reversing the language shift to Mandarin as the default language for public discourse, basic linguistic competence in Taiwanese and literacy in simple reading and writing of Romanized Taiwanese will serve the purpose of constituting a symbolic identification marker for Taiwanese people. This will help to identify people who have grown up and been educated in Taiwan as being different from people from Mainland China. As Dr. Tiu expressed, the accomplishment of this goal makes their endeavors in creating Taiwanese language curriculum worthwhile regardless of whether or not they are able to accomplish the more ambitious goals of reversing language change and replacing Mandarin with Taiwanese as the default language in Taiwanese society:

We hope that our language is preserved or revitalized and we can promote and cultivate this language to be used very fluently by a lot of people. OK, that's the ideal goal of my cause. But if we can just make everyone know 
some mother language skills and speak some mother language, it's OK with me too. You pay a low price to get a lot of profit, right?

\section{Conclusion}

The study group members are choosing to speak Taiwanese in domains that are considered to be Mandarin-speaking domains by most other members of contemporary communities. Through their activism, study group members are attempting to challenge the linguistic dominance of Mandarin and create new language conventions that both raise the status of the Taiwanese language and symbolically authenticate an alternative national identification. Therefore, the study group members have selected locations where the symbolic foundations of this hegemony are passed on to the population as sites of resistance, namely educational institutions.

Doctors are in a privileged position to carry out this task because they are qualified to be instructors and curriculum planners at medical universities, and they also have a genuine use for Taiwanese language skills as a part of their occupational duties. Therefore, the study group members' language activism serves as an example of how people who are involved in nation building projects tend to draw from the linguistic resources that are valued in their occupations when constructing a national language. Doctors are also able to engage in alternative linguistic behaviors because they occupy an occupational niche 
that allows them to practice noncompliance with mainstream language domain norms without experiencing negative consequences in their professional lives. Therefore, the study group members' activism also exemplifies how changes in power structures are typically initiated by people who are employed in specific occupations that enable them to introduce alternative behavioral norms into society.

The timing of the study group's language preservation and revitalization activities is significant because most people feel that Taiwan's political and economic autonomy has already reached its high point and is receding as Taiwan is increasingly being absorbed into Greater China. In addition, after the current generation of elderly patients passes away, doctors will have less of a use for Taiwanese language skills in their professional work; therefore, the justification for implementing Taiwanese language medical curriculum will not be as strong. Consequently, the study group members are digging in and trying to establish symbolic footholds in an effort to preserve as much autonomy as possible. These footholds are especially important to establish in education institutions, where language ideology is primarily propagated and educated students are most susceptible to internalizing language policies. The effectiveness of the study group members' curriculum planning will be further explored in the ethnography of students enrolled in Taiwanese 
language medical studies courses at Kaohsiung Medical University in Chapter VI and in the conclusion in Chapter VII. 


\section{Chapter V: Curriculum and Learning Materials}

The study group members' Taiwanese language medical school curriculum and learning materials are designed to convince students that the Taiwanese language is suitable for use in discourse domains that are associated with modern scientific and medical concepts. In addition, the study group members use the medical studies curriculum as a forum to persuade students that adopting the Romanized writing system for the Taiwanese language will be a productive step in the movement to establish Taiwan's status as a nation in the international community of modern developed nation states. Therefore, by encouraging the mainstream public to adopt these alternative language domain norms and literacy practices, study group members hope that they can pose a challenge to Chinese nationalist hegemony in Taiwan and replace it with an alternative Taiwanese nationalism.

This chapter provides a description of both the testing materials and textbook content that was edited in the study group meetings from December 2010 to July 2011 and the Taiwanese language medical studies curriculum that was taught at Kaohsiung Medical University during spring semester 2011. The data is based primarily on participant observation; however, some supplemental data from the recorded semi-structured personal 
interviews from Chapter IV is also used. The chapter is divided into two sections. The first section describes the learning materials that were drafted in the study group meetings, and the data is based on the handwritten notes that I took while participating in the meetings as data. The second section focuses on the curriculum used in two elective Taiwaneselanguage medical studies classes at Kaohsiung Medical University, and the data is taken from written notes that I took while auditing the classes during spring semester 2011.

\section{Part I: Testing Materials and Medical Language Textbook Chapters}

I attended nine study group meetings between December 2010 and July 2011, held from 1:00 to approximately 4:30 pm on Sundays in the dining room at Dr. Tenn's house in Kaohsiung City. The meetings started with the participants taking standardized Taiwanese language tests that were trial versions of tests that would later be used for Taiwanese language courses at medical universities. Study group members are engaged in the act of creating standardized testing materials as a way of authenticating Taiwanese language literacy as an officially recognized component of medical school curriculum. The content of the tests mostly consisted of medical issues; however, at times the test content also served the purpose of measuring the degree to which test takers were able to use Taiwanese to talk about subject matter that is characteristic of the kinds of topics which 
are typically discussed by well-educated people in contemporary Taiwan.

The first test section was designed to test reading comprehension skills, and participants had ten minutes to read two passages and answer four multiple choice questions about the first passage and three multiple choice questions about the second passage. The text was written in mostly Han characters, with some one-syllable terms written in Roman letters when there was no corresponding Han character for the meaning of the term. Writing the test in this format had the effect of making the questions comprehensible to anyone who is already literate in Han characters. If the questions had been written entirely using the Romanized writing system, most students would not be able to read the questions because they went to elementary school before the introduction of Romanized mother language teaching materials. Therefore, although study group members ideologically prefer Roman letters to Han characters for the writing system for Taiwanese, they choose to use Han characters in this case in order to make the testing materials accessible to university students. The figure below shows a text sample from one of the test paper drafts. 
若有高血㻺 ê 人eh án-chóa ${ }^{n}$ 處理 - - leh? 答案當然是去 chhōe 醫生chiah tióh, 不而過, 你 ka-ki mā 會 tàng 處理一部份。代先, 注意體重有超過--bô? Tī chia有一個簡單 ê公式：男 $=62+(\mathrm{Ht}-$ 170) x 0.6, 女 $=52+(\mathrm{Ht}-158) \times 0.5$, 其中 $\mathrm{Ht}$ 是身 $\mathrm{koan}$, 用 $\mathrm{cm}$ (公分) 表示, 標準加減是 $10 \%$ 。可比講, 若有一個人身kôan $160 \mathrm{~cm}$, 體 重 75公斤, lán來算 $\mathrm{i} \mathrm{e}^{\Gamma}$ 理想體重」=62+(160-170) x $0.6=62+(-6)$ = 56公斤, 標準加減是 56 公斤 ê $10 \%$ (= 5.6公斤), $\overline{\mathrm{m}}$-chiah lán知影 一個人 ê體重對(56公斤-5.6公斤)到 (56公斤 +5.6 公斤) lóng算正 常, 就真清楚i超過 13 公斤 - - lo ! Án-ne講--起来，第一項 tāi-chì 是 減肥, 希望會 tàng達到理想體重 ê $15 \%$ 以内。第二項, 盡量 mài 食

\section{Figure 5.1 Han Characters with Romanized writing}

Some examples of the topics were heart disease and cardiology, body temperature, flu viruses, blood cell count, kidney disease, chest pain symptoms, breathing difficulties, blood pressure, sanitation, and surgical procedures.

The second test section tested students' listening comprehension skills in Taiwanese, and during an allotted period of ten minutes, students were expected to answer multiple-choice questions about two sets of recorded dialog. The questions and answers were both written in the same format as the reading comprehension section. Some examples of topics in the listening comprehension section were insomnia, obesity, health checkups, soft bones in the voice box, vision, respiratory illness, liver function, bones, throat discomfort, and instructions for taking medications.

The testing materials also included oral questions that required test takers to give 
articulate one-minute long spoken responses to two topical questions. The goal of this section of the test was to encourage students to use the Taiwanese language as a medium for discussing issues that are usually discussed using Mandarin by most speakers in mainstream discourse. The content of the questions on the oral section tended to be geared more towards having test takers comment about contemporary current events and social issues than to demonstrate their knowledge of medical issues. Therefore, the tests appeared to be partially designed to encourage students to develop the ability to articulately discuss topics related to higher learning using Taiwanese. Some examples of topics in the oral section included how to deal with the declining birthrate; how learning foreign languages influences local language study; how to reduce the waste of resources in the National Health Insurance system; whether or not foreign degrees should be recognized in Taiwan; bullying on school campuses; relations between the United States and North Korea; environmental issues; the global overpopulation problem; and the certification and regulation of organic foods.

While taking the practice tests, participants in the study group would also take notes on the written test questions and the recordings and discuss whether or not some elements of the test should be changed. Some of the group members' discussions were 
about whether or not the questions were appropriately challenging and whether or not it would be clear which of the questions is correct on the multiple choice section. They also talked about linguistic issues, such as which terminology should be used and how the pronunciation should sound on the recorded questions.

\section{Textbook Chapters}

The second half of the study group meetings entailed reading drafts of chapters for a Taiwanese medical language textbook. In a similar vein to the testing materials, the textbook chapters also served to encourage readers to use Taiwanese to talk about modern medical concepts as a means of challenging language domain norms that normalize Mandarin as the proper language for discussing modern scientific topics. The topics for the different units included: dermatology, common colds, liver and digestive system, eyesight and vision, neurology, and psychology. Therefore, the purpose of each chapter was to train students to have a working knowledge of how to talk about each medical topic using the Taiwanese language.

Each chapter began with a short introduction about the medical topic for that chapter and a prelude to a sample dialog between a doctor and a patient in Taiwanese. Each introduction was one paragraph in length, and it was first written entirely in 
Romanized Taiwanese, and then the same paragraph was re-written under it in Taiwanese using mostly Han characters with a few Romanized terms. The texts were written in both formats in order to instruct students in how to pronounce the texts using the Romanized writing system, and to allow students to understand the meaning of the texts by allowing them to refer to the Han characters used in the second writing format. The figures below show samples of the two text formats.

Tân lú-sū kui-jit lóng án-ne hîn-hîn, āu-náu tsiok-sio--ê. I kám-kak he sī iỏh-á buē hảh ê kuan-hē. Gán-kho i-sing kā kóng i ū khui Pèh-lāi-tsiàng ê bảk-tsiu iỏh-á hōo i tiám. $\bar{M}$-kú ìng-kai buē ū tsit-tsióng tsìng-tsōng tsiah tióh. Tsiū kiàn-gī Tân lú-sū khì hōo Náu-sîn-king lāi-kho ê i-sing khuànn--tsit-ē tsiah hó, bô it-tīng sī ū kî-thann ê būn-tê.

Figure 5.2 Romanized Taiwanese

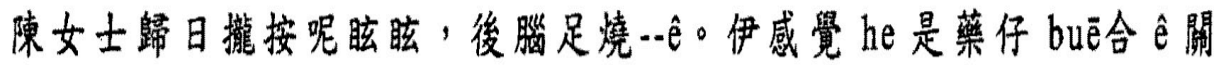



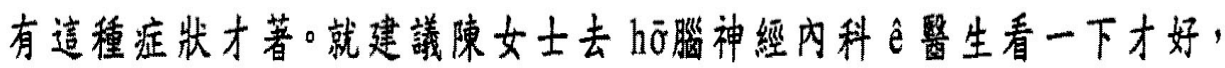
無一定是有其他 ê問題。

Figure 5.3 Taiwanese written using Han characters with some Romanized terms 
After the initial introduction, in each unit there was a Taiwanese dialog, which was nearly a page in length and written entirely in Roman letters. Underneath the dialog, there was then an English translation of both the introductory paragraph and the dialog. Following the English translation, the same Taiwanese dialog was printed once again, using Han characters with some Romanized terms. Each unit consisted of three sections of dialog in the format described above, with an introduction, followed by about a page-long dialog written first in Romanized Taiwanese, second in English, and third in Taiwanese written with Han characters with some Romanized terms.

\section{Style and Content Issues}

Much of the discussion about the testing materials and dialogs dealt with linguistic issues that related to how the content should be phrased and written in the texts in accordance with the language ideology that views the southern Taiwanese accent spoken in Kaohsiung and Tainan as the standard. This choice of the southern accent as the standard is related to a historical narrative that depicts the Tainan region as the location where members of Dutch, Han, and Aboriginal groups came into contact and formed the hybrid culture that is the root of the modern Taiwanese national identity promoted by the study group members. According to study group members, there are four regional 
variations of Taiwanese that are marked by differences in vowel pronunciation and intonation: the Tainan accent, the Ilan accent, the central Zhang-hua accent, and the central coastal accent. Because the study group members grew up in a variety of regional areas, they were able to draw from their background knowledge of the language and discuss how they remember the different terms being pronounced during their childhoods in their hometowns. They would then discuss how they believe the terms should be written based on the accepted accent differences between the different regional variations and the standard southern accent.

In addition to regional accent differences, due to the influence of the mainstream language domain norms that are prevalent in Taiwan, there were sometimes cases where there were no standardized ways of phrasing medical terms in Taiwanese. Consequently, there were frequent discussions about how to phrase some modern concepts that have no standardized terminology in Taiwanese. Some examples of this were discussions about what terms should be used for words such as "pap smear" and "prescription" in Taiwanese. A part of the study group members' linguistic ideology holds that because Taiwanese has been in use longer than Mandarin, and because Mandarin is a recently created language, Taiwanese is better suited as a medium for describing physical 
symptoms and feelings. This is reflected in remarks made by study group members that there are more descriptive words in Taiwanese than Mandarin for symptoms and subjective sensations such as itching, irritation, tickling, and types of pain and aches. Consequently, the study group members sometimes used the language learning materials as a medium to showcase these descriptive capabilities of the language, and during meetings, they sometimes discussed which terms would most accurately reflect the patients' subjective feelings in different medical situations using what they considered to be "authentic" Taiwanese speech.

Study group members engaged in the task of creating language conventions for medical Taiwanese as a part of the project of challenging the language domain norms that had confined Taiwanese to private informal spheres of discourse. The fact that there are not standardized ways of talking about medical concepts in Taiwanese is a result of the influence of these language domain norms; therefore, in the meetings, study group members discussed how different aspects of usage should be standardized for use in this language domain. Some of the discussion involved determining ways of phrasing concepts using language etiquette which study group members felt would be appropriate for medical doctors speaking in the language domain of medical concepts with patients. 
Through the development of testing and curriculum materials, then, the study group members were acting to encourage medical care professionals to challenge Mandarin language dominance in their professional lives by creating and authenticating conventions for the use of the Taiwanese language in the domain of clinical settings.

\section{Part II: The Courses at KMU}

The 2010-2011 academic year was the fifth year that the Taiwanese language medical studies courses were offered as an elective at Kaohsiung Medical University. The instructors consisted of either medical doctors who were employed at the Kaohsiung Medical University hospital or Taiwanese language instructors who were either affiliated with the Department of Taiwanese Language and Literature at National Cheng Kung University or Tainan Theological College and Seminary. Most of the study group members either served as instructors who taught one or more class or as assistant instructors who led students in small groups for practice testing or pronunciation drills. The class served as a platform for instructors to both demonstrate that Taiwanese language skills are a useful form of linguistic capital for medical doctors and to legitimate the format of Romanized Taiwanese language literacy taught in the course as a desirable component of Taiwanese national identification. Therefore, in addition to teaching 
language skills, the curriculum also promoted a nationalist ideology and encouraged affective identifications with this ideology through participation in the course activities. From the perspective of this nationalist ideology, the ability to speak Taiwanese language is a key index marker of Taiwanese national identity.

During the course, the language learning materials were intentionally taught together with a historical narrative that serve to both ideologically legitimate Taiwanese nationalism as a worthwhile cause and establish a niche for Romanized Taiwanese as a component of this national identification. The historical narrative also served the purpose of denaturalizing the legitimacy of Han-character based Mandarin language literacy by explicitly making the case that Roman writing systems are more practical to use, in accordance with standards for literacy conventions in other modern developed Western nations, and have historical precedence over the use of Han characters in Taiwan.

The primary language of instruction throughout the course in all of the instructors' lectures was Taiwanese, which is an unusual act on a university campus where Mandarin is the accepted default language for spoken and written communication. Even so, despite this ideological stance, because students had varying degrees of Taiwanese language proficiency, at times instructors had to switch to Mandarin out of necessity when making 
announcements or clarifying information that they felt was important for students to be able to clearly understand. The syllabi for both classes were also written in Mandarin using standard traditional Han characters instead of the Romanized Taiwanese writing system taught in the course in order to ensure that students clearly understood the course information. This use of Mandarin is an example of how although the curriculum planners ideologically support the practice of speaking entirely in Taiwanese, in some situations they are still constrained to act in accordance with dominant language conventions in order to make the classes accessible to students.

Whereas during the 2009-2010 school year and fall semester 2011, only a basic level course was offered, beginning in Spring 2011, both a basic level course and an intermediate level course were offered. In general, while both the basic class and the intermediate class had some overlapping curriculum, particularly early in the semester, the basic class was more geared towards teaching students about history and Taiwanese nationalism, whereas the curriculum in the intermediate class was more directly related to teaching students how to talk about medical issues in Taiwanese. Although students did not receive course grades for their participation in either of the classes, and there were no formal examinations, students earned credit for attending the courses, and they could 
apply the credits to serve as elective credits required to satisfy course requirements for graduation. As will be discussed in greater detail in the following chapter, students who were majors in a variety of different departments enrolled in the courses; however, the intermediate class consisted of more students who planned to become certified medical doctors than the basic class. Each of the classes met for two hours once a week on Tuesday afternoon from February 2011 to June 2011 on the main campus. In the basic level class there were sixty-four students, while the intermediate class had thirty students.

The attendance rate was high for both classes throughout the semester.

\section{Introductory Lecture: Course Ideology}

The goals and ideology of the Taiwanese language medical courses were detailed by Dr. Tenn during the first class period of the semester for both the basic and intermediate level classes. The introductory lecture was designed to both demonstrate that Taiwanese language skills are a useful form of linguistic capital for medical doctors and to legitimate the format of Romanized Taiwanese language literacy taught in the course as a desirable component of Taiwanese national identification. Although the initial introduction to the lecture was in Mandarin, on the whole, the lecture was delivered mostly in Taiwanese to set the tone for the language ideologies that would be promoted 
throughout the semester.

Dr. Tenn focused on both conveying to students reasons why learning Taiwanese is important for doctors, and promoting the ideological merits of learning to read and write Romanized Taiwanese. In the lecture, Dr. Tenn described the generation that grew up starting in the 1940s as a "lost generation" because they were not able to be educated in their mother languages due do the KMT's "Mandarin-only" policy in educational institutions. He used this as a staging point to then talk about the need to preserve the language as a part of Taiwanese identity and also to revitalize the language so that it can be used to talk about contemporary topics.

Dr. Tenn then talked about doctors' responsibilities to provide high-quality care to patients in the patients' native language and the importance of promoting Taiwanese identity. Dr. Tenn stressed the importance of doctors being able to speak Taiwanese because of the large number of elderly patients who are not proficient in Mandarin. He stated that it is particularly important to understand the patients when recording their "chief complaint" and listening to them talk about why they are seeking treatment and their physical symptoms. For example, there are a variety terms for "chest pains" in Taiwanese, and due to translation problems and not having equivalent terms in Mandarin, 
there is the danger that patients will be misdiagnosed. Dr. Tenn also stressed the need for doctors to understand how to explain medical information to patients using their native language in a way that is not culturally insensitive. For example, when the term "Hepatitis C" is translated from Mandarin to Taiwanese, it can sound like the term for "death sentence" in Taiwanese. This is problematic because, in general, talking about death is taboo in Taiwanese society. He also made reference to a case that had been covered in the media where a doctor had mistakenly used an insulting word in Taiwanese that roughly meant "bad seed" when explaining to a patients' parents that their daughter had a hereditary disease.

Overall, the students were amused and charmed by Dr. Tenn, and his lecture had the effect of establishing him as a charismatic figurehead in the cause to promote the learning of Romanized Taiwanese among students. Much of the lecture consisted of jokes and language puns, and sometimes the jokes were mildly crude and having to do with language misunderstandings in Taiwanese due to translation problems and regional accent differences. Therefore, the lecture was in part an attempt to persuade students to identify with Taiwanese nationalism by making the coursework seem entertaining and emotionally appealing to young students. 


\section{Pronunciation, Reading, and Writing}

One component of the curriculum provided students with a functional knowledge

of the Romanized Taiwanese writing system as an alternative literacy format to Han character based Mandarin language literacy. During the first few weeks of the semester, students in both the basic and intermediate classes were taught how to read and write Taiwanese in the Romanized writing system. The classes consisted of pronunciation and intonation drills, so that students would learn how to read Romanized Taiwanese texts aloud using a standard southern accent.

The textbook used in both classes, Peh-oe-ji ki-chho kau-chai, consisted of pronunciation drills and children's rhymes. The first half of the book was written in Romanized Taiwanese, and the second half consisted of the same chapters rewritten using Han characters. The instructors encouraged students to only use the textbook pages with Romanized Taiwanese text when they were doing the pronunciation drills and to wait until after the drills to look at the Han character translations in the back of the book for reference to help them understand the meanings of passages. Most of the students seemed to be able to partially understand the meaning of the dialogs by looking at the Han characters; however, in the rhymes there were also some Han characters that are not in 
common use in Taiwan.

\section{Medical Terminology}

Overall, for the basic class, the curriculum did not include much information on how to use the Taiwanese language to talk about medical terms or topics related to the medical profession. However, students were occasionally given writing practice exercises, where they listened to spoken samples of the pronunciation of body parts and organs and attempted to transcribe the words using Romanized Taiwanese.

The curriculum for the intermediate class included more material that was directly related to medical studies than the basic class, with students studying printed-out copies of selected dialogs from the teaching materials being edited by the Sunday study group. The intermediate class students also took practice examinations, which were taken from tests that had been edited by the Sunday study group at Dr. Tenn's house. Students took trial versions of the reading comprehension and listening comprehension sections of the tests, and after taking the test the first time, the instructor for that week would go over the passages using a Powerpoint presentation. After the terms in the passages were explained to the students, the instructors asked them to retake the test a second time. Students were also called on to attempt to answer the oral questions from the trial tests in small groups 
supervised by instructors from the Sunday study group.

Literacy and Taiwanese Identification

Aside from teaching students how to read and write Romanized Taiwanese texts, in both the basic and the intermediate classes much of the curriculum involved providing students with information about the Taiwanese language and educating students about the ideology of Taiwanese language literacy and its importance to Taiwanese identification. Instructors also provided students with information about some of the contemporary uses for Romanized Taiwanese. For example, one week a guest lecturer, Lin Mei-xue, from National Cheng Kung University talked about her work in developing Unicode for Romanized Taiwanese writing and other computer and Internet resources for Romanized Taiwanese. She also discussed the National Museum of Taiwan Literature in Tainan and her work for the literary magazine Bong. Students were also told about the development of the General Taiwanese Proficiency Test, and they were encouraged to take the examination in order to win scholarship money.

The curriculum also raised awareness of other movements to replace Han character based literacy formats with alternative writing systems in other countries in Asia. For example, a guest instructor from National Cheng Kung University, Professor Chiung 
Wei-wen, delivered a lecture about the history of "Desinification" in Korea, Japan, and Vietnam. According to Professor Chiung, the adoption of alternative writing systems has been an important symbolic act in nations neighboring China in asserting their national autonomy. Dr. Chiung looks especially to Vietnam as a model in adopting Roman letters for their writing system as opposed to Han Characters. This lecture underscored the viewpoint that the promotion of a Romanized literacy format as a means of promoting national autonomy is a commonly practiced strategy for nationalist movements in Asia that are seeking to resist the influence of Chinese cultural and political hegemony.

\section{History and Literacy}

Some aspects of the curriculum involved creating symbolic associations between the linguistic practices promoted by the study group, historical narrative, and Taiwanese nationalism. The purpose of these lectures was to promote the ideological viewpoint that the Taiwanese language has unique characteristics that clearly distinguish it from Chinese languages and it should therefore be written using the Romanized writing system instead of Han characters. In their accounts of Taiwanese history, instructors made the case that because of the large number of European, Japanese, and aboriginal words that are now a part of the vocabulary and have no corresponding Han characters, using Han characters to 
write in Taiwanese is impractical. Students were also provided with information that was designed to encourage them to refer to the language as Taiyu or Taigi and debunk the viewpoint that Minnan should be the proper term for the Taiwanese language. The curriculum designers made this distinction as a way of emphasizing that Taiwanese, or Taiyu, is a distinct language from other variants of Hokkien, or Minnan, spoken in southern Mainland China and Southeast Asia. This act is an example of Irvine and Gal's assertion that "identifying a language presupposes a boundary or opposition to other languages with which it contrasts in some larger sociolinguistic field" (2009:402).

One of the lectures introduced students to the history of Romanized Taiwanese language texts in Taiwan. The lecture taught students that not only could Romanized Taiwanese be used to write about a variety of modern concepts, including medical studies, but also that historically, the development of Romanized Taiwanese-language texts predates the development of both the Chinese language revolution and Mandarin medical studies texts by a few decades. This was done in an attempt to dispel the popularly held belief that using Romanized Taiwanese to write Taiwanese is a recent invention, and that because most education has been through the medium of Han character literacy during the past sixty years, students should also be educated in other languages in Taiwan using Han 
characters.

For example, a guest instructor named Huang Ling-ling from the Department of Taiwanese Languages and Literature at National Cheng Kung University in Tainan gave a lecture about the history of written Taiwanese. In the lecture, she showed students slides of Bible translations, newspapers, dictionaries, tombstones, short stories and Braille that were written in either Han characters with some Romanized terms or in Romanized Taiwanese and were the products of missionary activities in the late nineteenth and early twentieth century. Most notably, the students were introduced to a medical studies text, called “Yi-hak Tai-gi Kau-hak” 醫學台語教學, that was written in 1917 at an English Presbyterian Ministry Hospital and published in 1922 by James Maxwell et al. Students were also taught about the history of language restrictions carried out by the Japanese colonial government and then the Kuomintang in Taiwan as a means of making the case that the repression of information about these alternative literacy formats is the reason that the current generation of students are unfamiliar with Romanized Taiwanese texts.

International Links

Some of the coursework also involved appealing to international law to convince students that the promotion of Taiwanese language literacy is a legitimate endeavor that 
will both facilitate retaining links with a traditional past and establish Taiwan's membership in an imagined international community of modern nation-states. For example, in one lecture, an instructor taught students about United Nations legislation on language rights and talked about how promoting local languages is not just a form of promoting localism, but how it can also facilitate contact with the outside world. Similarly, when Dr. Tiu was the guest speaker one week, he stated that one of the merits of the Romanized Taiwanese system is that learning it will enable Taiwanese students to have a head start when learning Western foreign languages because they are also written with Roman letters. Making this claim served the purpose of associating the use of the Beiweiji Romanized writing system with participation in the international arena of developed Western nations. Therefore, the course served as an attempt to authenticate Taiwanese language literacy as a symbolic identification marker for a vision of a Taiwanese nation that is symbolically linked to the international community of modern developed nationstates.

\section{Conclusion}

The courses and curriculum materials primarily functioned as a way of exposing students to a method of developing literacy in Taiwanese using Romanized Taiwanese 
texts and presenting an ideology that portrays this form of literacy as something that is a legitimate component of Taiwanese identity. The courses also promoted an alternative nationalism; an alternative historical narrative about the development of the Taiwanese language; and an alternative narrative about the development of literacy in Taiwan that rejected many of the ideological tenets of the Republic of China that have been taught in mainstream education since the KMT established its rule in Taiwan sixty years ago.

The medical topics that were presented in the courses were only briefly touched on in the curriculum; therefore, the primary purpose of the courses was more to raise awareness of the existence of this form of literacy in Romanized Taiwanese that would facilitate medical professionals' ability to conduct professional activities in Taiwanese, rather than to teach the students more than a cursory amount of medical knowledge in Taiwanese itself. While the linguistic market for medical occupations currently values the ability to speak Taiwanese, the ability to read and write Taiwanese is not currently well established as a form of linguistic capital in the field of medicine. Therefore, courses at KMU functioned as a platform to persuade students to attach value to literacy in Romanized Taiwanese as both a desirable form of linguistic capital for medical professionals and as a means of asserting Taiwanese identification. 
The students' feelings about the course curriculum will be further discussed in the next chapter. Although the students agreed with much of the ideology presented in the course curriculum about the usefulness of Taiwanese language skills for medical care workers and the desirability of preserving the Taiwanese language as a component of local identity, for them, Taiwanese language skills and literacy were not as strong of index markers of this identity as it was for the study group members who designed the curriculum. Consequently, they had mixed feelings about the importance of the "Desinocization" ideologies and Romanized writing system presented in the course materials. 
Chapter VI: The Students Enrolled in Taiwanese Language Medical Studies Classes

at Kaohsiung Medical University

University students' attitudes towards literacy and language use are closely related to their professional goals and to their ethnic and national identifications. For the most part, the students enrolled in the Taiwanese language medical courses at Kaohsiung Medical University believe that efforts should be made to preserve the Taiwanese language as a symbol of Taiwanese identity, and they also feel that spoken Taiwanese will be useful in their future professional lives as medical care workers. However, most of the students enrolled in the courses do not currently support the study group members' more radical position that Han-character-based Mandarin literacy should be replaced with Romanized Taiwanese language literacy as the dominant form of literacy in Taiwan. Consequently, while most of the students support mother language education and ideologically support the use of spoken Taiwanese in certain domains, in their daily lives, they do not practice language habits that include speaking Taiwanese in public domains where Mandarin dominance is already well-established.

Language policies in Taiwan requiring public school curriculum to be taught in the national language have had the effect of influencing the public to adopt Mandarin as the 
medium of communication in other discourse domains as well. This is because, over time, students have tended to continue using the same language that is taught in schools in their personal and professional lives. Laura Ahearn writes, "As a language dies, it disappears from various domains of use. For some languages, this is a top-down process in which the language is no longer used in public domains or official institutions but is retained, for at least a while, in the home" (2012:255). The shift towards Mandarin language dominance in Taiwan has followed this pattern, with Mandarin first replacing Taiwanese in public domains of discourse and later in private domains of informal discourse.

Todd Sandel's study of the generational effects of the KMT language policies on students' linguistic habits supports this viewpoint. According to Sandel, the first generation of students who attended public schools after 1945 typically spoke Mandarin at school because it was the required language of instruction; however, they still continued speaking Taiwanese at home and in their social lives (2003:533). Because students of this first generation who did not have strong Mandarin language skills were subject to punishment and humiliation at school for speaking Taiwanese, most parents made a point of training the second generation of students who attended schools in the 1970s and 1980s to speak Mandarin well in order to avoid being subjected to these hardships in school 
(2003: 533-534). As a result, this second generation of students frequently spoke Mandarin both at school and at home (2003: 533-534). Therefore, by the late 1980s, the effect of this language policy was to make Mandarin, which is the language of instruction in the national public school system, to also become the dominant language spoken in most other language domains by educated people.

This chapter is an ethnographic study of the language habits of students enrolled in Taiwanese language medical studies classes at Kaohsiung Medical University, and it is divided into three sections. The first section is based on handwritten notes that I took at three university campuses in Kaohsiung when I was conducting preliminary research on students' linguistic behaviors during Fall Semester 2010. This section illustrates the state of Mandarin language dominance as reflected in the mainstream language practices of contemporary university students. The second section is based on data that I obtained from written questionnaires, which were filled out by all of the students enrolled in two Taiwanese-language medical studies courses at Kaohsiung Medical University during Spring Semester 2011. This section illustrates the relationship between students' demographic backgrounds and their contemporary language practices. The final section is based on recorded interviews that I conducted with thirteen students, who were enrolled in 
the Taiwanese language medical studies courses at KMU. This final section describes both the students' evaluations of the course curriculum and their attitudes about language, identity, and occupation in Taiwan.

\section{Part I: Students' Linguistic Behavior on University Campuses in Kaohsiung}

During Fall semester 2010, I collected data through participant observation and conversations with student representatives and faculty advisors of student associations at three university campuses in Kaohsiung, Taiwan: National Sun Yat-sen University (NSYSU); National Kaohsiung First University of Science and Technology (NKFUST); and Kaohsiung Medical University (KMU). I had originally planned to conduct research at universities in Kaohsiung because I expected to find campus environments where students from heterogeneous language backgrounds would regularly interact with one another and have diverse language speaking habits that were related to different forms of linguistic capital valued in different occupational fields. One generation ago, most members of the Taiwanese-speaking Benshengren middle class were employed in small and medium-sized enterprises, and many contemporary students' families were members of this middle class. Therefore, prior to observing students on campus, I believed that contemporary students whose parents were members of this middle class a generation ago 
and who were planning to seek employment in small and medium sized businesses after graduation, would also be likely to value Taiwanese language skills.

Through observing the linguistic practices of students on the three university campuses in Kaohsiung and having conversations with students and admissions officers, I learned that this assumption was incorrect and instead found that contemporary students speak almost exclusively in Mandarin, regardless of the degree of prestige accorded to the different universities, the students' academic majors, or the occupational spheres where they planned to seek employment after graduation. Students also appeared to conform to these linguistic norms regardless of their regional origins or their families' linguistic backgrounds. Past research by M. E. Van Den Berg indicated that in the mid-1980s, Mandarin language use was more prominent in Taipei than in southern Taiwan, and I was interested to learn whether or not having a minority of students from northern Taiwan enrolled as students in universities in Kaohsiung would influence students' language practices (1986:102). From my observations on these campuses, I found that even though the majority of students were from the south and their parents were former members of the Taiwanese-speaking middle class, the student body as a whole had assimilated into the language habits associated with the Waishengren Mandarin-speaking middle class and the 
northern Taipei region a generation ago. In addition, little language shift had occurred in the opposite direction, with students whose parents were from the north or part of the Mandarin-speaking middle class learning to speak Taiwanese and speaking it on a regular basis with their peers on campus or with their coworkers in the workplace.

This Mandarin linguistic dominance is so firmly established that when I asked workers in offices of academic departments if I could attend student association meetings in order to observe the students' linguistic habits, although the office workers did not object, they were puzzled that I would attempt to find instances of students speaking Taiwanese during club meetings. The office workers in the departments that I visited informed me that the students speak almost exclusively in Mandarin during school functions, and I found this to be the case during campus visits and during student association meetings that I attended during Fall semester 2010.

Through conversations with admissions officers and student and faculty representatives of student associations, I found that the prevailing language ideology views Mandarin as the normal language of communication for university students in Kaohsiung in most domains of discourse. Therefore, Mandarin is spoken not only during class and student association meetings but also in most informal settings, when students 
interact with one another both on and off campus. It is unusual for students to speak in Taiwanese with other peers in their same age group, and when they do, it is generally reserved for the purposes of cursing and profanity or making jokes. This tendency to confine Taiwanese speech to language domains of extremely informal discourse and use Mandarin in most other discourse domains fits the pattern of what Gumperz considers to be linguistic domination (1982:66).

From conversations with students and admissions officers, I learned that one reason Mandarin is the unmarked language among students is because the campus environment is one where students come from a variety of different regional backgrounds and from families that spoke diverse languages at home when students were growing up. It is common knowledge that all university students are able to speak Mandarin, but because not everyone can speak Taiwanese, it is considered impolite to speak it with someone who might not understand it. As a result, classes and meetings are held in Mandarin, and it is very unusual to hear Taiwanese spoken on campus. This need felt by students to speak Mandarin as a consideration of politeness and inclusiveness is a typical trait of what Gal considers to be language dominance (Gal 1988:257-8).

The lack of Taiwanese language use on the NSYSU and NKFUST campuses was 
the primary factor in my decision to instead conduct research at Kaohsiung Medical University. Because I was unable to find any observable variation between the linguistic practices of students planning to seek employment in different academic departments at these other two universities, I decided to seek out a campus environment where speakers were engaged in activities that I thought might have the potential to constitute a challenge to status quo linguistic practices in Taiwan. I found a suitable environment for study in the Taiwanese language medical studies classes at Kaohsiung Medical University, where curriculum planners were using the courses as a platform to influence students to adopt alternative language practices as a component of a Taiwanese national identity.

\section{Part II: Questionnaire Data}

While auditing the Taiwanese language medical studies courses at KMU during Spring Semester 2011, I administered a written questionnaire to all of the ninety-four students enrolled in the classes. The written questionnaire (Appendix A) was designed to gain an understanding of the students' demographic and linguistic backgrounds in order to investigate whether or not there was a relationship between students' demographic and linguistic backgrounds and the likelihood that they would be receptive to the linguistic and nationalist ideologies promoted in the coursework. I was especially interested in 
finding out whether or not parents' membership in the Benshengren or Waishengren middle class a generation ago would be an influence on contemporary students' career choices and language habits. I also wanted to investigate whether or not there was a strong relationship between students' academic majors and their language practices.

I had originally planned on having access to similar statistical information about the entire student population through the Office of Admissions so that I could learn whether or not there were significant differences between the demographic backgrounds of the students enrolled in the courses and the KMU student population as a whole. Unfortunately, in accordance with university policy, the Office of Admissions does not make statistical information about the demographic backgrounds of the student population available to the public. Therefore, I was only able to make limited inferences about the relationship between students' backgrounds and their language practices and ideologies based on the questionnaire data. In the questionnaire students were asked their age, gender, and birthplace; their parents' native languages; the first language they learned growing up; their parents' occupations; their academic major; the type of occupation that they hope to pursue after graduation; and the type and size of company or government bureau where they plan to seek employment in the future. 
About two thirds of the students in both classes claimed that Taiwanese was the language that their parents spoke at home when they were growing up. For the most part, students claimed that both of their parents spoke Taiwanese, with only a few students claiming that only their fathers and not their mothers spoke Taiwanese during their childhood. Only a few students in either class wrote that Taiwanese was the first language that they learned as children, but the vast majority instead claimed to have spoken Mandarin as their first language during childhood. This data supports Sandel's assertion that although many the second generation of students who graduated from the post-war education system were still able to speak Taiwanese, they chose to speak Mandarin with their children instead in accordance with the dominant language ideologies that resulted from KMT language policies (2003: 533-534). 
Table 6.1: Students' Linguistic Backgrounds

\begin{tabular}{|c|c|c|c|}
\hline \multicolumn{4}{|c|}{ Basic Level Class: 64 Students } \\
\hline & Mother's Language & Father's Language & $\begin{array}{l}\text { First } \\
\text { Language }\end{array}$ \\
\hline Taiwanese & 30 & 32 & 7 \\
\hline Mandarin & 18 & 18 & 54 \\
\hline $\begin{array}{l}\text { Mix Taiwanese/ } \\
\text { Mandarin }\end{array}$ & 7 & 7 & 2 \\
\hline Hakka & 5 & 4 & \\
\hline $\begin{array}{l}\text { Mixed Hakka/ } \\
\text { Mandarin }\end{array}$ & 1 & 1 & 1 \\
\hline $\begin{array}{l}\text { Mixed Hakka/ } \\
\text { Taiwanese }\end{array}$ & 1 & & \\
\hline $\begin{array}{l}\text { Mixed English/ } \\
\text { Mandarin }\end{array}$ & & & 1 \\
\hline Other & 3 & 2 & 2 \\
\hline \multicolumn{4}{|c|}{ Intermediate Level Class: 30 Students } \\
\hline & Mother's Language & Father's Language & \begin{tabular}{|l} 
First \\
Language
\end{tabular} \\
\hline Taiwanese & 11 & 14 & 2 \\
\hline Mandarin & 7 & 7 & 24 \\
\hline $\begin{array}{l}\text { MixedTaiwanese } \\
\text { Mandarin }\end{array}$ & 5 & 5 & \\
\hline Hakka & 1 & & \\
\hline Cantonese & 3 & 2 & 2 \\
\hline English & 1 & & \\
\hline Chaozhou & 1 & & \\
\hline Hokkien & 1 & 1 & \\
\hline Bunun & 1 & 1 & \\
\hline Unsure & 1 & & \\
\hline
\end{tabular}


The students' terminology to refer to different language varieties on the questionnaires reflects their overall conformity to mainstream language ideologies in Taiwan, which view Mandarin as the official language of the Republic of China state structure and Taiwanese as a language indexing local identity. When referring to the Taiwanese language, students usually used the term Taiyu in Mandarin, which translates as "Taiwanese," and only a small number used the term Minnan instead, which was the preferred term used by the KMT, carrying a connotation that associated it with other Hokkien language varieties spoken by ethnic Chinese groups in Mainland China and Southeast Asia. Also the vast majority of the students used the term Guoyu to refer to Mandarin. The term Guoyu translates to "national language" in English, and it is also the term for Mandarin that was used by the KMT administration. A small number of students also used the term Zhongwen, which translates as "Chinese" in English and carries an association with Chinese cultural identity, but not necessarily Chinese nationalism. Unless the students were overseas students from Southeast Asia, however, none of them used the term Huayu, which is the term that study group members prefer to use to refer to Mandarin and carries the connotation of a language used by ethnic Han speakers but without any privileged 
status as an official national language.

The majority of students enrolled in the classes were from regional backgrounds where Taiwanese was the language that was predominantly spoken in everyday use at the end of World War II. For instance, the questionnaire data showed that in both classes only a minority of students were from Taipei, which was the regional area in Taiwan where Mandarin language use was most prominent one generation ago (Van Den Berg 1986:102). In the basic class, the greatest numbers of students were from Kaohsiung and Taipei, numbering $18.7 \%$ and $21.8 \%$ respectively, with $14 \%$ coming from Tainan and other students coming from locations scattered all over Taiwan with only one or two coming from each location. The intermediate class had the most students from Kaohsiung at 30\%, with $16 \%$ and $13 \%$ coming from Taipei and Tainan respectively, and other individual students also coming from a variety of other locations in Taiwan. There were also a few overseas ethnic Chinese students from Malaysia and Hong Kong in both classes. 
Table 6.2: Regional Backgrounds

\begin{tabular}{|c|c|c|}
\hline Location & Basic Class & Intermediate Class \\
\hline Taipei & 14 & 5 \\
\hline Kaohsiung & 12 & 9 \\
\hline Tainan & 9 & 4 \\
\hline Taichung & 3 & \\
\hline Pingtung & 1 & 1 \\
\hline Chiayi & 3 & \\
\hline Ilan & 2 & 1 \\
\hline Hualian & 1 & \\
\hline Keelung & 1 & 1 \\
\hline Penghu & 1 & \\
\hline Changhua & 2 & 1 \\
\hline Yulin & 2 & \\
\hline Miaoli & 2 & \\
\hline Taidong & 1 & \\
\hline Malaysia & 6 & 2 \\
\hline Hong Kong & 2 & 2 \\
\hline Taoyuan & 1 & 2 \\
\hline USA & 2 & \\
\hline $\begin{array}{l}\text { Taiwan } \\
\text { (unspecified) }\end{array}$ & & 2 \\
\hline
\end{tabular}

The questionnaire data showed that the students' parents were from a mixture of occupational backgrounds. This data could be viewed as preliminary evidence that some of the students' parents hailed from what would have previously been the Mandarinspeaking Waishengren middle class and some hailed from what would have been the Taiwanese-speaking Benshengren middle class one generation ago. For instance, some students claimed that their parents worked in professional fields, such as engineering, 
manufacturing, and sales, which were typical occupations for people who would have been from the Taiwanese-speaking middle class one generation ago. There were some also students who reported that their parents were employed in occupations, such as education, finance, and public administration, which were typical of people who would have been from the Mandarin-speaking middle class a generation ago. In both of the classes, nearly half of the students claimed that only their fathers worked and that their mothers were not employed when they were growing up. In addition, students rarely reported planning to enter the same occupational fields that their parents had worked in a generation ago; for instance, very few of the students claimed that their parents were doctors.

The usefulness of this data for analysis should be qualified by noting that even though all of the students filled out the questionnaire, the questionnaire sample is too small to make any strong inferences about relationships between their parents' occupations and the students' current language practices and ideologies. Therefore, this study views this data as only preliminary evidence that the Taiwanese-language medical school classes are an environment where students whose parents were from both the Mandarin-speaking middle class, which was previously more oriented to Chinese national identity, and the Taiwanese-speaking middle class, which was more oriented towards 
Taiwanese national identity one generation ago, are now interacting with one another in the same contemporary classroom environment at KMU.

Table 6.3: Parents' Occupations

\begin{tabular}{|c|c|c|}
\hline Father's Occupation & $\underline{\text { Basic Class }}$ & Intermediate Class \\
\hline Medical Care & 2 & 5 \\
\hline Public Servant & 4 & 6 \\
\hline Education & 11 & 4 \\
\hline Sales & 10 & 2 \\
\hline $\begin{array}{l}\text { Engineering/ } \\
\text { Manufacturing }\end{array}$ & 10 & 2 \\
\hline $\begin{array}{l}\text { Fishing/ } \\
\text { Agriculture }\end{array}$ & 4 & 2 \\
\hline $\begin{array}{l}\text { Banking/ } \\
\text { Finance }\end{array}$ & & 1 \\
\hline Automotive & 1 & \\
\hline Corporate Employee & 1 & \\
\hline Accountant & 1 & \\
\hline Broadcasting & 1 & \\
\hline $\begin{array}{l}\text { Independent Company } \\
\text { Owner }\end{array}$ & 1 & 1 \\
\hline Skilled Laborer & 4 & \\
\hline $\begin{array}{l}\text { Construction/ } \\
\text { Architecture }\end{array}$ & 3 & 2 \\
\hline Service & 3 & 1 \\
\hline Chef & 1 & \\
\hline Technician & 1 & \\
\hline Factory Worker & & 1 \\
\hline $\begin{array}{l}\text { Translation/ } \\
\text { Editing } \\
\end{array}$ & & 1 \\
\hline $\begin{array}{l}\text { None/ } \\
\text { Other }\end{array}$ & 6 & 2 \\
\hline
\end{tabular}




\begin{tabular}{|l|l|c|}
\hline Mother's Occupation & \multicolumn{1}{l}{ Basic Class } & Intermediate Class \\
\hline Medical Care & 2 & 2 \\
\hline Public Servant & 2 & 7 \\
\hline Education & 9 & 2 \\
\hline Sales & 4 & 1 \\
\hline Manufacturing & & \\
\hline Agriculture & 1 & 10 \\
\hline Domestic & 22 & 2 \\
\hline Banking/Finance & & \\
\hline Hairdresser & 2 & 1 \\
\hline Service & 8 & \\
\hline Clerical & 1 & 2 \\
\hline Factory Owner & 1 & 1 \\
\hline Accountant & 5 & \\
\hline Corporate Manager & 2 & 2 \\
\hline Skilled Laborer & 1 & \\
\hline Translator/Editor & 1 & \\
\hline Other & 3 & \\
\hline
\end{tabular}

In the basic Taiwanese class, about $30 \%$ of the students were pharmacology majors, $12 \%$ studied in the Department of Medical Sociology and Social Work, and 12\% studied occupational therapy. Other student majors included dentistry, medical school, biology, psychology, nursing, and cosmetics. In the intermediate class, however, over twothirds of the students were enrolled in the School of Medicine, and the other students were either in the Department of Medical Sociology and Social Work or the Department of Respiratory Therapy. Students almost always stated that they wanted to pursue a career 
that was directly related to their majors after graduation. The differences in the students' majors in the different classes may have been related to differences in the course curriculum, with the basic class being more oriented to teaching students basic literacy skills and ideology and the intermediate class placing a greater emphasis on learning actual medical terms in Taiwanese. Future research will investigate this relationship in greater detail.

Table 6.4: Students' Majors

\begin{tabular}{|l|l|l|}
\hline Majors & \multicolumn{2}{l|}{ Basic Class } \\
\hline Occupational Therapy & 8 & 21 \\
\hline Medical School & 2 & 5 \\
\hline Medical Sociology & 8 & 4 \\
\hline Respiratory Therapy & & \multicolumn{1}{l|}{ Class } \\
\hline Pharmacology & 19 & \\
\hline Dentistry & 2 & \\
\hline Biology & 2 & \\
\hline Psychology & 3 & \\
\hline Cosmetology & 5 & \\
\hline Nursing & 4 & \\
\hline Physical Therapy & 3 & \\
\hline Healthcare & 1 & \\
Administration & & \\
\hline Public Health & 1 & \\
\hline Biomedical Imaging/ & 2 & \\
\hline Radiological Sciences & & \\
\hline Sports Medicine & 1 & \\
\hline Medical Lab Science & 3 & \\
\hline
\end{tabular}


Interestingly, the questionnaire data provides evidence that the student population enrolled in the classes was exactly the type of diverse demographic make-up that I was hoping to find when I originally decided to research university students in Kaohsiung. However, instead of finding an environment where alternative language norms were practiced, I found that Mandarin was firmly entrenched as the dominant language among the students enrolled in the courses at KMU. This pervasiveness of Mandarin in the students' regular daily language habits on campus is especially striking in light of the fact that more of the students come from Taiwanese-speaking family backgrounds than Mandarin-speaking family backgrounds, and only a minority of the students enrolled in the classes were from Taipei. Students also voluntarily enrolled in the course, knowing that it emphasizes Taiwanese language use as a symbol of Taiwanese identity. Despite these factors, in their everyday linguistic behavior, the students enrolled in the Taiwanese language medical studies courses at KMU conformed to the same mainstream language domain norms practiced by most other university students.

\section{Part III: Student Interviews}

The data for this section was primarily collected through semi-structured recorded interviews with thirteen students enrolled in the Taiwanese language courses during spring 
semester 2011. Students volunteered to participate in the interviews, and the interviews were recorded on mp3 files in dining areas on campus in June and July of 2011. Interview times were fifteen to twenty minutes, and students were selected to be interviewed based on their regional backgrounds and academic majors.

Students from urban and rural areas of northern, central, southern, and northeastern Taiwan were represented in the interview sample. The interviewees consisted of seven women and six men, and the interviewees' geographic hometowns were as follows: Tainan County (1), Kaohsiung County (1), Chiayi City (1), Yunlin County (1), Ilan City (1), Taichung City (1), Georgetown, Malaysia (1), Tainan City (2), Kaohsiung City (2), and Taipei City (2). The interview sample consisted of students who were enrolled in a variety of different academic departments in an attempt to find any relationships that may exist between students' future career aspirations and their language practices. For example, five of the interviewees were medical school students, two were physical therapy majors, three were pharmacology students, and the other three students majored in occupational therapy, respiratory therapy, and dentistry. Although the interview sample consisted of students with diverse academic majors, subsequent analysis of this data has revealed that is difficult to establish clear relationships between students' majors 
and their language ideologies because not enough students were interviewed to form representative samples of different occupational groups. Consequently, the main value of the data presented in this section is to serve as preliminary data to be used for reference when planning future studies that will entail interviewing greater numbers of students in different academic disciplines.

During the interviews, students were all asked the same set of questions (Appendix B) about their language practices at home, in the workplace, and in informal situations. Students were also asked about their impressions of the types of people who speak different language varieties, and their feelings about the relationship between language use and Taiwanese identification. Finally, students were asked their opinions on the necessity and desirability of language preservation and revitalization policies. The goal of the interviews was to learn about students' linguistic habits and inquire about whether or not their linguistic practices differed from most other students' linguistic behaviors on campus. I also hoped to learn about any relationships that may exist between the students' occupational goals and their language values. Finally, I wanted to gain an understanding of the extent to which students were influenced by the content of the coursework in their daily language use and in their conceptions of ethnic and national identifications. 


\section{Language Use During Childhood}

Many of the students interviewed stated that they could understand Taiwanese

because they used it to communicate with their grandparents when they were growing up.

For example, a physical therapy student stated that her grandparents usually spoke to her

in Taiwanese, and she would speak back to them in mostly Mandarin with a little

Taiwanese. As a result, although she has well-developed listening comprehension skills in

Taiwanese, her speaking ability is not very strong. Another male medical student had this

to say about his language background:

My grandparents all speak Taiwanese. My parents speak Taiwanese too, but when we started studying they just spoke to us in Mandarin. Most people my age in Tainan can understand Taiwanese but don't really speak it. When my grandparents speak to me, I can listen in Taiwanese, but I speak to them in Mandarin or in a mixture of Mandarin and Taiwanese.

These generational differences in language habits were not universally reported, however. For example, a first-year pharmacology major from Tainan County claimed that her entire family almost always speaks Taiwanese regardless of the speakers' age or generation. On the other hand, another pharmacology student stated that all of her family members in Taipei County speak entirely in Mandarin, and consequently, as an adult, she understands very little Taiwanese. 
Whether or not students reported speaking Taiwanese with the peers in their own age group as children was highly influenced by whether they lived in an urban or rural area. For example, one student stated that he sometimes spoke Taiwanese with his classmates in a junior high school he attended in a smaller rural town in the south called Chiayi, but starting in high school, it became the norm for him to speak in Mandarin with his classmates. He believes that this is because he moved from the countryside to the city to go to high school, and Mandarin is the dominant language spoken by students in cities. He noted the relationship between urban and rural locations and language practice in the following interview excerpt:

In junior high school Taiwanese was still spoken, but in high school Mandarin was spoken. The place I went to junior high school was more in the countryside, but my high school was in more of an urban area, so most people spoke Mandarin.

Another pharmacology student from Tainan County also stated that she frequently spoke Taiwanese with her classmates in Tainan County and that sometimes in school her teachers would also speak Taiwanese. Consequently, she believes that people in rural Tainan County are especially likely to speak Taiwanese in their everyday lives. 


\section{Student Life and Linguistic Habits}

The interviewees stated that in their linguistic interactions on campus, they speak almost exclusively in Mandarin, and on the rare occasion that they speak Taiwanese, it is very briefly and in extremely informal situations to express emotions, such as anger or humor. During the time that I observed the class, I also found that unless students were participating in classroom activities where they were expected to speak Taiwanese, such as pronunciation drills, oral testing, or presentations, they spoke Mandarin. Before and after classes and during the ten-minute breaks when students were talking among themselves, I never heard the students speak Taiwanese, unless they were practicing pronunciation drills from the class curriculum. In one interview, a student from Taipei County stated that she has rarely heard Taiwanese spoken during her time studying at KMU, and she believes that the large number of students from Taipei on campus may be one reason why almost no students speak Taiwanese on campus.

In the recorded interviews, the students also stated that even when they are not on campus, they almost never speak Taiwanese with friends of their same age group in informal social situations. For example, when I asked a student from Chiayi about the accent differences between Kaohsiung and Chiayi, he stated: 
I rarely speak Taiwanese here. I always speak Mandarin, so I'm not sure what the accent is like.

In other words, he would not even be able to recognize a Kaohsiung accent because it is so unusual for him to hear it spoken as a student at KMU. Several students indicated that in the rare occasion Taiwanese is spoken by students, it is used informally to express strong emotions. For example, a physical therapy student stated that most of the students that she knows do not even speak Taiwanese in informal social situations with peers in their same age group, but if they do, it is for the purpose of making jokes or cursing and profanity:

Sometimes they speak it if they want to say bad words (laughs). Some people also use it to tell jokes because it's funnier if you say it in Taiwanese.

Most of the students interviewed stated that they were already able to understand some Taiwanese before enrolling in the classes, and many of the students were also able to engage in at least simple dialogs about the kinds of everyday topics that they might talk about with older relatives at home. A minority of students in the class also claimed they had the ability to speak Taiwanese fluently. However, none of the students indicated that they knew how to talk about topics that are associated with high levels of literacy, such as scientific theory or medical data, and none of the students appeared to be proficient in any 
way of reading or writing in Taiwanese prior to taking the Taiwanese language courses at KMU.

\section{Gender and Language}

When I asked students about the relationship between gender and language use, most students indicated that they did not believe that there is a strong relationship between gender and speaking Taiwanese. I found this surprising because in another recent study Hsi-Yao Su stated that due to the connotations associated with Taiwanese as representing a lack of refinement, women are less likely to speak Taiwanese in public situations than men (2008: 348). In addition, in the interviews with the study group members in Chapter IV, some of them indicated that they felt that there is a relationship between language use and gender. It did not appear that most of the students interviewed had given the issue of language and gender much thought prior to the interview, however, and this lack of reported association between language use and gender may be because the act of speaking Taiwanese is very rare for female and male students alike at the medical university. It may also be because the elderly populations of Taiwanese speakers that students are most likely to have contact with, such as grandparents and vendors at traditional markets, are equally comprised of women and men. 
One exception was a male medical school student from Tainan who stated that he felt it was less acceptable for women to say curse words in Taiwanese than men. This statement is consistent with Su's assertion that for many people, Taiwanese is the language variety of choice for expressing profanity, and swearing is considered more acceptable behavior for male speakers than female speakers (2008:346,357). However, in the following interview excerpt he also made a distinction between using Taiwanese to swear and general speech in Taiwanese and stated that in terms of regular everyday speech he did not think that men were more likely to speak Taiwanese than women:

I think that men are more likely to scold other people, so they'll say those kinds of things more. But they might not be doing it on purpose. They're just showing those emotions. But I don't think that women will say these things as much. A few women will. I don't feel good about it when I hear women talk like that. If most people hear women say those things they don't like it, but with men it's not as bad. But as for me, I don't like it when people say bad words. In general, I don't hear many men speak Taiwanese, but I don't think that women speak it any less.

There is most likely a stronger association between Taiwanese speech and gender than students indicated in the interviews. However, in the context of the medical university and the Taiwanese language classes, it is also possible that this relationship is not as salient as it would be in other contexts where speakers' socioeconomic statuses and 
access to job opportunities are more strongly influenced by their conforming to etiquette associated with gender roles. For example, Qing Zhang notes that language use is a particularly salient form of symbolic capital in transnational companies that operate in the Greater China regional area, and the workforce in these companies also includes positions characterized by "the conspicuously decorative placement of women in the foreign sector" (Zhang 2005: 434,439).

It is possible that gendered identities that are indexed by linguistic practices may not be as salient as resources for employees in the field of medical care as they are for employees at transnational companies in the Greater China region. If this is the case, this could be because the status of doctors is determined more by educational credentials than by acting in conspicuous conformity with gendered identities. If so, this would be a good example of how gendered behavior is not static, but instead is indexed in everyday behaviors, such as language practices that are associated with achievement in different occupations. According to Ahearn, "gender is not something we have in an unchanging essentialistic way but rather something we $d o$ repeatedly and continuously throughout our lives" (2012:170). Therefore, future studies should seek out differences in the relationships between gender and language use among doctors and employees in other 
professional fields in Taiwan. It is possible that the employees in occupational spheres that are more incorporated into transnational capitalist networks operating in the Greater China region are more likely to practice linguistic behavior that is associated with gendered identities than people who are employed in medical professions.

\section{Occupation and Language}

Although the students interviewed had a variety of different majors, they all believed that knowing how to speak Taiwanese would probably be useful in their future careers. Therefore, as a language ideology, linguistic competence in spoken Taiwanese is perceived to be a form of linguistic capital that is beneficial for people who are employed in medical care job markets. Most of the students interviewed stated that they decided to enroll in the medical Taiwanese language courses in order to improve their listening and speaking skills and learn how to talk about topics that would be helpful in carrying out their occupational duties in their future jobs after graduation.

Medical school students in particular stated that they felt it was important for them to learn Taiwanese in order to be able to communicate with patients in their future occupations as doctors. For example, one medical school student stated that doctors should be able to speak Taiwanese in order to establish emotional connections with 
patients:

Doctors often deal with elderly people so they have to speak Taiwanese. They have to give the patients a feeling of closeness. I think that feeling of closeness is important.

Another medical school student stated that because many elderly patients do not

have high levels of linguistic competence in Mandarin, there is a danger that they will

misunderstand medical advice or practical information, such as drug dosage, and doctors

should therefore be able to convey information to patients in Taiwanese:

I think they should be able to speak Taiwanese. Even though more and more people speak Mandarin, a lot of elderly people still speak Taiwanese and can't communicate well in Mandarin. When people hear doctors speak, they respect it. What a doctor says must be right. So communication is very important. A doctor may give you a prescription, and you'll definitely take it because a doctor said to. But there can be misunderstandings. So people have to communicate better so that the doctor doesn't give patients the wrong drugs or be wasteful.

In addition to conveying practical information, several students also indicated that it is important for doctors to be able to speak Taiwanese in order to foster better rapport with patients and allow them to feel more emotionally at ease during treatment. One student in the Department of Respiratory Therapy stated that he felt using Taiwanese to develop a good rapport with patients would be important for his work because many 
respiratory illnesses patients are treated by doctors who visit the patients in their homes. He decided to take the class in part because he thought his future job would entail being dispatched to patients' homes, which are in rural areas where Taiwanese is more widely spoken than Mandarin.

The older age demographic of the patients and the tendency for elderly people in Taiwan to speak Taiwanese was another factor that influenced students to enroll in the courses. For example, a physical therapy student claimed that the main reason that she enrolled in the basic Taiwanese course was that she thought it would be important to know how to communicate with elderly patients in her future career. Another physical therapy student also mentioned that she believes that speaking Taiwanese is important because when you explain medical information to patients, it is best to not be too technical to ensure that patients can understand the information being conveyed.

\section{Language and Character Type}

Many students had internalized notions of personality traits that they associated with the use of Taiwanese in everyday speech; furthermore, these associations with Taiwanese were a mixture of positive and negative personality characteristics. These associations between character type and Taiwanese language use are reflective of the low 
status of Taiwanese as a form of linguistic capital in mainstream occupations on one hand, and its positive status as a symbolic marker of Taiwanese identification on the other. This mixture of positive and negative associations with the Taiwanese language is particularly noteworthy because it illustrates that for students, the decision not to speak Taiwanese is largely a result of its low value as a form of linguistic capital despite its positive connotation as a symbol of Taiwanese identification. Therefore, the data suggests that among the students enrolled in the classes at KMU, conforming to language practices that function as linguistic capital in mainstream discourse domains is more important than conforming to the language practices that are presented in the curriculum as being key index markers of Taiwanese identification. The theoretical implications of this observation will be discussed in greater detail in Chapter VII.

Some students reported positively associating spoken Taiwanese with respect for elderly people and traditional values. Besides speaking Taiwanese in their homes with elderly relatives, a number of students stated that they would also expect to hear it spoken in other environments where they regularly interact with elderly people. For example, one student mentioned that when he goes to traditional markets, he often encounters vendors who speak to him in Taiwanese. 
I'm used to hearing it in vegetable markets, where older people speak Taiwanese. So I understand it. For example, the vendors say "this cost NT\$50", and I understand. I'll speak Mandarin to them, and they speak Taiwanese with me. We can communicate with one another.

Some people also had positive evaluations associated with the act of speaking Taiwanese because they viewed it as a sign of friendliness. For instance, one student stated that when she hears people speak Taiwanese, she thinks of them as having rural mannerisms and being authentically Taiwanese. Some students also indicated that they felt that speaking Taiwanese serves as a means of coming across to others as being non-elitist. For example, a medical student stated that when Taiwanese is spoken, it generally gives the listener the impression that the speaker is a common down-to-earth person. The student similarly expressed the belief that people living in the south of Taiwan interpret the speaking of Taiwanese as a sign of friendliness; therefore, speaking it is an effective way to establish a feeling of emotional closeness with others. Students also stated that it is a commonly held belief that speaking Taiwanese is important in interpersonal relations because its wide range of vocabulary and intonation makes it better for conveying subtle emotions than Mandarin.

Most students interviewed also expressed the belief that there is a strong link between language use and level of education. For example, in the following excerpt, one 
student stated that there is a negative association with Taiwanese speakers as being uneducated, of lower socioeconomic status, and being from underdeveloped rural backgrounds:

Since they speak Taiwanese, sometimes it feels like they're not as educated because construction workers and farmers speak it. People who are more educated speak Mandarin or English. Taiwanese is more for people who don't come from affluent backgrounds or aren't from a big city, and their language environment is all Taiwanese.

One the other hand, however, some people also associated speaking Taiwanese with being more learned in classical literature. For example, in the excerpt below, one medical school student stated that although Taiwanese speech is stereotypically associated with being from lower-status backgrounds, he also thinks of Taiwanese as a language that is sometimes spoken by intellectuals and professors as well:

Some professors have to be very learned in order to speak it because most people think that just being able to speak Mandarin is $O K$.

This may be related to a linguistic ideology that Jean DeBernardi has noted in which Taiwanese speech is associated with ancient Chinese literature because Taiwanese retains some of the tones and pronunciation found in classical Chinese (1991:9-10). 


\section{Language and Authenticity}

Most of the students expressed beliefs that are similar to the study group members' beliefs about relative degrees of authenticity when Taiwanese is used in different contexts. Furthermore, the students had more positive evaluations of Taiwanese language use that they considered to live up to these standards of authenticity than when it did not meet these criteria. For instance, both a pharmacology student from Tainan County and a medical school student from Tainan City stated that when they hear Taiwanese in the media, they feel that it sounds inauthentic, and they would prefer to hear speakers in the media who speak Taiwanese in a manner that sounds more like they are actual native speakers of the language. They both stated that when they hear Taiwanese spoken on televised news broadcasts, it sounds to them like the script was originally written in Mandarin and translated into Taiwanese and that the announcers sound like they are native speakers of Mandarin who are speaking Taiwanese as a second language. One of the students conveyed this viewpoint about the lack of authenticity among television announcers and also expressed negative feelings about hearing northern-accented Taiwanese on television:

It's not very similar. They speak with a northern accent. You can hear it. The way they speak it in Tainan sounds more Taiwanese, but maybe in the north 
it's a new language. When they speak Taiwanese on TV, it sounds like

Mandarin translated into Taiwanese.

When I asked students what they thought about politicians using Taiwanese, many

of them felt that both major political parties used the language as a manipulative tactic to attract voters, but it was more likely to be considered meaningful to older voters than to members of the students' generation. However, in contrast to negative evaluations of the way that Taiwanese was phrased and pronounced in news broadcasts, the students who were interviewed did not seem to find the sound of the Taiwanese spoken in political announcements to be conspicuously different from the way it sounds when they hear it spoken by older relatives.

\section{Language Loyalty}

In general, most students conveyed a sense of loyalty to the Taiwanese language and agreed with the message of the curriculum that the Taiwanese language is in danger and measures should be taken to preserve the language. For example, one pharmacology student expressed the viewpoint that learning Taiwanese is important because young people should be able to communicate well with their older relatives. A first year medical student also stated that he feels speaking Taiwanese is important because it is a unique language to Taiwan, and by speaking it, people retain a link of tradition with their 
ancestors. He also stated that he supports measures to preserve local culture and language, and expressed his viewpoint that it is important to preserve local character to prevent Taiwan from becoming too much of a generic globalized society:

Even though it's being used less and less, it's still a part of the lifestyle and history of our country, and we have a feeling of identification with it. We need to preserve our local culture to let ourselves feel that this is our country and our land, and it has history and culture. I don't want it to be like you can go everywhere and it's all the same. That's not a good feeling.

Although most of the people interviewed expressed similar feelings of loyalty to the Taiwanese language and hope that the language will be preserved as a symbol of local identity, this feeling was not universal. Furthermore, the student quoted above was the only student who explicitly referred to Taiwan as a country. The other students were more ambiguous in the way they expressed their feelings about their Taiwanese identifications and did not overtly refer to Taiwan as a country. This suggests that for the students that were interviewed the act of speaking Taiwanese is not necessarily a direct marker of identification with Taiwanese nationalism. For instance, in one interview a medical school student from Tainan expressed his belief that the Taiwanese language does not need to be preserved as a symbol of Taiwanese identification because there are a lot of people in Taiwan who do not speak Taiwanese. Similarly, in the following interview excerpt, a 
physical therapy student from Taipei stated that she did not feel that speaking Taiwanese is a key component of Taiwanese identity because the same language is also spoken in language communities outside of Taiwan:

Me: Do you think that the language should be preserved because speaking Taiwanese is very important for Taiwanese identity? Student: Maybe it should be preserved, but people from other countries also speak the same language, so I think the identity issue is another matter.

Therefore, she did not subscribe to the belief promoted in the curriculum that Taiwanese is a distinct language from other Hokkien language varieties spoken in Fujian Province and Southeast Asia. More importantly, in contrast to the study group members, who viewed the ability to speak Taiwanese to be a key component of Taiwanese identity, she did not view the practice of speaking Taiwanese to be as salient an index of Taiwanese identity as some Taiwanese nationalists. This study takes the position that this difference in perspective is reflective of two different viewpoints concerning the relationship of language practice and Taiwanese identification. This difference in perspective between the study group members and today's generation of university students in Taiwan will be discussed in greater detail in Chapter VII.

Some students also questioned the practicality of requiring Taiwanese-language 
education for all students on the grounds that for most people working in fields other than medical care, linguistic competence in Mandarin and English are more likely to be useful language skills in the future job market than Taiwanese language skills. For example, the same medical school student from Tainan referenced above also stated that he plans to speak Mandarin with his children and encourage them to learn English as a second language because he thinks that Mandarin and English will be more useful languages than Taiwanese for them to learn in the future. He also stated that it does not bother him that the Taiwanese language will most likely diminish in use in future generations. In his opinion, promoting Taiwanese is impractical as an official language because the intonation and pronunciation are more complex than Mandarin. Consequently, he expressed his viewpoint that Mandarin is a more suitable choice as an official language because it is easier to teach and learn.

I don't think it's necessary to teach it. You can only use Taiwanese in Taiwan and in a few places in Fujian Province in Mainland China. Also when the Chinese government came here and they had to choose a language, they didn't choose Taiwanese because Taiwanese is difficult to learn. They chose Mandarin because it's easier to learn. So now Mandarin is the official language. 


\section{Students' Evaluations of the Writing System}

While most students were supportive of the sentiment that the Taiwanese language should be preserved, the Romanized writing system that was promoted in the coursework was particularly controversial, with students having very mixed views about its effectiveness and desirability. For example, one student criticized it on the grounds that learning it is difficult, even for people who can speak Taiwanese, and that most people think of Taiwanese as a spoken language and not a written language. Another student in the basic class stated that he would not return to take the intermediate class because he found the writing system inconvenient to learn, and he felt that he would be unlikely to find any use for it outside of class. Although he had enrolled in the class with the intention of improving his listening skills for his future career as a doctor, he felt that being able to understand what patients are saying is good enough, and there is no reason to learn how to read and write in Taiwanese. A pharmacology student from Taipei also expressed disappointment in the class because of the Romanized Taiwanese in the textbook. She felt that since students had to flip to the back of the textbook to look at the Han characters in order to understand the dialogs, she felt that the Romanized Taiwanese was impractical and that Han characters should instead be used for the writing system since they are more 
widely understood in Taiwan.

I've got an opinion about this. I think there's something wrong with the Taiwanese class. They should use Chinese characters to teach us and read it again and again until we can say it. But they want to change to Roman letters. We can understand Chinese characters but not Roman letters. I think this is strange, and so I'm a little disappointed in the class. Some people find the Roman writing difficult to learn, so they give up. Also you don't have to write down Taiwanese because it's just for communication. In this respect I think they're off base. They should find a way for us to use Chinese characters and then we can read it a lot more naturally. If we read it a few times, we'll be able to say it. During class, we just flip to the Chinese characters section to read.

However, other students were supportive of the Romanized Taiwanese system presented in the coursework. For example, one medical student expressed his support for the writing system and stated that one of the main reasons he chose to enroll in the intermediate class was because it would give him the opportunity to learn more about the Romanized writing system. Another student also praised the writing system because he thinks it is an effective way to convey how words should be pronounced with proper pronunciation and intonation to people who do not live in environments where Taiwanese is regularly spoken. Since future generations will most likely grow up in predominantly Mandarin-speaking environments, he feels that promoting literacy in Romanized Taiwanese will be a useful step in the preservation of the Taiwanese language. 


\section{Conclusion: Identification, Literacy Formats, and Language Domain Norms}

Overall, although the students mostly accepted the linguistic skills and concepts presented in the Taiwanese language curriculum as desirable symbols of Taiwanese identification, the course materials did not have the effect of inspiring students to realign their identifications in such a way that radically undermines the symbolic foundations of the contemporary Greater China regional hegemony. Even though most of the students enrolled in the classes were sympathetic to the goals of preserving the Taiwanese language and promoting Taiwanese identity, few of the students seemed to share as strong of an ideology of "Desinicization" as the members of the Sunday study group. For example, none of the students interviewed expressed feelings that they did not think of themselves as being ethnically Han, other than the one female interviewee who is of aboriginal descent, and whose concept of her ethnicity as a non-Han minority would already be widely accepted as true in mainstream thought.

The interviewees unanimously agreed that Taiwanese linguistic skills are useful for employees in the field of medical care when they speak with elderly patients. Judging from their statements in interview conversations, the students who grew up in Taiwan all identified themselves as being Taiwanese and mostly believe that the ability to at least 
understand a little spoken Taiwanese is a component of this identification. They also shared the sentiment that the overall decline in the use of the Taiwanese language is a negative development.

Despite this ideological loyalty to the Taiwanese language, however, even after having been enrolled in the Taiwanese language medical studies courses for one semester, in their linguistic behavior outside of the classes, students still conformed to mainstream language domain norms of speaking in Mandarin with peers in their own age group in both formal and informal situations. The data presented in this chapter suggests that when students speak Taiwanese, it is generally restricted to the domains of speaking with older relatives and elderly people who they encounter in places such as traditional markets where elderly people are employed as vendors.

This study predicts that in their future professional lives as medical care workers, the students will most likely continue to practice these same language domain norms and only use Taiwanese as a medium of communication reserved for speaking with older family members or with patients who are elderly, from rural backgrounds, and from lower socio-economic backgrounds. Similarly, the data in this study suggests that contemporary students are unlikely to support measures to challenge Han-character based Mandarin 
language literacy as the dominant form of literacy in Taiwan. In the interviews, the students did not express strong feelings against the use of Han characters, especially as a medium for writing in Mandarin. The students were divided in their opinions about the Romanized writing system for the Taiwanese language that was promoted in the coursework, with some being opposed to it but others accepting it as a pragmatic learning tool. However, even the students who enjoyed learning the writing system tended to view it more as a useful learning tool in the domain of language classes, rather than a form of literacy that should replace the use of Han characters as an independent orthography in other domains of language use.

Therefore, the immediate effect of the Taiwanese language medical school curriculum has not been to bring about a major reconfiguration in the way the students utilize literacy and language domain norms in their everyday lives. However, this study takes the position that students may have internalized some of the basic ideological tenets presented in the curriculum, which espouse the view that as Taiwanese people, they share a historical and linguistic heritage that gives them a different identity from people who grew up in other administrative areas in the Greater China region. Furthermore, in some current and future contexts, the act of speaking Taiwanese may serve as a symbolic 
marker that evokes this conception of their Taiwanese identity. Because the act of speaking Taiwanese can be associated with a variety of different character types, speakers have leeway to symbolically appropriate Taiwanese language speech acts for a variety of different purposes. If Romanized Taiwanese language literacy continues to serve as a component of mother language education curriculum in public schools for future generations, it is also likely to occupy a niche as an educational tool that is used to pass on basic knowledge of the Taiwanese language to all students in public schools in Taiwan. Therefore, basic knowledge of this literacy format may also serve as a mark of identification shared by all people who have been educated in the public school system in Taiwan that distinguishes them from people who have been educated in other school systems in the Greater China regional area. 


\section{Chapter VII: Conclusion}

\section{Overview}

This case study has investigated the link between occupation, language use, and national identification in Taiwan. In traditional conceptions of nation-states, national languages have functioned as both necessary qualifications for employment and identity markers. Consequently, for much of the twentieth century the inhabitants of Taiwan utilized the same linguistic resources that were valued in their professional fields to also identify themselves with national power structures. In nineteenth and twentieth-century nation-states, characteristic elements of nationalism, such as official languages and mass literacy conventions, typically served the dual function of both creating an educated work force and indoctrinating the population with a nationalist ideology. In addition, the integration of national languages and writing systems into public school curriculum also served to create associations between language practice and officially-approved historical narratives.

The university students in contemporary Taiwan who are the subjects of this study are the third generation of students to have studied in the post-war school system in Taiwan. Despite having ideological sympathy for being identified as Taiwanese, 
contemporary university students continue to conform to language practices and literacy conventions that have served as symbolic markers of Chinese identification in post-war Taiwan because they currently continue to function as valued forms of linguistic capital in most mainstream spheres of social and economic prestige. Therefore, this study has found that, so far, the Taiwanese language preservation and revitalization measures, which have been used as tools of resistance against the influence of Chinese nationalism in Taiwan, have only been able to yield modest results in influencing everyday language practices.

There are two likely reasons why attempts to reverse this language shift are producing only limited results. This first reason is related to the context of Taiwan's ambiguous national status and the increasing influence of Greater China. The findings of this study suggest that as the Republic of China has lost its viability as a national entity and the prospect of declaring an independent Republic of Taiwan has been rendered unfeasible due to the threat of war with the People's Republic of China, for young people living in Taiwan, national identity has become less salient than it was for previous generations. This viewpoint is supported by a feature article printed by Reuters during the 2011 presidential campaign entitled: “Taiwan's young voters: forget China, it's jobs and pay" (Reuters 2011). The title of this article reflects the current social climate in which 
younger voters are more influenced by economic considerations than national identity.

This tendency is summarized in the following quotation: "the younger generation is less interested in issues of identity than their parents, and become irritated when politicians focus on that instead of more immediate problems: low wages, a weak job market and expensive housing" (Reuters 2011).

During the post-war decades of single-party Kuomintang rule, the Republic of China's state power largely coincided with the hegemonic symbolic forms and ideology of the ROC's Chinese nationalism. However, in contemporary Taiwanese society, national identity has become disassociated from the power of the Republic of China state apparatus, and the Greater China regional hegemony is now the dominant economic and cultural power structure exerting influence on young people's social practices. This study suggests that when seeking to understanding how people exercise agency in relation to contemporary regional hegemonies, national identity may not occupy the same central position that it has held in theoretical understandings of how people have identified themselves with nation-states in the past.

A consequence of the shift from nation-states to regional hegemonies as the dominant forms of power is that, in principle, even though different groups of people may 
identify themselves differently in terms of nationalism, they may still act in similar ways in relation to dominant regional hegemonies. For example, in Taiwan, regardless of whether people identify themselves as Chinese or Taiwanese in terms of nationality, they still engage in similar practices in relation to the Greater China regional hegemony. This is because they are using resources other than national identity to position themselves in relation to this hegemony in order to gain access to power and prestige. Therefore, this study suggests that when analyzing how people in Taiwan currently exercise agency, linguistic, economic, and symbolic capital should be conceptualized as being as important, if not more important influences on everyday practice than national identity. As a result, the findings of this study suggest that university students in Taiwan are more likely to conform to linguistic practices privileging Han character-based Mandarin-language literacy as the dominant form of cultural and linguistic capital in the Greater China regional hegemony than to adopt alternative linguistic practices that identify themselves with Taiwanese nationalism.

A second probable reason why the study group members' linguistic activism has only been able to yield modest results, is because Taiwanese identity is not as strongly indexed by the practice of speaking Taiwanese as it was during the Tangwai and early 
DPP-eras of anti-KMT activism in the 1970s and 1980s. For instance, although most of the students grew up speaking Mandarin, they still tend to largely identify themselves as Taiwanese. This suggests that currently there may not be as strong of a link between the practice of speaking Taiwanese and Taiwanese identification as language activists and Taiwanese nationalists believe. In addition, due to the infeasibility of declaring formal Taiwanese independence, the current generation's identification with Taiwan appears to be more of a local cultural identification than a full-fledged national identity. Therefore, it is untenable to assume that there should be a direct relationship between language practice and national identity in Taiwan. Laura Ahearn cautions against the pitfalls of adopting overly reductionist views on the relationship between language and identity in the following quotation:

"Remembering that languages are multifunctional can help prevent simplistic, if well-intentioned, efforts that assume a one-to one mapping of languages onto ethnic or national identities. Habitual linguistic practices can create patterns related to the cultural norms and social meanings associated with endangered languages. These practices in turn often index particular identities, hierarchies, or values. The language ideologies that emerge from this process of indexicality can affect the likelihood of a language's survival" (2012:257).

\section{Predicted Effects}

The accomplishments of the study group members' language preservation and 
revitalization measures will most likely be limited because of the continued pervasive influence of the Chinese nationalist hegemony put in place by over half a century of Kuomintang administrative rule in Taiwan. Although the Republic of China's nationalist hegemony was originally created through the Kuomintang's administrative rule over Taiwan in the context of the Cold War, Taiwan's current incorporation into Greater China is being accomplished through the continuation of many of the same symbolic practices, which now serve to align people in Taiwan with the contemporary Greater China regional hegemony. The primary reason why this hegemony is so pervasive is that symbolic and linguistic practices that associate people with this hegemony also function as forms of cultural and linguistic capital that are necessary prerequisites to obtaining work in most desirable fields of employment.

Because as symbols, the dominance of the Mandarin language in the domain of public speech and the use of Han character-based literacy accomplish the dual functions of serving as gateways to employment opportunities and identification markers, most people are reluctant to challenge them. Although students enrolled in the Taiwanese language medical studies courses at KMU are both sympathetic to the ideological viewpoints promoted in the curriculum and feel they will have a use for spoken Taiwanese 
language skills in their future occupations, due to the pervasive influence of the Greater

China hegemony over Taiwanese society as a whole and the influence of having spent many years in formal education institutions, they still choose to conform to the symbolic norms of the status quo in their everyday lives.

Although it is unlikely that the "Desinicization" ideology promoted by the study group members through the development of Taiwanese language medical curriculum will to catch on and become part of mainstream practice in Taiwan, the activities of the study group members may influence the symbolic connotations associated with speaking the Taiwanese language and create a new domain for the use of Romanized Taiwanese language literacy in language classes that are a part of public school education in Taiwan. Study group members have already been influential in policy decisions to have the Romanized Beiweiji writing system adopted as the standard writing system used in mother language school curriculum throughout Taiwan, and they may continue to have a degree of influence on education policy. It is possible that due to the influence of Taiwanese language preservation and revitalization efforts, for future generations, having a basic knowledge of how to read Romanized Taiwanese and the ability to speak a small amount of Taiwanese will become a marker of identification that will shared by everyone who is 
educated in the public school system in Taiwan.

Bernard Spolsky and Elana Shohamy state that the results of some language preservation policies, such as granting Maori the status of an official language in New Zealand, are symbolic gestures that elevate the ideological prestige of the language rather than increase the use of the language in daily life (Spolsky and Shohamy 1999:61). Sue Wright similarly notes that in the Republic of Ireland, having studied the Irish language as part of public school curriculum for children serves as a mark of national identification, even though few people speak it proficiently or on a regular basis (Wright 2004:46). According to Wright, this is due to both the economic advantages of English proficiency being greater than Irish language proficiency and the distinctiveness of the variety of English spoken in Ireland (Wright 2004:46).

In the same way that Irish English is distinctive enough to serve as a mark of identification for Irish nationals, it is also likely that Taiwanese Mandarin will fulfill this function in creating an identification marker that distinguishes people who grew up in Taiwan from people who grew up in Mainland China. It is also likely that the economic advantages of Mandarin language proficiency and English language proficiency in the Greater Chinese linguistic market will continue to influence people to attach greater 
importance to these language skills than proficiency in Taiwanese. Therefore, as Spolsky and Shohamy note, there is tendency for language preservation and revitalization policies to fail to accomplish goals of bringing about radical changes in everyday language use."[T] he failures come from inability to take into account all the myriad factors which act and interact on language practice. This is not to say that policy does not have an effect, but that its effect can be less than or different from what is hoped" (1999:262).

This study takes the position that linguistic competence in Taiwanese can indeed be salient as a symbolic identification marker and instrumental in creating a consciousness of group belonging that functions as a precursor to alternative future identities that can be used as resources to contest the Greater China regional hegemony. However, a far more radical policy that creates occupations where Taiwanese language skills are highly valued as forms of linguistic capital would be needed in order to accomplish the study group members' more ambitious task of reversing the trend of Mandarin-language dominance in public discourse.

\section{Future Research}

For future projects, I plan to continue to conduct two branches of research that are related to this topic: archival research of documents and contemporary ethnographic 
fieldwork. The archival research will involve seeking out a variety of documents from the past, which were written using different languages and writing systems, and investigating which domains of commerce and discourse have been associated with which different types of literacy in Taiwan. Of particular interest will be finding out the difference between documents written by people associated with the activities of Presbyterian missionaries using Romanized Beiweiji Taiwanese writings and documents written in Han characters for those involved in activities associated with Qing Dynasty officials. The content of educational curriculum in Qing Dynasty schools in Taiwan is also not well understood, and understanding differences between the literacy practices of the prenational dynastic regimes and the nationalist Japanese and Kuomintang regimes can provide theorists with a clearer understanding of the literacy practices that were unique to the development of different nationalisms in Taiwan. The historical archives at National Taiwan University will be a valuable source of data for this project (S. P. Chen et al. 2007:49-50).

I also hope to gain a clearer understanding of the influence of Presbyterian Missionary activities on the development of alternative literacy formats and non-Han ethnic identifications in Taiwan. The preliminary findings in this study suggest that a 
generation ago, there may have been a direct relationship between social class, occupation, and participation in Taiwanese-language Presbyterian Church activities. For example, in one recorded interview, study group participant Tan Hong-hui stated that she believes that when she was growing up, a majority of the participants in the Taiwanese-language Presbyterian Church activities were also members of the Taiwanese-speaking middle class of employees in small and medium-sized business that was described by Hill Gates during the 1970s and 1980s (1981:273,279).

The historical relationship between language preservation and revitalization activities and gender ideologies through the influence of Presbyterian Church activities in Taiwan is also a worthwhile topic for further research in the future. Preliminary research suggests that Presbyterian missionaries were instrumental in promoting higher degrees of gender equality in the Chinese region during the late nineteenth century. For example, Stevan Harrell observes that American female protestant missionaries were especially active in promoting literacy as a part of their evangelical activities in China during the nineteenth and twentieth centuries (1995: 20). Margaret Byrne Swain also notes that during the same time period, missionaries were active in the development of both foreign language and mother language-study materials for minority ethnic groups in China; 
furthermore, missionaries were also critical of the "highly negative Han opinion of the position of women in many peripheral societies based in relative gender equality" and praised ethnic minority groups in Mainland China such as the Sani, who displayed greater degrees of gender equality $(1995: 143,144,158)$. Because Presbyterian missionaries came to Taiwan during the same time period, it is possible that they promoted both language preservation and greater degrees of gender equality as a part of their missionary activities, and some of this influence continues to be a part of the language preservation and revitalization efforts promoted by some Taiwanese nationalists. In his study entitled, Romanization and Language Planning in Taiwan, Dr. Chiung Wei-wen supports this claim, noting that up until the 1970s, aside from being widely used for Bible study by members of the Presbyterian Church, the Romanized Beiweiji writing system was also used by women who were illiterate in Han characters for alternative literacy practices, such as writing letters to friends and family members (2001:23).

Future ethnographic research will involve continuing to observe and analyze both the curriculum content and student responses to Taiwanese language medical studies curriculum. Currently, the Taiwanese language medical studies classes have only been offered for a few years. To gain a more thorough understanding of the effect of these 
courses on students' language ideologies, I plan to continue to monitor the classes and observe both whether or not they continue to increase in popularity and whether or not students' attitudes began to shift towards the values of the study group members over time. This study has been limited in its ability to gain an understanding of the relationship between students' future occupations and their patterns of language use because not enough students were interviewed to form representative samples of different occupational groups. Consequently, future research will also involve conducting more interviews with students enrolled in a variety of different academic departments and at multiple universities in order to establish a more broad and comprehensive understanding of the link between occupation and language use among university students.

Future ethnographic research will also take the form of trying to understand how people are currently using linguistic resources to position themselves and others in relation to the Greater China hegemony in both Taiwan and other localities, such as Mainland China and Hong Kong. The theory to understand and articulate this hegemony is underdeveloped, but observing the way people intuitively position themselves in relation to this hegemony is a means of further understanding it. Current research suggests that young professionals who are employees in different occupational fields are already 
creating different identities to position themselves in relation to the current Greater China hegemony, and they are making these identifications by using linguistic resources that are also forms of linguistic capital in their fields of employment. For instance, Zhang Qing notes that linguistic skills have become a prerequisite requirement that is as important as academic degrees and professional experience in order to gain access to employment opportunities in transnational corporations that operate in Mainland China, Taiwan, Hong Kong, and Singapore (Zhang 2005:434). In addition, different language skills are valued differently in different economic spheres.

In her fieldwork in Mainland China, Zhang Qing has also documented how people involved in different occupational spheres are speaking different language varieties that identify themselves as both employees in different professional circles and as playing different roles in relation to current integration into the Greater China regional economy. In observing the behavior of employees in Mainland China, Zhang notes that the standard variety of Putonghua Mandarin in Mainland China is highly valued in large state-run companies, government bureaucracies, state schools, and broadcasting (Zhang 2006:225). However, in other occupational spheres where employees seek employment in privatized companies that operate in the Greater China regional area, employees are creating an 
alternative form of linguistic capital that is valued in what Zhang has labeled the "transnational Chinese linguistic market" (2005:454). Because the employees of these companies frequently interact with English and Mandarin speakers from places outside of Mainland China, they speak a variant of Mandarin, referred to by Zhang as "Cosmopolitan Mandarin," that makes use of these alternative linguistic resources and identifies themselves as belonging to a social class which is suitable for employment in the high-status "transnational Chinese linguistic market" (Zhang 2005 431,454;2006 228).

There is also some evidence that suggests gendered identities may be becoming more salient as symbolic resources for women who hope to gain access to employment opportunities in companies operating in the Greater China region. For instance, Zhang has stated that some linguistic features of the Putonghua Mandarin spoken by employees in public state occupations index different gendered identities than the Cosmopolitan Mandarin spoken by employees in transnational companies operating in Greater China (2008:216-217). Zhang notes that women who are employed in transnational companies tend to not make use of vocal features from Beijing Putonghua that are associated with "maleness," and this may be due to a tendency of companies that practice "the conspicuous decorative placement of women in the foreign sector" to place greater value 
on female employees' conforming to gendered constructions of "femininity" in the workplace $(2008: 217 ; 2005: 439)$. The data from student interviews in Chapter VI similarly suggests that women who are employed in medical care professions in Taiwan may be under less pressure to conform to gendered norms that influence women to refrain from speaking Taiwanese. This is possibly because employees in medical care occupations have less to gain from conforming to constructions of femininity that are valued in other job markets where employees are more strongly influenced by the genderrelated values associated with the Greater China regional hegemony. Future research will focus on gaining a greater understanding of the relationship between gendered identifications and language practice among employees in different occupational spheres in the Greater China region.

\section{Value of Case Study}

This study has contributed to the field of anthropology by documenting language preservation and revitalization policies being carried out by a group of medical care workers as a form of resistance against Taiwan's incorporation into the Greater China regional hegemony. This resistance draws attention to the role played by linguistic domination in creating and maintaining this hegemony in the Greater China regional area. 
From the perspective of Abu-Lughod's theoretical framework of viewing resistance as "a diagnostic of power," documenting resistance activities is valuable as a means of exposing power relations that may not be overtly articulated in hegemonic discourses (1990:42). Taiwan's incorporation into Greater China is being accomplished through a continuation of two symbolic components of the KMT's post-war Chinese nationalism: Mandarin language dominance and the use of a Han-character-based literacy format. The fact that resistance against this hegemony is taking the form of language activism designed to contest Mandarin-language dominance and Han-character-based literacy is evidence that these linguistic practices are salient symbolic components of the contemporary Greater China hegemony. Therefore, this study's research findings suggest although this regional hegemony is not directly affiliated with a nation-state, its hegemonic forms retain the "culturalism" that was an element of the Chinese nationalism which was constructed in the early twentieth century (Townsend 1992:112).

This case study also has value in pointing out that theoretical frameworks which were devised for understanding social behavior in nineteenth and twentieth-century nation-states may need to be revised in order to understand the influence of contemporary regional hegemonies as power structures influencing social practices. From the 
perspective of people in Taiwan who are engaged in social action in the context of the Greater China regional hegemony, this study provides evidence that national identity may not be as salient an influence on social practices as it was during the post-war period of one-party Kuomintang rule in Taiwan. The findings of this study suggest that, despite the lifting of formal restrictions on language use and the implementation of Taiwaneselanguage curriculum in public schools, most people in Taiwan continue to engage in the same language practices that were valued in the Republic of China nation-state for two reasons: Mandarin language skills and Han-character literacy function as valued forms of linguistic capital in the Greater China region, where linguistic, cultural, and economic capital are stronger influences on people's social behavior than national identity. In the context of Taiwan's ambiguous national status, there is not as direct a relationship between Taiwanese language skills and Taiwanese identity as would be expected from the perspective of conventional theories about national identity that were formulated by analyzing social practices in the context of nineteenth and twentieth century nation-states.

The contemporary Greater China regional hegemony is still not well defined in contemporary anthropological theory; however, anthropologists can gain a clearer understanding of the logic of this hegemony through ethnographic research into how 
different groups of people are using symbols and creating identities to position themselves in relation to this hegemony. Besides being a medium for documenting and communicating information, language and writing systems also function as both forms of linguistic capital and symbolic identification markers. Therefore, language use is an especially salient symbolic tool for making identification claims in the context of Taiwan's ambiguous status as a national entity, and the study of language practice is a valuable means of arriving at a greater understanding of power relations in contemporary society. 


\section{$\underline{\text { References }}$}

Abu-Lughod, Lila.

1990 The Romance of Resistance: Tracing Transformations of Power Through Bedouin Women. American Ethnologist. Vol. 17. No. 1: 41-45.

Ahearn, Laura M.

2001 Language and Agency. Annual Review of Anthropology. Vol. 30: 109-137.

Ahearn, Laura M.

2004 Literacy, Power, and Agency: Love Letters and Development in Nepal. Language and Education. Vol. 18. No. 4: 109-137.

Ahearn, Laura

2012 Living Language: An Introduction to Linguistic Anthropology. Sussex: Wiley-Blackwell.

Anderson, Benedict

1991 Imagined Communities, Revised Edition ed. London, New York: Verso.

Arrigo, Linda Gail

1994 From Democratic Movement to Bourgeois Democracy: The Internal Politics of the Taiwan Democratic Progressive Party in 1991 . In The Other Taiwan 1945 to The Present: Taiwan in the Modern World. pp.145-180. Murray Rubinstein ed. Armonk, New York, London, M.E. Sharpe.

Ash, Robert F. and Kueh, Y.Y.

1993 Economic Integration within Greater China: Trade and Investment Flows between China,Hong Kong and Taiwan. The China Quarterly, No. 136: 711-745.

Billing, Michael

2003 Banal Nationalism.pp.127-144. In The Language, Ethnicicy, and Race Reader. Harris and Rampton eds. Routledge. 
Blundell, David

2009 Taiwan's Indigenous Peoples. In Taiwan: Austronesian Taiwan: Linguistic, History, Ethnology, Prehistory. pp. 9-60. David Blundell, ed. Berkeley, CA: Phoebe A. Hearst Museum, University of California.

Bourdieu, Pierre

1991 Language and Symbolic Power. John B. Thompson ed. Cambridge, Massachusetts: Harvard University Press.

Bourdieu, Pierre

1977 Outline of a Theory of Practice. Cambridge: Cambridge University Press.

Brenner, Neil.

1999 Globalisation as Reterritorialisation: The Re-scaling of Urban Governance in the European Union. Urban Studies. Vol. 36, No. 3, 431-451.

Brown, Melissa J.

2004 Is Taiwan Chinese?: The Impact of Culture, Power, and Migration on Changing Identities. Berkley, Los Angeles London: University of California Press.

Brown, Mellissa J.

2001 Reconstructing Ethnicity: Recorded and Remembered Identity in Taiwan. Ethnology. Vol. 40, No 2: 153-164.

Brubaker, Rogers and Cooper, Frederick

2000 Beyond "Identity". Theory and Society. Vol. 29, No 1: 1-47.

Bucholtz, Mary

2003 Sociolinguistic Nostalgia and the Authentication of identity. Journal of Sociolinguistics. Vol. 7, No 3: 398-416. 
Bucholtz, Mary and Hall, Kira

2008 All of the Above: New Coalitions in Sociocultural Linguistics. Journal of Sociolinguistics. Vol. 12, No 4: 401-431.

Bucholtz, Mary and Hall, Kira

2004 Language and Identity. In A Companion to Linguistic Anthropology. 268294. Alessandro Duranti ed. Oxford: Basil Blackwell.

Bucholtz, Mary and Hall, Kira

2004 Theorizing Identity in Language and Sexuality Research. Language in Society. Vol. 33, No 4: 469-515.

Bucholtz, Mary and Hall, Kira

2005 Identity and Interaction: A Sociocultural Linguistc Approach. Discourse Studies. Vol. 7, No 4-5: 585-614.

Central Intelligence Agency

2012 The World Factbook. Taiwan. https://www.cia.gov/library/publications/theworld-factbook/geos/tw.html. Accessed March 25,2012.

Chang, Han Yu and Myers, Raymond

1963 Japanese Colonial Development Policy in Taiwan, 1895-1906: A Case of BureaucraticEntrepreneurship. The Journal of Asian Studies, Vol. 22, No. 4: 433449.

Chen, Chiukun

1999 From Landlords to Local Strongmen: The Transformation of Local Elites in Mid-Ch'ing Taiwan, 1780-1862. In Taiwan: A New History. pp. 133-162. Rubinstein, ed. Armonk, New York, London, England: M.E. Sharpe, Inc. 
Chen, Jialu

2011 Taiwan's Young Voters: Forget China, It's Jobs and Pay. Rueters, November 9.

http://thestar.com.my/news/story.asp?file=/2011/11/9/worldupdates/2011-

11-09T101555Z_01_NOOTR_RTRMDNC_0_604076-

$1 \& \mathrm{sec}=$ Worldupdates. Accessed November 9.

Chen, S.P., Hsiang, J., Tu, H.C., \& Wu, M.C.

2007 On Building a Full-Text Digital Library of Historical Documents. In Lecture Notes in Computer Science: Vol. 4822. Asian Digital Libraries. Looking Back 10 Years and Forging New Frontiers. pp. 49-60. D. Goh, T. Cao, I.

Sølvberg \& E. Rasmussen, ed. Springer Berlin / Heidelberg.

Chiung, Wi-vun Taiffalo

2001 Romanization and Language Planning in Taiwan. The Linguistic Association of Korea Journal. Vol. 9, No 1: 15-43.

Chou, Tein-chen

1995 Industrial Organization in a Dichotomous Economy. Aldershot, Brookfield, Hong Kong, Singapore, Sindney: Avebury Ashgate Publishing Limited.

Chu, Yun-han

2004 Taiwan's National Identity Politics and the Prospect of Cross-Strait

Relations. Asian Survey, Vol. 44, No. 4: 484-512.

Chu, Yun-peng

2004 Transformation of Traditional Manufacturing Industries. In The New Knowledge Economy of Taiwan. Pp 103-117. Chen and Lee eds. Cheltham and Northampton: Edward Elgar Publishing Limited.

Chun, Allen

1994 From Nationalism to Nationalizing: Cultural Imagination and State Formation in Postwar Taiwan. The Australian Journal of Chinese Affairs, No. 31:. 49-69. 


\section{Cooper, John F.}

2003 Taiwan: Nation-State or Province. Boulder: Westview Press.

Cummings, Bruce

1984 The Origins and Development of the Northeast Asian Political Economy:

Industrial Sectors,Product Cycles, and Political Consequences. International

Organization, Vol. 38, No. 1: 1-40.

Dalby, Andrew

1998 Dictionary of Language. London: A \& C Black.

DeBernardi, Jean

1991 Linguistic Nationalism: The Case of Southern Min. Sino-Platonic Papers. No 25.

Duara, Prasenjit

1999 Nationalists Among Transnationals: Overseas Chinese and the Idea of China, 1900-1911. In Ungrounded Empires. Pp 39-60. Ong and Nonini, eds. New York, London: Routledge.

Fadiman, Anne

1997 Spirit Catches You And You Fall Down: A Hmong Child, Her American

Doctors, and the Collision of Two Cultures, New York: Farrar, Straus and Giroux.

Fei, Hsiau-tung

1980 Ethnic Identification in China. Social Sciences in China. No. 1: 94-107.

Fishman, Joshua A.

1999 Sociolinguistics. In Handbook of Language and Ethnic Identity. New York: Oxford University Press.

Foucault, Michel

1978 The History of Sexuality: Volume I: An Introduction. New York: Vintage Books. 
Gal, Susan

1988 The Political Economy of Code Choice. In Codeswitching:

Anthropological and Sociolinguistic Perspectives. pp.245-264. Monica

Heller ed. Berlin, New York, Amsterdam: Mouton de Gruyter.

Gardella, Robert

1999 From Treaty Ports to Provincial Status, 1860-1894. In Taiwan: A New

History. pp. 133-162. Rubinstein, ed. Armonk, New York, London, England:

M.E. Sharpe, Inc.

Gates, Hill

1981 Ethnicity and Social Class. In The Anthropology of Taiwanese Society. Pp

241-181. Gates and Ahern eds. Stanford: Stanford University Press.

Hall, Stuart

1992 The Question of Cultural Identity. In Modernity and Its Future. Pp 274-316.

Hall, Held, and McGrew eds. Cambridge: The Open University.

Harrell, Stevan

1995 Introduction: Civilizing Projects and the Reaction to Them In Cultural

Encounters on China's Ethnic Frontiers, Stevan Harrell, ed. Pp.3-36.

University of Washington Press.

Heller, Monica

1992 The Politics of Codeswitching and Language Choice. In Codeswitching. Pp.

123-142. Carol M. Eastman ed. Clevedon, Philadelphia, Adelaide:

Multilingual Matters Ltd.

Hsiao A-Chin

2000 Contemporary Chinese Cultural Nationalism. London and New York:

Routledge. 
Hsiao A-Chin

1997 Language Ideology in Taiwan: The KMT's Language Policy, the Tai-yu Language

Movement, and Ethnic Politics. Journal of Multilingual and Multicultural

Development. Vol. 18, No 4: 302-315.

Hsing, You-tien

1997 Building Guanxi Across the Straits: Taiwanese Capital and Local Chinese

Bureaucrats. In Ungrounded Empires. pp 143-166. Ong and Nonini, eds.

New York, London: Routledge.

Hobsbawm, Eric

1983 Introduction: Inventing Traditions. In The Invention of Tradition. Pp 1-14.

Hobsbawm and Ranger eds. Stanford: Stanford University Press.

Hobsbawm, Eric

1990 Nations and Nationalism Since 1780: Programme, Myth, Reality. Cambridge University Press.

Hsu Cheng-guang and Hsiao Hsin-huang

1995 客家族群的語言問題——台北地區的調查分析。民族學研究所資料

彙編第 10 期 (Field Materials Institute of Ethnology Academia Sinica, No. 10)，頁 $1-40$ 。

Irvine, Judith and Gal, Susan.

2009 Language Ideology and Linguistic Differentiation. In Linguistic Anthropology: A Reader. pp.402-434. Alessandro Duranti ed. West Sussex: John Wiley \& Sons.

Liu, Chung-tung

1998 Health Care Systems in Transition II. Taiwan, Part I. A General Overview of the Health Care System in Taiwan. Journal of Public Health Medicine. Vol. 20, No 1: 5-10.

Liu, Jie-qiu ed.

2003 Peh-oe-ji Ki-chho Kau-chai. The Presbyterian Church of Taiwan. 
Mair, Victor

1991 What Is a Chinese "Dialect/Topolect"? Reflections on Some Key Sino-

English Linguistic Terms. Sino-Platonic Papers. No 29.

Malkki, Liisa

1995 Purity and Exile: Violence, Memory, and National Cosmology Among

Hutu Refugees in Tanzania. London, Chicago: The University of Chicago

Press.

McBeath, Gerald

1998 Wealth and Freedom: Taiwan's New Political Economy. Aldershot,

Brookfield, Singapore, Sidney: Ashgate Publishing Limited.

Myers-Scotton, Carol

1988 Code Switching and Types of Multilingual Communities. In Language and Language Policy: Issues, Implications, and Case Studies. Peter H.

Lowenberg, ed. Pp. 61-82. Washington, D.C.: Georgetown University Press.

Newsweek

2012 The Best of Taiwan's Universities.

http://ciae2.kmu.edu.tw/front/bin/ptdetail.phtml?Part=CIA201201160002.

Accessed February 21, 2012.

Ong, Aihwa

2006 Neoliberalism as Exception: Mutations in Citizenship and Sovereignty. Pp. 1-27. Durham: Duke University Press.

Ortner, Sherry B.

2006 Anthropology and Social Theory: Culture, Power, and Acting Subject.

Durham and London: Duke University Press. 
Ortner, Sherry

1990 Patterns of History: Cultural Schemas in the Foundings of Sherpa Religious Religious Institutions. In Culture Through Time. Pp 57-93. Ohnuki-Tierney, ed. Stanford University Press.

Philips, Steven

1999 Between Assimilation and Independence: Taiwanese Political Aspirations Under Nationalist Chinese Rule, 1945-1948. In Taiwan: A New History. pp. 275-319. Rubinstein, ed. Armonk, New York, London, England: M.E. Sharpe, Inc.

Reader's Digest Association

1989 Reader's Digest Atlas of the World, Rand McNally Maps.

Rubinstein, Murray A.

1999 Taiwan's Socioeconomic Modernization, 1971-1996. In Taiwan: A New History. pp. 366-402. Rubinstein, ed. Armonk, New York, London, England: M.E. Sharpe, Inc.

Rubinstein, Murray A.

1999 The Eras of Chiang Ching-Kuo and Lee Teng-hui, 1971-1994. In Taiwan: A New History. pp. 436-480. Rubinstein, ed. Armonk, New York, London, England: M.E. Sharpe, Inc.

Rubinstein, Murray

1994 The Other Taiwan 1945 to The Present: Taiwan in the Modern World. pp.145-180. Armonk, New York, London, M.E. Sharpe.

Said, Edward

1979 Orientalism, Revised Edition New York: Vintage Books.

Sandel, Todd L.

2003 Linguistic Capital in Taiwan: The KMT's Mandarin Language Policy and Its Perceived Impact on the Language Practices of Bilingual Mandarin and Tai-gi Speakers. Language in Society. Vol. 32, No 4: 523-551. 
Schlesinger, Philip.

1997 From Cultural Defence to Political Culture: Media, Politics, and Collective

Identity in the European Union. Media, Culture \& Society. Vol 19: 369-391.

Shepherd, John R.

1999 The Island Frontier of the Ch'ing, 1684-1780. In Taiwan: A New History. pp. 107-132. Rubinstein, ed. Armonk, New York, London, England: M.E. Sharpe, Inc.

Smith, Anthony D.

1992 National Identity and the Idea of European Unity. International Affairs. Vol. 68, No. 1: 55-76.

Spencer, Philip and Wollman, Howard

2006 Nationalism: A Critical Introduction, London, Thousand Oaks, New Delhi: Sage Publications.

Spolsky, Bernard and Shohamy, Elana

1999 Languages of Israel: Policy, Ideology and Practice, London, Thousand Oaks, New Delhi: Sage Publications.

$\mathrm{Su}$, Hsi-yao

2005 Language and Styling and Switching in Speech and Online Contexts:

Identity and Language Ideologies in Taiwan. (unpublished dissertation).

Su, Hsi-Yao

2008 What Does It Mean To Be A Girl With Qizhi?: Refinement, Gender, and Language Ideologies in Contemporary Taiwan. Journal of Sociolinguistics.

Vol. 12, No 3: 334-358.

Suleiman, Yasir

2004 War of Words: Language and Conflict in the Middle East, Cambridge:

Cambridge University Press. 
Swain, Margaret Byrne

1995 Pere Vial and the Gni-p'a: Orientalist Scholarship and the Christian Project In Cultural Encounters on China's Ethnic Frontiers, Stevan Harrell, ed. Pp.140-185. University of Washington Press.

Townsend, James

1992 Chinese Nationalism. Australian Journal of Chinese Affairs, No. 27 : 97130.

Tsai Shu-ling

2000 語言使用與職業階層化的關係：比較台灣男性的族群差異。台灣社會 學第一期 (Taiwanese Sociology No. 1), 頁 $65-111$ 。

Tsao Feng-fu

1999 The Language Planning Situation in Taiwan. Journal of Multilingual and Multicultural Development. Vol. 20, Nos 4\&5: 328-375.

Tse, John Kwock-Ping

1986 Standardization of Chinese in Taiwan. International Journal of Society and Language. Vol. 59: 25-32.

Tsurumi, Patricia

1979 Education and Assimilation in Taiwan under Japanese Rule, 1895-1945. Modern Asian Studies, Vol. 13, No. 4: 617-641.

Van Den Berg, M.E.

1986 Language Planning and Language Use in Taiwan: Social Identity, Language Accomodation, and Language Choice Behavior. International Journal of Society and Language. Vol. 59: 97-115.

Vermeer, Eduard B.

1999 Up the Mountain and Out to the Sea: The Expansion of Fukienese in the Late Ming Period. In Taiwan: A New History. pp. 45-83. Rubinstein, ed. Armonk, New York, London, England: M.E. Sharpe, Inc. 


\section{Wang, Jiann-Chyuan}

2005 Taiwan's Knowledge-based Service Industry. In The New Knowledge

Economy of Taiwan. Pp 168-187. Chen and Lee eds. Cheltham and

Northampton: Edward Elgar Publishing Limited.

Wang, Peter Chen-main

1999 A Bastion Created, A Regime Reformed, 1949-1970. In Taiwan: A New

History. pp. 320-338. Rubinstein, ed. Armonk, New York, London, England:

M.E. Sharpe, Inc.

Wei, Jennifer M.

2003 Codeswitching in Campaigning Discourse: The Case of Taiwanese

President Chen Shui-bian. Language and Linguistics. 4(1):139-165.

2006 Language Choice and Ideology in Multicultural Taiwan. Language and Linguistics 7(1):87-107.

Weller, Robert P.

1999 Identity and Social Change in Taiwanese Religion. In Taiwan: A New History. pp. 339-365. Rubinstein, ed. Armonk, New York, London, England: M.E. Sharpe, Inc.

\section{Williams, Raymond}

1977 Marxism and Literature. Oxford, New York, Toronto: Oxford University Press.

Willis, John E. Jr.

1999 The Seventeenth-Century Transformation: Taiwan Under the Dutch and the Cheng Regime. In Taiwan: A New History. pp. 84-106. Rubinstein, ed. Armonk, New York, London, England: M.E. Sharpe, Inc.

Woodside, Alexander

1983 Some Mid-Qing Theorists of Popular Schools: Their Innovations, Inhibitions, and Attitudes Towards the Poor. Modern China. Vol. 9, No. 1: 3-35. 
Wright, Sue

2004 Language Policy and Language Planning: From Nationalism to Globalism, New York: Palgrave Macmillan.

$\mathrm{Wu}$, Zhong-wei ed.

2003 Contemporary Chinese. Hua-yu Jiao-xue Publishing.

$\mathrm{Wu}$, Wen-Hsing and Chen, Shu-Fen

1989 The Development of Higher Education in Taiwan. Higher Education. Vol. 18, No 1: 117-136.

Yow Fu Culture Co., Ltd.

2009 Ren-shi Bo Po Mo Fo. Taipei: Yow Fu Culture Co., Ltd

Zhang, Qing

2005 A Chinese Yuppie in Beijing: Phonological Variation and the Construction of a New Professional Identity. Language in Society. Vol. 34, No 2: 431466.

Zhang, Qing

2006 Cosmopolitan Mandarin: Linguistic Practice of Chinese Waiqi

Professionals. Journal of Asian Pacific Communication. Vol. 16, No 2: 215 235.

Zhang, Qing

2005 Rhotocization and the 'Beijing Smooth Operator': The Social Meaning of a Linguistic Variable. Journal of Sociolinguistics. Vol. 12, No 3: 201-222.

Zheng, Liang-wei et al. ed.

2005 Sheng-huo Taiyu. Taipei: Zi Li Wan Bao Publishing Co. 


\section{Appendix A: Written Questionnaire for KMU Students}

Please do not write your name on this form and provide brief answers to the following questions:

Where is your birthplace?

What is your age?

What is your gender?

What is your mother's native language (ie Mandarin, Taiwanese, Hakka etc.)?

What is your father's native language?

What is the first language(s) that you learned to speak as a child?

What is your mother's occupation?

What is your father's occupation?

What is your major?

What type of employment do you plan to seek after graduation? (For example, software developer, computer programmer, civil engineer, accountant, graphic designer, etc.)

Do you know of any companies that you would like to work for after graduation? If so, what are they? 
Do you have any preference concerning the size of the company where you will seek employment after graduation? For example, would you prefer to work in a small-sized business, in a medium-sized business, in a government bureau, or in a large sized company?

Could you provide an estimate of the salary that you think is reasonable for you to be paid after graduation? If so, how much? 
What language(s) do you usually speak at home?

What language(s) did different members of your family speak when you were growing up?

What language(s) do you usually speak with your friends and classmates in informal situations?

Do you think that there are some types of situations where it is more appropriate to speak Mandarin or Taiwanese? If so, can you think of any examples?

Are you enrolled in this class because you feel that knowing Taiwanese will help you in your future career?

Why might knowing Taiwanese be useful in your future occupation?

After you graduate and become employed, what languages do you think you will speak at work?

How do you feel about people speaking Taiwanese in the workplace?

Do you think that gender is an influence on the likelihood that someone will speak Taiwanese?

What is your general impression when people in Taiwan speak Mandarin?

What is your general impression when people in Taiwan speak Taiwanese?

Do you think that the decision to speak Mandarin or Taiwanese is important in making up Taiwanese people's identities?

Do you think less people speak Taiwanese now than they did during past generations?

Do you think it is important to preserve the Taiwanese language? Why or why not? 
How do you think Taiwanese people's use of Mandarin and Taiwanese will change in the future?

How do you feel about these changes? 
Appendix C: Informal Interview Questions for Study Group Members

How long have you been a member of the study group?

When did you first become interested in the promotion of Taiwanese identity and the Taiwanese language?

How do you feel about the Romanized writing system? How did you first learn to read and write in Taiwanese?

Why is it important to teach history and language together?

Why do you think it is important to preserve local languages in Taiwan?

What language(s) do you usually speak at home?

What language(s) did different members of your family speak when you were growing up?

What language(s) do you usually speak with your friends and coworkers in formal and informal situations?

What are some types of situations where Taiwanese people might be likely to feel that it is more appropriate to speak Mandarin or Taiwanese? If so, can you think of any examples?

Why might knowing Taiwanese be useful in some occupations but not others?

Do you think that gender is an influence on the likelihood that someone will speak Taiwanese? If so, why?

What is the general impression that most people have when they hear other people speak Taiwanese? Why do you think they have those impressions?

Why do you think that the decision to speak Mandarin or Taiwanese is important in making up Taiwanese people's identities? 
Why do you think less people speak Taiwanese now than they did during past generations? Is there any way to reverse this language change?

How do you think Taiwanese people's use of Mandarin and Taiwanese will change in the future?

What are some goals that you hope can be accomplished through the Taiwanese language medical studies curriculum? 